LBNL-50573

\title{
Microstructural Evolution of Eutectic Au-Sn Solder Joints
}

\author{
Ho Geon Song \\ Ph.D. Thesis \\ Department of Materials Science and Engineering \\ University of California, Berkeley \\ and \\ Materials Science Division \\ Ernest Orlando Lawrence Berkeley National Labaratory \\ University of California \\ Berkeley, CA 94720
}

May 2002

This work was supported by the Director, Office of Science, Office of Basic Energy Sciences, Materials Sciences Division, of the U.S. Department of Energy under Contract No. DE-AC03-76SF00098. 
Microstructural Evolution of Eutectic Au-Sn Solder Joints

by

\section{Ho Geon Song}

B.S. (Seoul National University) 1989

M.S. (Seoul National University) 1991

A dissertation submitted in partial satisfaction of the

requirements for the degree of

Doctor of Philosophy

in

Engineering - Materials Science and Engineering

in the

GRADUATE DIVISION

of the

\section{UNIVERSITY OF CALIFORNIA, BERKELEY}

Committee in charge:

Professor John W. Morris, Jr., Chair

Professor Eicke R. Weber

Professor Liwei Lin

Spring 2002 
Microstructural Evolution of Eutectic Au-Sn Solder Joints

Copyright $@ 2002$

by

Ho Geon Song

The U.S. Department on Energy has the right to use this document for any purpose whatsoever, including the right to reproduce all or any part thereof. 


\author{
Abstract \\ Microstructural Evolution of Eutectic Au-Sn Solder Joints \\ by \\ Ho Geon Song \\ Doctor of Philosophy in Materials Science and Engineering \\ University of California, Berkeley \\ Professor John W Morris, Jr., Chair
}

Current trends toward miniaturization and the use of lead $(\mathrm{Pb})$-free solders in electronic packaging present new problems in the reliability of solder joints. This study was performed in order to understand the microstructure and microstructural evolution of small volumes of nominally eutectic Au-Sn solder joints ( $80 \mathrm{Au}-20 \mathrm{Sn}$ by weight), which gives insight into properties and reliability. The study particularly concentrated on the effects that the joint size and the type of substrate metallization have on both the bulk and interface microstructures of the joints. The systems studied were eutectic $\mathrm{Au}-\mathrm{Sn}$ on $\mathrm{Cu}$ and $\mathrm{Cu} /$ electroless $\mathrm{Ni} / \mathrm{Au}$ and for each system, two sets of sample geometries were used.

Eutectic $\mathrm{Au}-\mathrm{Sn}$ solder joints on $\mathrm{Cu}$ have microstructures that are very coarse on the scale of the joint, where the microstructure is strongly affected by the amount of $\mathrm{Cu}$ dissolution during reflow process. During aging, steady diffusion of $\mathrm{Cu}$ leads to the growth of $\mathrm{Cu}$-rich interfacial intermetallic layers, significant consumption of substrate $\mathrm{Cu}$, and formation of Kirkendall pores along the interface. Thermal cycling of the joints caused decomposition of the thick $\zeta(\mathrm{Cu})$-phase into a fine-grained 
multiphase microstructure. The microstructures of eutectic Au-Sn solder joints on $\mathrm{Cu} /$ electroless $\mathrm{Ni} / \mathrm{Au}$ are also very coarse due to the dissolution of $\mathrm{Au}$ used as a protective layer during soldering. Electroless $\mathrm{Ni}$ is shown to effectively act as a diffusion barrier for $\mathrm{Cu}$. The electroless $\mathrm{Ni}$ near the interface evolves into a complicated structure due to the interfacial reaction.

The solubility characteristics and diffusional behavior of substrate metals into eutectic Au-Sn solder determines the detailed microstructure and microstructural evolution of the ultrafine eutectic Au-Sn joints. Two important things to be noted from the results are as follows: First, the overall microstructures of these joints are very coarse with respect to the size of joint, and hence the properties of the joints cannot be assumed from bulk solder data. Second, despite having a nominally similar starting eutectic $\mathrm{Au}-\mathrm{Sn}$ composition, the microstructural features of the joints are unique for a given substrate metallization. Both of these results should be take into consideration during the design of reliable eutectic Au-Sn solder joints. 
To my parents,

my wife, Sun Sook, and my daughter, Hyun Joo. 


\section{TABLE OF CONTENTS}

List of Figures $\quad$ V

List of Tables viii

Acknowledgments $\quad$ ix

Chapter 1 Background and Objectives 1

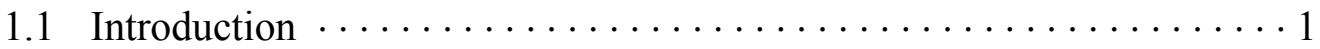

1.2 Solders versus Solder Joints $\quad \ldots \ldots \ldots \ldots \ldots \ldots \ldots \ldots \ldots \ldots$

1.2.1 Characteristics of Solder Alloy $\ldots \ldots \ldots \ldots \ldots \ldots \ldots \ldots$

1.2.2 Differences between Solder Joints and Bulk Solders $\ldots \ldots \ldots 3$

1.3 Trends in Design of Solder joints: Microstructural Concerns $\ldots \ldots \ldots 8$

1.3.1 Moving towards Lead(Pb)-free Solder Compositions $\ldots \ldots .9$

1.3.2 Miniaturization in Joint Geometry $\ldots \ldots \ldots \ldots \ldots \ldots$

1.4 Major Factors Influencing Joint Reliability $\ldots \ldots \ldots \ldots \ldots \ldots \ldots$

1.5 Microstructural Evolution and Failure in Solder Joints . . . . . . 12

1.5.1 Bulk Solder of the Joint $\ldots \ldots \ldots \ldots \ldots \ldots \ldots \ldots \ldots$

1.5.2 Interfacial Intermetallics $\ldots \ldots \ldots \ldots \ldots \ldots \ldots \ldots \ldots$

1.6 Solder of Interest in This Study: Eutectic Au-Sn $\ldots \ldots \ldots \ldots \ldots$

1.6.1 Characteristics of Eutectic Au-Sn $\ldots \ldots \ldots \ldots \ldots \ldots \ldots$

1.6.2 Applications $\ldots \ldots \ldots \ldots \ldots \ldots \ldots \ldots \ldots \ldots \ldots \ldots \ldots \ldots \ldots \ldots \ldots$

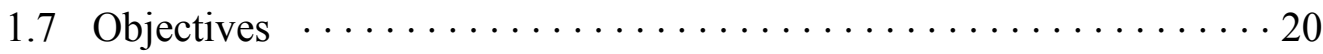

Chapter 2 Microstructure of Eutectic Au-Sn Solder Joints on Cu 22

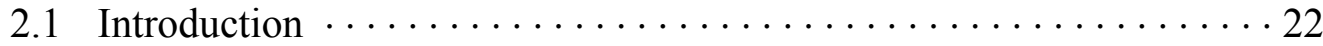

2.2 Experimental Procedure $\ldots \ldots \ldots \ldots \ldots \ldots \ldots \ldots \ldots \ldots \ldots \ldots \ldots \ldots \ldots \ldots$

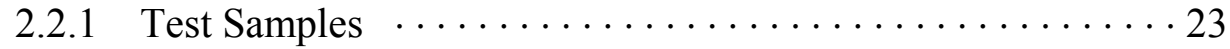

2.2.2 Thermal Treatments and Microstructural Characterization $\cdots 24$ 


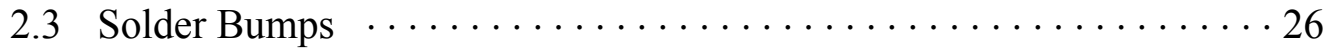

2.3.1 As-Solidified Bumps $\ldots \ldots \ldots \ldots \ldots \ldots \ldots \ldots \ldots \ldots \ldots \ldots \ldots$

2.3.2 "Reflow Treated" Bumps $\ldots \ldots \ldots \ldots \ldots \ldots \ldots \ldots \ldots \ldots \ldots \ldots \ldots \ldots$

2.3.3 Isothermally Aged Bumps $\ldots \ldots \ldots \ldots \ldots \ldots \ldots \ldots \ldots \ldots \ldots \ldots \ldots \ldots$

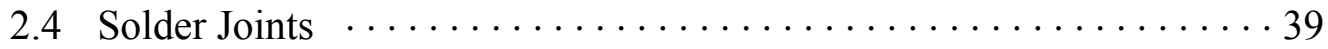

2.4.1 As-Solidified Joints $\ldots \ldots \ldots \ldots \ldots \ldots \ldots \ldots \ldots \ldots \ldots$

2.4.2 Formation of Joint Microstructure $\ldots \ldots \ldots \ldots \ldots \ldots \ldots$

2.4.3 Isothermally Aged Joints $\ldots \ldots \ldots \ldots \ldots \ldots \ldots \ldots$

2.4.3.1 Bulk Solder of the Joint $\ldots \ldots \ldots \ldots \ldots \ldots \ldots$

2.4.3.2 Interface of the Joint $\ldots \ldots \ldots \ldots \ldots \ldots \ldots \ldots \ldots$

2.4.4 Thermally Cycled Joints $\ldots \ldots \ldots \ldots \ldots \ldots \ldots \ldots \ldots \ldots$

2.5 Summary and Conclusions $\ldots \ldots \ldots \ldots \ldots \ldots \ldots \ldots \ldots \ldots \ldots \ldots \ldots$

Chapter 3 Microstructure of Eutectic Au-Sn Joints on Cu/electroless Ni/Au 64

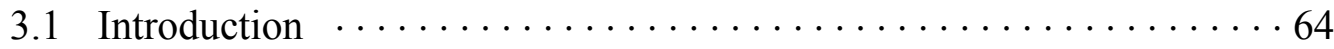

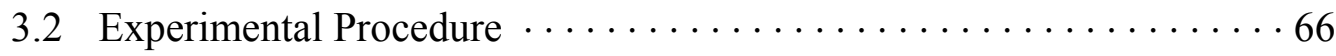

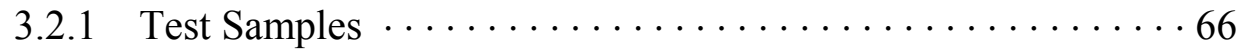

3.2.2 Au-Ni-Sn Alloys and Eutectic Au-Sn/Electroless Ni Couples * 68

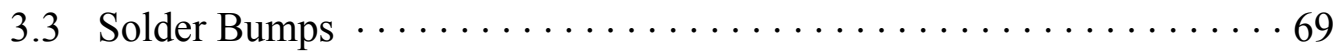

3.3.1 As-Solidified Bumps $\ldots \ldots \ldots \ldots \ldots \ldots \ldots \ldots \ldots \ldots \ldots \ldots \ldots \ldots$

3.3.1.1 Bulk Solder of the Bump $\ldots \ldots \ldots \ldots \ldots \ldots$

3.3.1.2 Interface Structure of the Bump $\ldots \ldots \ldots \ldots \ldots 72$

3.3.1.3 Verification of Interface phases $\ldots \ldots \ldots \ldots \ldots$

3.3.2 Aged Solder Bumps $\ldots \ldots \ldots \ldots \ldots \ldots \ldots \ldots \ldots$

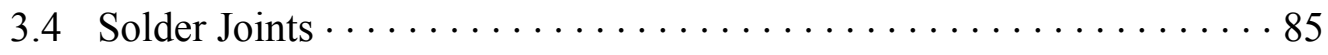

3.5 Detailed Interface Microstructure $\ldots \ldots \ldots \ldots \ldots \ldots \ldots \ldots \ldots$

3.5.1 Interface in As-Solidified Bump $\ldots \ldots \ldots \ldots \ldots$

3.5.2 Interface in Aged Bump $\ldots \ldots \ldots \ldots \ldots \ldots \ldots \ldots$

3.6 Summary and Conclusions $\ldots \ldots \ldots \ldots \ldots \ldots \ldots \ldots \ldots \ldots \ldots \ldots \ldots \ldots \ldots$ 
Summary and Conclusions

References 


\section{LiST OF FIGURES}

Figure 1.1. Typical microstructure of $\mathrm{Sn}-4 \mathrm{Ag}-0.5 \mathrm{Cu}$ solder ball used in Ball Grid Array (BGA) package prior to form a joint.

Figure 1.2. Microstructural features observed in $\mathrm{Sn}-4 \mathrm{Ag}-0.5 \mathrm{Cu}$ solder joint when the solder ball in Figure 1.1 is reflowed on $\mathrm{Ni} / \mathrm{Au}$ metallization.

Figure 1.3. Schematic illustration of current trends in the design of the solder joint in microelectronics.

Figure 1.4. Relationships of actual temperatures of use for melting points on the alloys (redrawn with modification from [21]).

Figure 1.5. Au-AuSn binary phase diagram.[33] The eutectic Au-Sn solder has a nominal composition of $80 \mathrm{Au}-20 \mathrm{Sn}$ by weight and $71 \mathrm{Au}-29 \mathrm{Sn}$ by molar content.

Figure 2.1. Schematic diagrams and pictures of sample geometries used in this study. (a) solder bump: unjoined bump (b) solder joint: joined bump.

Figure 2.2. Cross-sectional micrographs of as-solidified solder bump (a) SEM image at low magnification (b) BSE image at high magnification.

Figure 2.3. Isothermal cross section of the ternary Au-Cu-Sn system at $190^{\circ} \mathrm{C}$.[36]

Figure 2.4. Schematic illustration of possible formation mechanism of mushroomshaped phases.

Figure 2.5. TEM bright filed image of as-solidified solder bump. Diffraction pattern analysis shows that the mushroom-shaped phase is a $\zeta$-based single crystalline.

Figure 2.6. Cross-sectional micrographs of 8 times-reflowed (peak temperature of $260^{\circ} \mathrm{C}$ ) solder bump (a) SEM image at low magnification (b) BSE image at high magnification.

Figure 2.7. Cross sectional BSE images of solder bumps aged at $200^{\circ} \mathrm{C}$ for (a) 1 day, and (b) 4 days.

Figure 2.8. Cross-sectional SEM micrographs of solder bump aged at $200^{\circ} \mathrm{C}$ for 80 days (a) at low magnification (b) at high magnification.

Figure 2.9. Thickness of (a) the $\mathrm{CuAu}$ layer, and (b) the $\mathrm{Cu}_{3} \mathrm{Au}$ layer in solder bumps with the square root of aging time at $200^{\circ} \mathrm{C}$.

Figure 2.10. Cross-sectional SEM micrographs of as-solidified joint with typical microstructure. 
Figure 2.11. Schematic vertical section along 71 Au29Sn-Cu.

Figure 2.12. Isothermal sections of Au-rich corner of $\mathrm{Au}-\mathrm{Cu}-\mathrm{Sn}$ system near $320^{\circ} \mathrm{C}$ from ref. 42. (a) just above $320^{\circ} \mathrm{C}$ (b) at $320^{\circ} \mathrm{C}$ (c) at just below $320^{\circ} \mathrm{C}$. The line was drawn between $\mathrm{Cu}$ and eutectic $\mathrm{Au}-\mathrm{Sn}$ on each section to measure the phase region with respect to $\mathrm{Cu}$ content.

Figure 2.13. Cross-sectional SEM micrographs of as-solidified joint with typical microstructure.

Figure 2.14. Cross-sectional SEM micrographs of a solder joint aged at $200^{\circ} \mathrm{C}$ for 10 days (a) at low magnification (b) at high magnification.

Figure 2.15. Cross-sectional SEM micrographs of a solder joint aged at $200^{\circ} \mathrm{C}$ for 50 days (a) at low magnification (b) at high magnification.

Figure 2.16. Thickness of (a) the $\mathrm{CuAu}$ layer, and (b) the $\mathrm{Cu}_{3} \mathrm{Au}$ layer in solder joints with the square root of aging time at $200^{\circ} \mathrm{C}$.

Figure 2.17. The average consumed thickness of $\mathrm{Cu}$ in solder joints with the aging time at $200^{\circ} \mathrm{C}$.

Figure 2.18. Pores observed along the interface between $\mathrm{Cu}$ and the interfacial layer. (a) SEM micrograph of aged joint at $200^{\circ} \mathrm{C}$ for 10 days. TEM micrographs of aged bump at $200^{\circ} \mathrm{C}$ for 31 days (b) before fully thinning (c) after thinning.

Figure 2.19. Cross-sectional BSE image of solder joint aged at $150^{\circ} \mathrm{C}$ for 20 days.

Figure 2.20. Cross-sectional SEM micrograph of solder joint thermally cycled from 65 to $150^{\circ} \mathrm{C}$ for 500 cycles.

Figure 3.1. Schematic diagrams of sample geometries used in this study. (a) solder bump: unjoined bump (b) solder joint with same metallizations on both top and bottom (c) solder joint with dissimilar metallizations.

Figure 3.2. Cross-sectional micrographs of as-solidified solder bump on $\mathrm{Cu} / \mathrm{electroless}$ $\mathrm{Ni} / \mathrm{Au}$. (a) SEM image at low magnification (b) BSE image at high magnification.

Figure 3.3. Isothermal cross section of the ternary Au-Ni-Sn system (a) at room temperature, [105] (b) $400^{\circ} \mathrm{C}$, [106].

Figure 3.4. BSE micrographs of bulk Au-Ni-Sn alloys. (a) 90(eutecitc Au-Sn)-10Ni (at.\%): $\zeta$ (matrix), $\delta(\mathrm{Ni}$ )(gray phase) (b) 80(eutecitc $\mathrm{Au}-\mathrm{Sn}$ )-20Ni (at.\%): $\zeta$ (matrix), $\mathrm{Ni}_{3} \mathrm{Sn}_{2}(\mathrm{Au})$ (dark phase) (c) 65(eutecitc $\mathrm{Au}-\mathrm{Sn}$ )-35Ni (at.\%): $\mathrm{Au}(\mathrm{Ni}, \mathrm{Sn})($ matrix), $\mathrm{Ni}_{3} \mathrm{Sn}(\mathrm{Au})$ (gray phase), $\mathrm{Ni}_{3} \mathrm{Sn}_{2}(\mathrm{Au})$ (dark phase). 
Figure 3.5. X-ray diffraction pattern of 80(eutecitc Au-Sn)-20Ni (at.\%) alloy.

Figure 3.6. Cross-sectional micrographs of solder bumps aged at $200^{\circ} \mathrm{C}$ (a) optical micrograph for 50 days, (b) SEM micrograph near interface for 50 days, (c) optical micrograph for 365 days, (d) SEM micrograph near interface for 365 days, and (e) BSE micrograph image near interface for 365 days.

Figure 3.7. Thickness of total Au-Ni-Sn interfacial intermetallic layers with the square root of aging time at $200^{\circ} \mathrm{C}$.

Figure 3.8. Thickness of total $\mathrm{Cu}-\mathrm{Au}$ interfacial intermetallic layers with the square root of aging time at $200^{\circ} \mathrm{C}$ that are observed in eutectic Au-Sn solder bump on $\mathrm{Cu}$.

Figure 3.9. SEM micrographs showing changes of phase distribution at the interface of the eutectgic Au-Sn/electroless Ni couples during aging at $200^{\circ} \mathrm{C}$ for (a) 0 day (asplated), (b) 10 days, (c) 25 days, (d) 50 days, and (e) 85 days.

Figure 3.10. Cross-sectional SEM micrographs of as-solidified joints that have electroless $\mathrm{Ni} / \mathrm{Au}$ metallizations on both the top and the bottom substrates.

Figure 3.11. Cross-sectional SEM micrographs of as-solidified joints that have $\mathrm{Cu}$ on the top pad and electroless $\mathrm{Ni} / \mathrm{Au}$ on the bottom pad.

Figure 3.12. Illustration of the interface between the solder and the electroless $\mathrm{Ni}$ in the as-solidified bump. (a) bright field TEM micrograph, and (b) schematic diagram of the interface microstructure.

Figure 3.13. Selective area diffraction patterns of interface layers. (a) reaction layer (b) P-rich layer.

Figure 3.14. TEM micrographs showing interface microstructure of aged solder bump at $200^{\circ} \mathrm{C}$ for 31 days.

Figure A-1. Schematic diagrams of Z-MAJIC ${ }^{\mathrm{TM}}$ processes. 


\section{LIST OF TABLES}

Table 1.1. Compositions and melting temperatures of common solders used in microelectronics.

Table 1.2. Properties of eutectic Au-Sn solder with other solders.[35]

Table 3.1. Comparison of constituent phases in different isothermal sections. 


\section{ACKNOWLEDGMENTS}

There are many people who I am indebted to for their support throughout my stay at Berkeley.

I would first like to thank my research adviser, Professor J.W. Morris, Jr. for his support and guidance through the years at Berkeley. There is no doubt that he is a great materials scientist, but I will also remember him as a great educator who generously thinks of his students. Additionally I thank Prof. E.R. Weber and Prof. L. Lin along with Prof. Morris for serving on my thesis committee.

I wish to thank Dr. Mark McCormack for giving me an opportunity to do this work, and Dr. Jae Pyung Ahn and Sung Hwan Lim for their friendship and assistance with TEM work. I am grateful to Dr. Jin Chan and Dr. Dan Dietderich for their guidance with the lab equipment and suggestion for my research, and to James $\mathrm{Wu}$ and Rudy Bartolo for helping me with sample preparation. I have also benefited from helpful discussion with Chris Krenn.

Special thanks to Andy Minor, who has willingly let me share with him all of my difficulties and success from the beginning, and who also corrected this thesis draft with valuable comments. In addition, many thanks are due to other Morris group members past and present, Dave Mitlin, Zhen Guo, Monica Barney, Jackie Gamble, Dr. Seung Hyuk Kang, Koji Sato, Tae-Kyu Lee, Brian Dracup, Dave Clatterbuck, Dr. Erica Lilleodden, Miao Jin, Prof. Young-Ho Kim, Dr. Hee Jin Kim, and Rosemary Cole for their advice, friendship and help along the way. 
Most importantly, I wish to thank my family who has supported me with their earnest desire for me to achieve my Ph.D. at Berkeley. I am forever indebted to my parents for their love and encouragement throughout my life. A formost thanks to my wife, Sun Sook, and my duaghter, Hyun Joo, whose love, understanding and patience throughout the years have been the greatest help to me.

This research was supported by Fujitsu Computer Packaging Technologies and by the Director, Office of Science, Office of Basic Energy Sciences, Division of Materials Sciences and Engineering, of the U.S. Department of Energy under Contract No. DE-AC03-76SF00098. 


\section{CHAPTER 1. BACKGROUND AND OBJECTIVES}

\subsection{INTRODUCTION}

Electronic packaging is focused on how to package electronic components in an electronic device efficiently and reliably. Since each electronic component is not isolated but needs to communicate with each other, they must in some way be interconnected. In addition, the delicate components should be mechanically supported. As an interconnection material, solder alloys are commonly used at all levels of the electronic packages due to the great virtue of enabling low temperature joining with excellent electrical characteristics. Through various soldering technologies the solder alloy is melted and wets the substrates of joined components, which upon solidification forms a solder joint. It is the solder joints that provide both electrical and mechanical connections between a chip, a chip carrier, and a board, which enables the device to operate. Therefore the solder joints are one of the most indispensable parts in the electronic packaging of essentially all electronic devices.

Computers and other electronic systems are rapidly heading towards higher performance and higher density while at the same time shrinking more and more. As a result, it becomes a more important issue in electronic packaging to design reliable solder joints for the life of electronic products as well as to design them smaller and electrically more efficient. This is because the failure of a single solder joint could conceivably result in degradation and malfunction of a device component, which might ultimately lead to failure of the entire system. In general, as a trade off to their superior properties as interconnects, solder joints are susceptible to reliability 
problems due to inherent characteristics of solder alloys and the normal service environment of solder joints. Due to low melting points of the solders, the solder joints are ordinarily used at high homologous temperatures, which leads to high temperature creep deformation and significant microstructural evolution. Additionally, due to the mismatch of thermal expansion between the joined materials, the solder joints experience cyclic stress when temperature fluctuations occur during service.

Furthermore, combined with these inherent reliability issues, current trends toward the miniaturization and use of lead $(\mathrm{Pb})$-free solders in the design of solder joints brings with it additional reliability problems. Since most of the important failure mechanisms that influence the joint reliability are governed by the microstructure, the understanding of microstructure of the solder joints and its evolution during service is crucial for designing reliable solder joints. A fundamental study on the microstructure of solder joints is not only technologically important but also scientifically interesting.

From this perspective, this research focuses on the microstructure and the microstructural evolution of small volumes of eutectic $\mathrm{Au}-\mathrm{Sn}$ solder joints. Specifically, the microstructural evolution was studied during isothermal aging and thermal cycling with regards to its effect on mechanical reliability. This is the first study focused on the microstructural features of small volume eutectic Au-Sn solder joints. 


\subsection{SOLDERS VERSUS SOLDER JOINTS}

Solder joints inherently have unique characteristics over bulk solder alloys due to their geometry. Despite this, solder joint properties are commonly referred to as being the same as those of the bulk solder. A clear understanding of their basic differences is necessary when considering the reliability of microelectonic packaging.

\subsubsection{Characteristics of Solder Alloy}

The most important feature of a solder alloy is its low meting temperature, which allows one to avoid thermal damage to joined materials when processing. The melting temperatures of the solders used in microelectronics are usually below about $350^{\circ} \mathrm{C}$, and eutectic or near eutectic compositions are chosen to minimize the melting temperature (see Table 1.1). For a specific application, the melting point of the solder directly determines the maximum allowable temperature that a product can be exposed to in service and the maximum processing temperature that devices and substrates can withstand during processing.[1,2] Another required characteristic of an effective solder alloy is its good wetting behavior with the desired substrate. This allows for the making of a strong bond between the metals to be joined. Most common solders (as listed in Table 1.1) contain Sn or In so that they inherently create strong bonds by producing stable intermetallic phases with common substrate metals such as $\mathrm{Cu}, \mathrm{Ni}$ and $\mathrm{Au}$.

\subsubsection{Differences between Solder Joints and Bulk Solders}


The solder joint consists of three parts; the bulk solder of the joint, the bonding layers at the interface (usually intermetallic compound layers), and the substrates that are joined by the solder. While the mechanical properties of the solder joint are dominated by the solder itself, the other parts of the joint can still affect the overall properties of solder joint. Thus, the properties of a solder joint are not equivalent to those of the bulk solder alloy of the same composition.

Table 1.1. Compositions and melting temperatures of common solders used in microelectronics.

\begin{tabular}{c|c}
\hline Composition (wt.\%) & Melting Point $\left({ }^{\circ} \mathrm{C}\right)$ \\
\hline $95 \mathrm{~Pb}-5 \mathrm{Sn}$ & 312 \\
$80 \mathrm{Au}-20 \mathrm{Sn}$ & 280 \\
$95 \mathrm{Sn}-5 \mathrm{Sb}$ & 240 \\
$99.3 \mathrm{Sn}-0.7 \mathrm{Cu}$ & 227 \\
$96.5 \mathrm{Sn}-3.5 \mathrm{Ag}$ & 221 \\
$\mathrm{Sn}-3 \mathrm{Ag}-0.5 \mathrm{Cu}$ & 218 \\
$91 \mathrm{Sn}-9 \mathrm{Zn}$ & 199 \\
$62 \mathrm{Sn}-38 \mathrm{~Pb}$ & 183 \\
$58 \mathrm{Bi}-42 \mathrm{Sn}$ & 138 \\
$52 \mathrm{In}-48 \mathrm{Sn}$ & 118 \\
\hline
\end{tabular}

The differences in the mechanical properties of solder joints as compared to bulk solder arises from the following reasons: First, the solder joint inherently shows different mechanical behaviors compared to the bulk solder due to its geometry. 
When a solder joint is mechanically tested using conventional methods, the constraint imposed by the interface between the solder and the substrates may alter the results significantly. For example, when a thin joint is tested in tension, the stresses will be elevated relative to bulk materials. Plastic deformation occurs at constant volume, so in a bulk tensile specimen as the specimen extends in the tensile loading direction the cross-section in the perpendicular plane becomes smaller. In a thin joint, the interfaces impose a constraint that resists this contraction; consequently, the joint itself experiences triaxial loading rather than uniaxial tensile loading.[2]

Secondly, the microstructure of the solder joint, which governs its mechanical behavior, is not purely determined by the nominal composition of the solder used in a joint. This is because the microstructure of the solder joint is determined by the reaction at the interface between the solder and substrates as well as the solidification behavior of the solder. For example, Figure 1.1 shows the microstructure of a Sn4Ag- $0.5 \mathrm{Cu}$ (wt.\%) solder ball used in Ball Grid Array (BGA) packaging prior to forming a joint. The solder ball has the microstructure which consists of large islands of nearly pure $\mathrm{Sn}$ divided by regions that are decorated with mostly fine $\mathrm{Ag}_{3} \mathrm{Sn}$ intermetallic phase and a small amount of $\mathrm{Cu}_{6} \mathrm{Sn}_{5}$ phase. However, once this solder ball is reflowed on $\mathrm{Ni} / \mathrm{Au}$ metallization to form a joint, it has not only a different scale of the bulk microstructure but also more constituent phases as illustrated in Figure 1.2. By the reaction between the solder and substrate metals, additional phases such as $(\mathrm{Cu}, \mathrm{Ni})_{6} \mathrm{Sn}_{5}$ intermetallic compounds at the interface and $\mathrm{AuSn}_{4}$ plates within the bulk part of the joint are formed. 

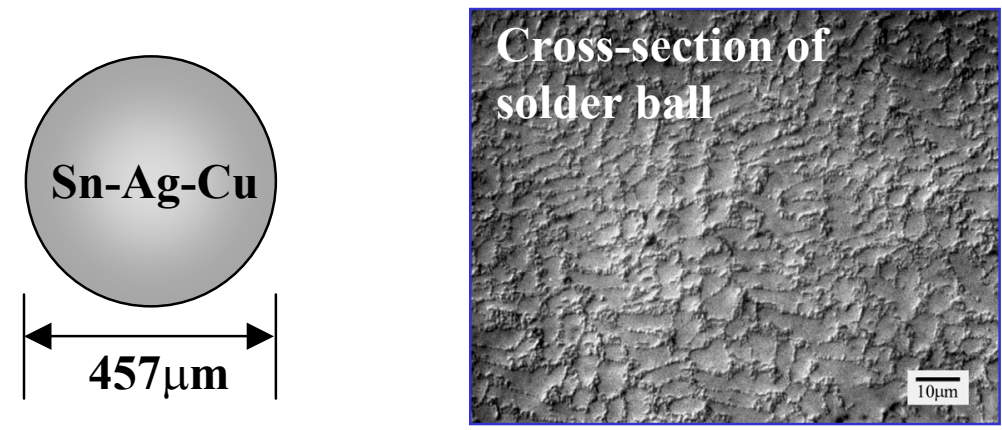

Figure 1.1. Typical microstructure of Sn- $4 \mathrm{Ag}-0.5 \mathrm{Cu}$ solder ball used in Ball Grid Array (BGA) package prior to form a joint.
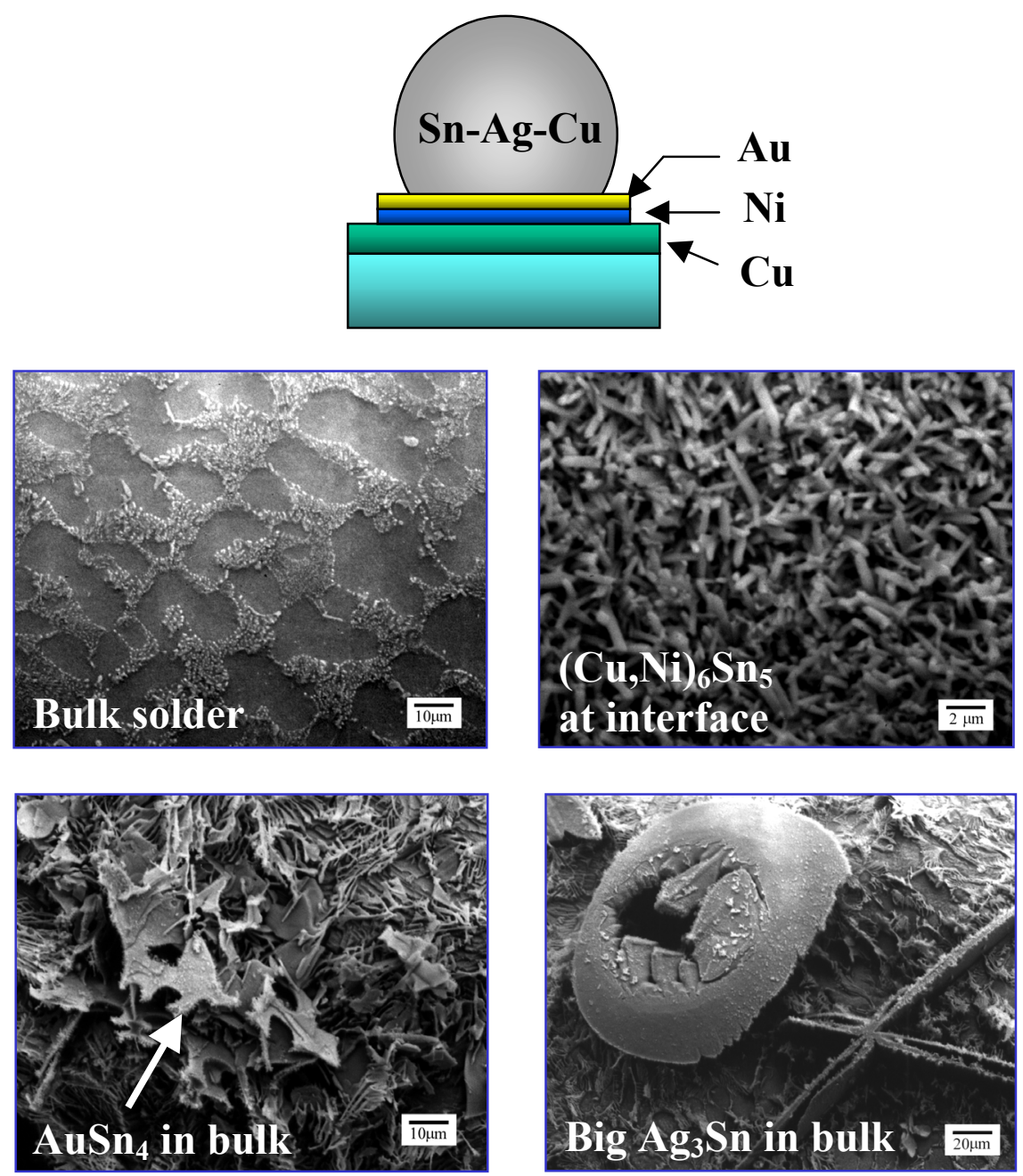

Figure 1.2. Microstructural features observed in $\mathrm{Sn}-4 \mathrm{Ag}-0.5 \mathrm{Cu}$ solder joint when the solder ball in Figure 1.1 is reflowed on $\mathrm{Ni} / \mathrm{Au}$ metallization. 
The large $\mathrm{Ag}_{3} \mathrm{Sn}$ phases are also uniquely found only in the joint, not in the unformed bulk solder ball. These phases differentiate the mechanical properties of the solder joints from the bulk solder, and affect joint reliability. Among other concerns, the $\mathrm{AuSn}_{4}$ phase is known to embrittle the eutectic $\mathrm{Pb}-\mathrm{Sn}$ solder joint.[3-5]. Small alterations in solder composition due to reactions at the interface can significantly modify the microstructure of the solder joint and lead to significant effects on its mechanical behavior.

In addition to compositional changes due to interfacial reactions, solder joints show inherently different solidification behaviors compared to bulk solders. This is because a joint has a relatively high surface to volume ratio, resulting in a large number of heterogeneous nucleation sites during solidification.[6] It is important to note that the scale of joint microstructure is primarily determined by the solidification rate, which depends largely on the physical size of the joint. Since the solder joints in actual devices are usually cooled rapidly, their microstructural scales are different from those of bulk specimens that are solidified relatively slowly. This is particularly true for the very fine solder joints typically used in current electronic packages.[7,8,9]

It is clear that solder joints are more complex than bulk solders and thus we would expect them behave differently. Primarily, the difference is due to the geometric characteristics of the joints and the compositional changes resulting from exposure to substrate metallizations. It follows that the mechanical property data from the bulk solder or simulated joint specimen may not adequately represent the properties of the solder joint and therefore should be used only with verification their 
microstructural similarity. Furthermore, as the solder joint becomes smaller, the effects described previously are expected to become more significant. Accordingly, the properties of solder joints may become more altered and the failure mechanism may be different to that derived from the bulk solder or larger joint. Therefore, it is imperative that the properties and microstructures of the solder joint used to analyze joint reliability be based on investigation of actual fine solder joints.

\subsection{Trends in Design of Solder Joints: Microstructural Concerns}

As schematically illustrated in Figure 1.3, there are currently two notable trends in electronic packaging: a change in the composition to $\mathrm{Pb}$-free alloys and the continuing trend towards smaller sizes. Therefore, understanding solder joint microstructure is being of great importance for reliability as well as manufacturability.[1,9]
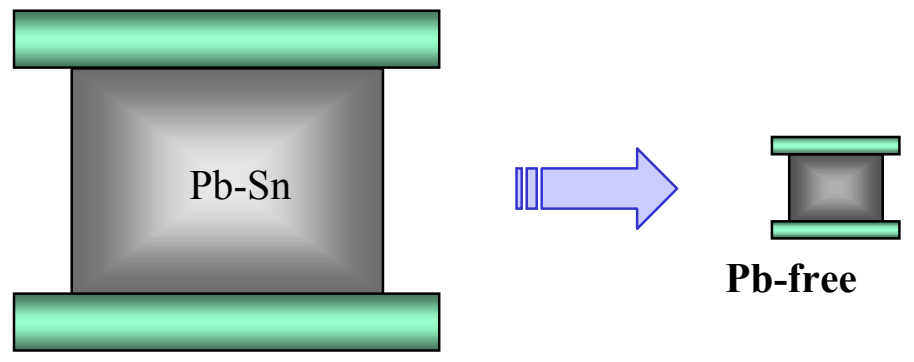

Pb-free

Figure 1.3. Schematic illustration of current trends in the design of the solder joint in microelectronics. 


\subsubsection{Moving towards Lead(Pb)-Free Solder Compositions}

$\mathrm{Pb}-\mathrm{Sn}$ solders have been the most prominent material for the interconnection and packaging of modern electronic components and devices for the past several decades. The widespread use of Pb-Sn solders is due mostly to their low cost and relatively good material properties. However, increasing attention to hazardous and toxic materials used in microelectronics has led to a strong push to use clean materials in the microelectronic industry. Accordingly, a very pressing trend in electronic packaging is the use of lead $(\mathrm{Pb})$-free solders driven by the environmental concerns of the toxicity of $\mathrm{Pb}$. This concern has been led to pending legislation in the EU, Japan and the US for banning the use of $\mathrm{Pb}$ in microelectronics.[2,9-15] Recently, lead-free products in electronic industries are also used as a "green" marketing strategy. A separate reason for the use of $\mathrm{Pb}$-free solders is the increased demands on the level of performance due to increased density and complexity of circuitry.[12-15] Pb-free alloys can provide these needed properties in specific applications and manufacturing processes.

For the $\mathrm{Pb}$-free solders to be acceptable for industry applications, they have to exhibit desirable material characteristics in terms of melting temperature, wettability, electrical and thermal conductivity, mechanical strength, creep and thermal fatigue resistance, corrosion resistance, manufacturability and cost.[13-15] Moving away from the large amount of existing knowledge on $\mathrm{Pb}-\mathrm{Sn}$ solder raises great reliability concerns as well as technical concerns, in spite of recent substantial efforts in the research and development for $\mathrm{Pb}$-free solders. For instance, the use of new $\mathrm{Pb}$-free alloys will inevitably modify the microstructure of the solder joints, the combination 
of phases, the defects, and the intermetallic layer characteristics, and many other important properties of solder joints.

\subsubsection{Miniaturization in Joint Geometry}

A trend toward the miniaturization of microelectronic packages necessitates the use of increasingly dense arrays of interconnects with increasingly fine solder joints.[16,17] The miniaturization of solder joints raises two commonly neglected issues that need to be addressed in order to design reliable packages.[18] First, when the solder joint is very small the microstructural features that govern its mechanical behavior (such as the mean grain size and thickness of interfacial intermetallics) may be large with respect to the size of the joint. If the joint contains only a few grains it is not obvious if its mechanical behavior can be predicted from conventional mechanical tests, and there may be a considerable variation in behavior from joint to joint.

Secondly, as a joint becomes smaller its surface to volume ratio increases, and hence its composition can be changed more significantly by diffusion from the substrate metallizations to which it is bonded, as discussed in section 1.2.2. This is particularly likely when the substrate metallization is $\mathrm{Cu}$ or $\mathrm{Au}$, which both diffuse fairly rapidly into most common solders.[19,20] The microstructure and properties of a small solder joint are easily affected by minor changes in the details of composition and processing, and may change further as the joint is strained and heated during service.

Considering the above demands and problems on the reliability of $\mathrm{Pb}$-free, fine solder joints, and also the fact that the different microstructures have different 
properties, the understanding of joint microstructure and its evolution during service needs to be addressed. So far, most of the research on the microstructure of solder joints has been confined to $\mathrm{Pb}$-Sn solder joints. The lead-free solder systems such as the Au-Sn solder joints in this work have rarely been studied. Additionally, microstructural studies on ultrafine solder joints have been even more limited. Therefore, this study focuses on the microstructure and the evolution of microstructure in small volumes of eutectic Au-Sn solder joints in order to find their effects on the mechanical reliability of the joint.

\subsection{MAJOR FACTORS INFLUENCING JOINT RELIABILITY}

The major factors influencing the reliability of solder joints are the intrinsic properties of the solder alloy, the geometry (design) of the joint including components and the board to be assembled, the process used to form the solder joints, and the longterm service conditions.[6] All of these factors have effects on the microstructure of the joint. Considering the fact that the microstructure of the material is determined by its composition and by the processing it has received, the first three factors listed determine the microstructure of the as-soldered joint. The last factor results in the microstructural change of the solder joint. In other words, the joint reliability is closely related to both the initial microstructure and the microstructural change of the solder joints.

The initial microstructure of relatively large joints usually have the microstructural features found in bulk solder. However, as the solder joint become as small as tens of micrometers in diameter, it may not have the typical microstructural 
features as we expected for the same solder composition.[7,8] Furthermore, their evolution is even more unpredictable. It follows that careful research is required to insure the reliability of devices that use very fine joints since they may show different mechanical behaviors and new failure mechanisms.

For properly designed solder joints temperature during service is the most universally influential factor that contributes to microstructural changes and reduces reliability of the solder joints. This is because solder joints are used at high homologous temperatures which are higher than the homologous temperatures of structural materials (shown in Figure 1.4).[21] Furthermore, temperature fluctuations arising from both environmental and power cycling conditions directly affect the failure of solder joints by inducing thermal stresses. Therefore, a study on the microstructure of the joint and its change during isothermal and thermal cycling conditions is undertaken in order to evaluate and predict the reliability problems of the solder joints.

\subsection{Microstructural Evolution ANd FAilure in Solder Joints}

Both bulk and interfacial microstructures are important to the behavior of solder joints. The as-solidified microstructure of solder joints is subject to change in service due to high homologous temperature and thermal stresses that it receives in service. The interfacial intermetallics that compromise the mechanical integrity of the joints also evolve by diffusion during processing and service. These microstructural changes become more unpredictable with the trends toward the use of $\mathrm{Pb}$-free solder and miniaturization. 


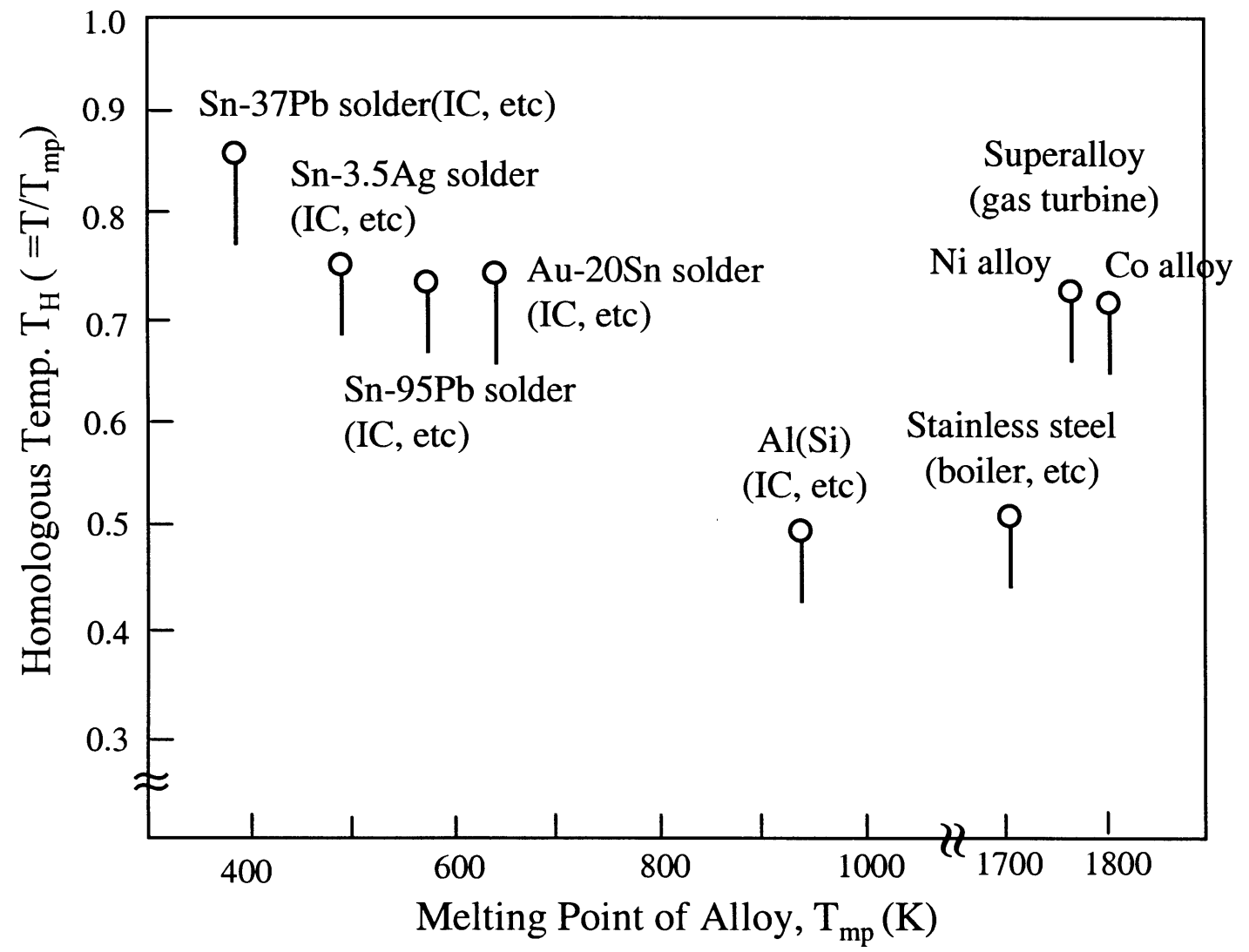

Figure 1.4. Relationships of actual temperatures of use for melting points on the alloys (redrawn with modification from [21]). 


\subsubsection{Bulk Solder of the Joint}

As shown in Table 1.1, commonly solders are used at either eutectic or neareutectic compositions in order to minimize their melting points. Among these solders, the solders that have comparable volume fraction between their constituent phases have a classic eutectic lamellar structure in the as-solidified condition, which has a large surface area per unit volume. Since the solder joint is used at high homologous temperatures where solid state diffusion can occur at an appreciable rate and the solder joints receive cyclic thermal stresses due to the thermal expansion mismatch of joined materials, the as-solidified microstructure of common solder almost always changes significantly during service in order to realize a more stable configuration.

The microstructural mechanisms used to relieve the excess surface energy in eutectic solder is the gradual coarsening and spheroidization of the eutectic lamellae.[22] This occurs gradually in all eutectic microstructures, at a rate that increases with the homologous temperature. This process can be accelerated by plastic deformation caused by thermal cycling. In this case the solder may spontaneously recrystallize into fine, equiaxed grains, an effect which is particularly likely in eutectic $\mathrm{Pb}-\mathrm{Sn}$ deformed in shear.[23] The recrystallization concentrates along bands of inhomogeneous shear and the development of this type of inhomogeneous microstructure can lead to the failure of joints or a dramatic deterioration in fatigue strength.[23,24] However, it is not straightforward that a failure mechanism resulting from the microstructural change in common $\mathrm{Pb}-\mathrm{Sn}$ joints can be also applied to the eutectic Au-Sn joints interested in this study. In the case of 
a ultrafine solder joints the evolution is more unpredictable due to anomalous initial microstructures.

\subsubsection{Interfacial Intermetallics}

Another notable feature of the microstructural change during service of solder joints can be found at the interface between the solder and the substrate, where there tends to be gradual growth of the interfacial intermetallic phases. Intermetallic phases that are formed by liquid-solid (during soldering) and solid-solid (during service) reactions at solder joint interfaces have both a negative and positive effect on the solder joints. Intermetallics give the solder joints good metallurgical bonds during soldering but their excessive growth during service may be deleterious to joint reliability. Due to their brittle nature, failures of the joint along the interface can occur either at an unacceptably low mechanical stress or by thermal fatigue.[25-27] Growth of intermetallics also cause the substrate metal to be consumed by the solder. Excessive consumption of the solderable metallization by excessive growth of intermetallics can result in fracture of the joint as well as dewetting of the solder in the liquid state.[25,26] In addition, when there is a large difference in the interdiffusional flux between constituent components of intermetallics, Kirkendall voids can be formed at the solder-substrate interface through the growth of interfacial intermetallics.[28,29] The formation of these voids can provide serious reliability concerns due to crack initiation and propagation. As the thickness of the solder joints becomes smaller with trend toward miniaturization, the above problems are expected 
to be more notable and the role of interfacial intermetallics is likely to be more important.

Since the majority of solder joint schemes in electronic packaging have been $\mathrm{Pb}-\mathrm{Sn}$ solders on $\mathrm{Cu}$ metallization, $\mathrm{Cu}-\mathrm{Sn}$ intermetallics such as $\mathrm{Cu}_{6} \mathrm{Sn}_{5}$ and $\mathrm{Cu}_{3} \mathrm{Sn}$ are most common in soldering process, and their formation and growth have been extensively studied.[25-27]. Although the growth kinetics of interfacial intermetallics is generally described by diffusion-controlled parabolic growth behavior, individual growth behaviors depend on the physical metallurgy of solder and substrate metals of specific joint geometries. For combinations of new solder systems with substrate metals, it is not well known what kind of intermetallic phases are formed, how fast they grow and how they affect the joint reliability.

\subsection{SOLder OF InTEREST In ThIS STUdy: EUTECTIC AU-SN}

High $\mathrm{Pb}$-containing alloys such as $95 \mathrm{~Pb}-5 \mathrm{Sn}$ (melting temperature of $312^{\circ} \mathrm{C}$ ) are commonly used in the first level interconnection in flip chip technology.[30] In order to avoid remelting in processes of subsequent level interconnections, the use of high temperature solders at the first level is necessary. However, high $\mathrm{Pb}$-containing solders bring with them potential problems due to environmental concerns and soft errors in complementary metal-oxide semiconductor (CMOS) technology caused by alpha particle emission.[31] To date most research on lead-free solders in electronic packaging focuses on the alternative for a conventional eutectic $\mathrm{Pb}-\mathrm{Sn}$ of melting temperature $183^{\circ} \mathrm{C} .[2,10-15]$ There are only few $\mathrm{Pb}$-free alloys of which melting points are around $300^{\circ} \mathrm{C} .[32]$ Among them, eutectic Au-Sn alloy has superior 
properties to $\mathrm{Pb}-5 \mathrm{Sn}$ with a similar melting point, so that it can substitute for high temperature solders.

\subsubsection{Characteristics of Eutectic Au-Sn}

Eutectic Au-Sn solder has a nominal composition of $80 \mathrm{Au}-20 \mathrm{Sn}$ by weight and $71 \mathrm{Au}-29$ by molar content. This composition has a eutectic reaction of $\mathrm{L} \leftrightarrow \zeta+\delta$ at $280^{\circ} \mathrm{C}$ as can be seen in Au-AuSn binary phase diagram (Figure 1.5).[33]. The $\zeta$ phase of Mg-type hexagonal close packed structure has been found to extend from 9.1 at. $\% \mathrm{Sn}$ at $521{ }^{\circ} \mathrm{C}$ to 17.6 at. $\%$ at $280^{\circ} \mathrm{C}$. The $\zeta^{\prime}$ phase of ordered hexagonal structure (nominally $\mathrm{Au}_{5} \mathrm{Sn}$ ) has a composition of approximately 16 at.\%, and forms from $\zeta$ through a peritectoid reaction at $190^{\circ} \mathrm{C}$. The $\delta$ phase is the AuSn intermetallic compound with a melting point of $419.3^{\circ} \mathrm{C}$. This phase has NiAs-type hexagonal structure with a homogeneity range between 50.0 and 50.5 at.\% Sn.[32,33] One thing to be noted in considering the $\mathrm{Au}-\mathrm{Sn}$ phase diagram is the steep liquidus lines on the Au-rich side of the eutectic. Unlike conventional eutectic $\mathrm{Pb}-\mathrm{Sn}$, slight deviation from eutectic composition can cause a much higher liquidus temperature, so careful control of the composition is necessary during the processing of this alloy.

The properties of eutectic Au-Sn solder are compared with other high temperature solders and a eutectic $\mathrm{Pb}-\mathrm{Sn}$ solder in Table 1.2.[34] It has high thermal and electrical conductivities, which is particularly attractive for flip chip bonding. Furthermore, this eutectic alloy also has relatively good mechanical properties, having the highest strength and lowest Young's modulus among Au-based eutectic solders. 
Because of its high strength eutectic Au-Sn has excellent fatigue and creep resistance.[34,35]

Table 1.2. Properties of eutectic Au-Sn solder with other solders.[35]

\begin{tabular}{c|c|c|c|c|c|c}
\hline $\begin{array}{c}\text { Alloy } \\
(\text { wt.\%) }\end{array}$ & $\begin{array}{c}\text { Melting } \\
\text { Point } \\
\left({ }^{\circ} \mathrm{C}\right)\end{array}$ & $\begin{array}{c}\text { Thermal } \\
\text { Conductivity } \\
\left(\mathrm{W} / \mathrm{m}^{\circ} \mathrm{C}\right)\end{array}$ & $\begin{array}{c}\text { Coefficient of } \\
\text { Thermal } \\
\text { Expansion } \\
\left(10^{-6} /{ }^{\circ} \mathrm{C}\right)\end{array}$ & \multicolumn{3}{|c}{ Yield Strength(MPa) at } \\
$23{ }^{\circ} \mathrm{C}$ & $100^{\circ} \mathrm{C}$ & $150^{\circ} \mathrm{C}$ \\
\hline $\mathrm{Au}-20 \mathrm{Sn}$ & 280 & 57.3 & 15.9 & 275 & 217 & 165 \\
\hline $\mathrm{Au}-12 \mathrm{Ge}$ & 356 & 44.4 & 13.3 & 185 & 177 & 170 \\
\hline $\mathrm{Au}-3 \mathrm{Si}$ & 363 & 27.2 & 12.3 & 220 & 207 & 195 \\
\hline $\mathrm{Pb}-63 \mathrm{Sn}$ & 183 & 50.6 & 24.7 & 35 & 15 & 4 \\
\hline $\mathrm{Pb}-5 \mathrm{Sn}$ & $308-312$ & 23 & 29.8 & 14 & 10 & 5 \\
\hline
\end{tabular}

\subsubsection{Applications}

Due to its relatively good properties and high melting temperature as compared to conventional eutectic $\mathrm{Pb}-\mathrm{Sn}$ solder, eutectic Au-Sn can be used for many high temperature applications. As a $\mathrm{Pb}$-free solder, it can be an alternative for the high temperature $\mathrm{Pb}$-bearing solders currently used in flip chip bonding. Also because of its high $\mathrm{Au}$ content, it allows fluxless soldering process, which is desirable for devices where contamination is concerned.[36] In tape automated bonding (TAB) packages, eutectic $\mathrm{Au}-\mathrm{Sn}$ has been used for the bonding of inner leads, where bonds can be formed between the gold bumps on a chip and the tin-plated copper leads on the TAB package.[37] In addition, there are applications for GaAs die attachment procedures, power amplifier packages[35] and hermetic sealing packages.[38] 


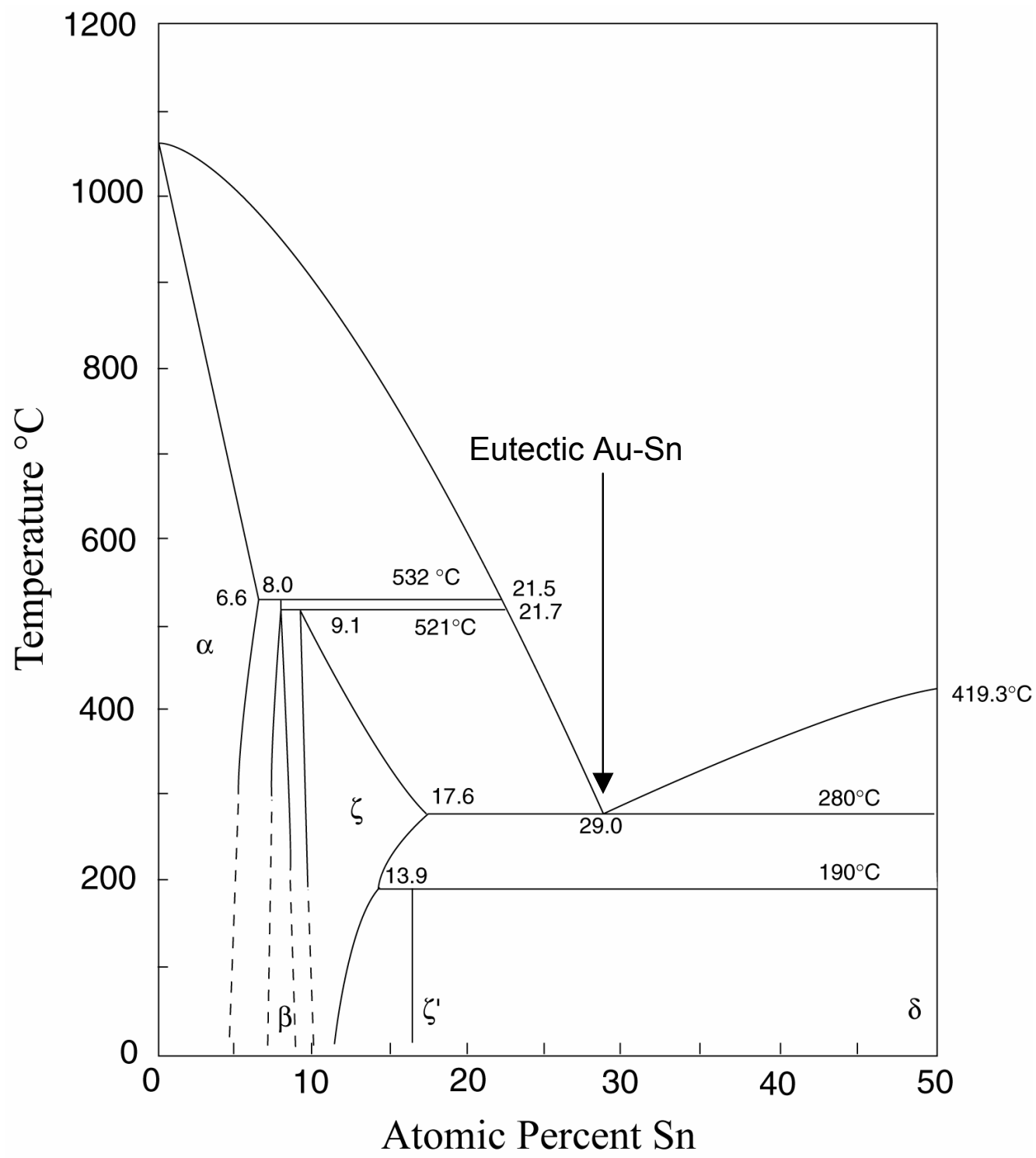

Figure 1.5. Au-AuSn binary phase diagram.[33] The eutectic Au-Sn solder has a nominal composition of $80 \mathrm{Au}-20 \mathrm{Sn}$ by weight and $71 \mathrm{Au}-29 \mathrm{Sn}$ by molar content. 


\subsection{OBJECTIVES}

This study emphasizes the microstructure and microstructural evolution of solder joints in microelectronic packaging, which directly affects their mechanical properties and reliability. Due to difficulties in characterization and testing, much of the data published up until now concerning the microstructure and mechanical properties of ultafine $\mathrm{Pb}$-free solder joints has been based on bulk solder or simulated joint specimens. In order to this study correctly actual solder joints need to be used for studying joint reliability. The uniqueness of this study can be found in both the ultrafine geometry and Au-Sn composition of the solder joints, since previous information on the microstructure and microstructural change of ultrafine eutectic AuSn joints has been extremely limited.

The purpose of this study is to understand the microstructural characteristics of ultrafine eutectic Au-Sn solder joints and relate the results to joint reliability. In the end this information can be useful for designing more reliable solder joints.

First, effects of the joint size and type of substrate metallization on the microstructure of eutectic Au-Sn solder joint is studied. Secondly, the effect of isothermal aging and thermal cycling on the microstructural evolution of eutectic AuSn solder joint is investigated. Importantly, both the bulk and interfacial structure of the solder joints were examined through the course of this study.

Specifically, Chapter 2 addresses most of the problems discussed in this chapter by studying eutectic $\mathrm{Au}-\mathrm{Sn}$ solder joints on $\mathrm{Cu}$, which is the most common pad metallization found in microelectronic packaging. Chapter 3 discusses using 
eutectic $\mathrm{Au}-\mathrm{Sn}$ on $\mathrm{Cu} /$ electroless $\mathrm{Ni} / \mathrm{Au}$ metallization as a diffusion barrier against $\mathrm{Cu}$ at the interface. 


\section{Chapter 2. Microstructure Of Eutectic AU-Sn \\ SOLDER JOINTS ON CU}

\subsection{INTRODUCTION}

Due to its high wettability with most solders and superior electrical properties, $\mathrm{Cu}$ is widely used as a base material for solder pads in electronic packaging. In flip chip technology, which requires a multilayer under-bump metallurgy, $\mathrm{Cu}$ is also a common choice for a solder wetting layer.[39-41] This chapter focuses on the microstructure and microstructural evolution of eutectic $\mathrm{Au}-\mathrm{Sn}$ when $\mathrm{Cu}$ serves as a terminal metal of the chip.

The mechanical reliability of solder joints depends critically on the microstructure of the solder joints, as discussed in chapter 1. Testing using simulated samples is inevitable due to the difficulty of testing using actual joints. However, simulated samples have representative microstructures, i.e. equivalent with the microstructure produced in actual solder joints. With the popular eutectic Pb-Sn alloy, the very limited studies that have been performed have been reference microstructures for solder joints of very small volume.

It has been shown that in eutectic $\mathrm{Pb}-\mathrm{Sn}$ solder joints with the size of 40 to 70 $\mu \mathrm{m}$ diameter (19 $\mu \mathrm{m}$ height) their microstructures are far from the classic eutectic lamellar structure due to a rapid solidification effect.[8] Since initial microstructures are different from the microstructure commonly assumed in larger joints, it is not known how temperature and deformation will affect the microstructural evolution in smaller joints and thereby their reliability. 
The present work concentrates on the microstructure and microstructural evolution of small volumes of nominally eutectic Au-Sn solder on $\mathrm{Cu}$. The solders were prepared as small bumps or joints with linear dimensions of $60-140 \mu \mathrm{m}$, made by the commercial Z-MAJIC ${ }^{\mathrm{TM}}$ process.[42] The work was conducted by studying the microstructures in the as-solidified condition, and followed their development during aging and thermal cycling. The results show that the initial microstructure can be quite coarse on the scale of the joint, and that both the microstructure and phase distribution can change significantly as the solder accumulates $\mathrm{Cu}$ from the substrates during aging and thermal cycling.

\subsection{Experimental Procedure}

The work was performed in the following steps: First, characterizing the microstructural features of as-solidified joints. Second, identifying microstructural changes during isothermal aging and thermal cycling.

\subsubsection{Test Samples}

The two sets of samples that were used in this study were made by Fujitsu Computer Packaging Technologies, and are illustrated in Figure 2.1. The first set of samples (Figure 2.1 (a)) was made as a 20x20 array of solder bumps of eutectic Au-Sn solder (80Au-20Sn by weight, $71 \mathrm{Au}-29 \mathrm{Sn}$ by molar content) on $\mathrm{Si}$ substrates electroplated with $15-20 \mu \mathrm{m} \mathrm{Cu}$. The bumps were spherical caps $140-145 \mu \mathrm{m}$ in diameter and 55-65 $\mu \mathrm{m}$ tall, and the array had a pitch of about $500 \mu \mathrm{m}$. The bumps were made with the "bumped" variation of the Z-MAJIC"M process.[42] 

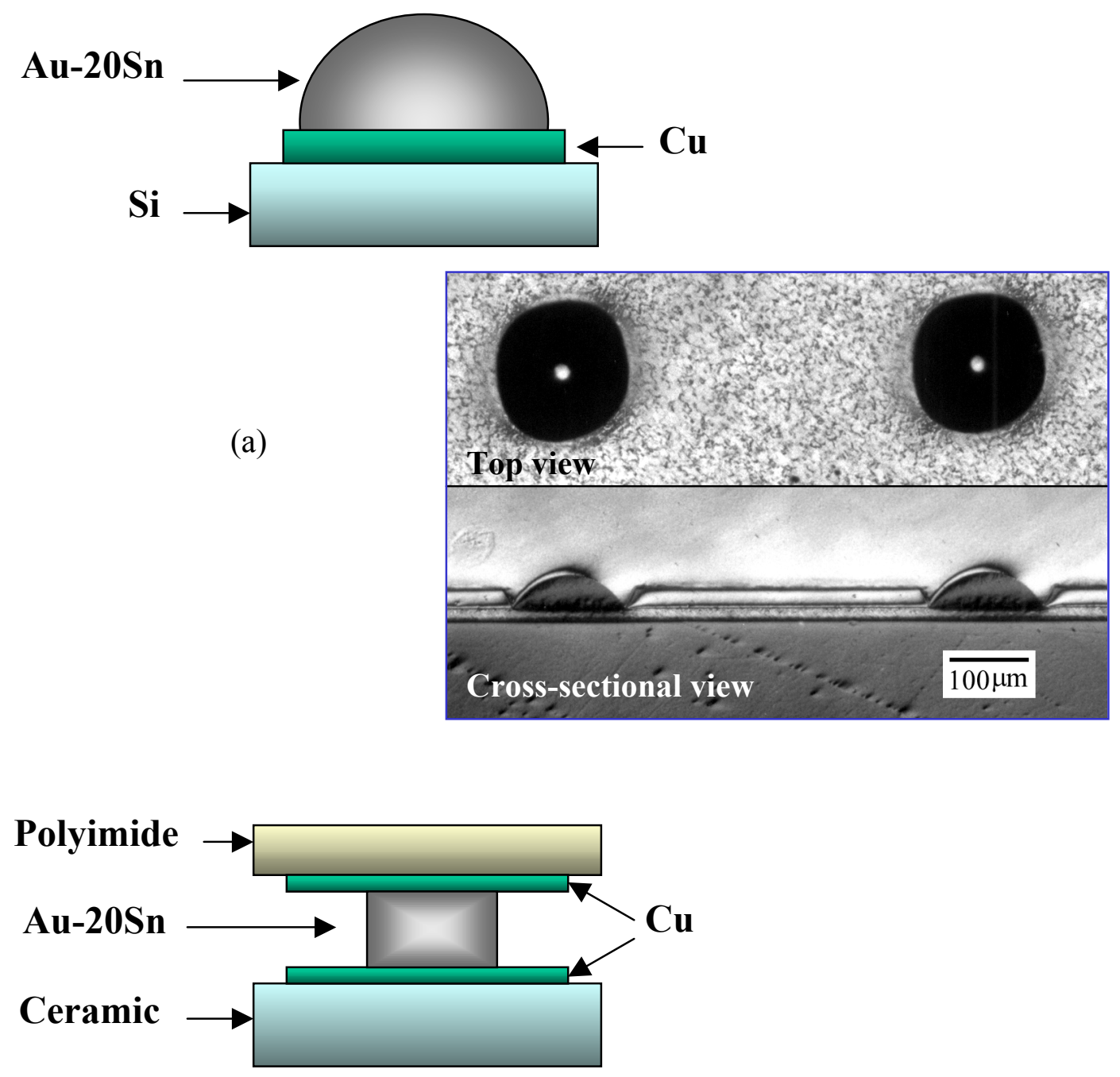

(b)

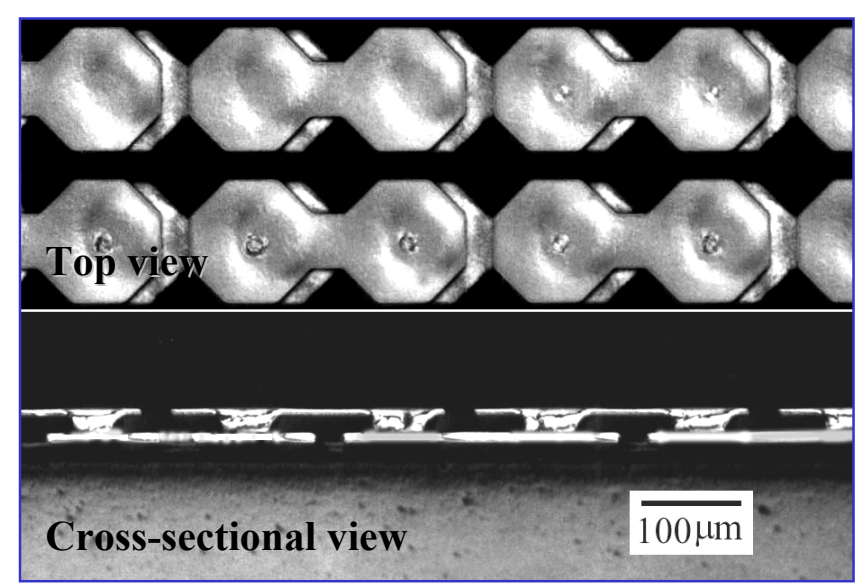

Figure 2.1. Schematic diagrams and pictures of sample geometries used in this study. (a) solder bump: unjoined bump (b) solder joint: joined bump. 
In this process a thermoplastic bonding sheet with a removable cover layer is tacked or laminated onto the substrate. The composite sheet has a pattern of cavities that expose the underlying $\mathrm{Cu}$ layer. Solder paste is deposited into the cavities and reflowed to form the bumps. The reflow treatment includes a $75 \mathrm{sec}$. exposure above $280^{\circ} \mathrm{C}$ with a peak temperature of $315^{\circ} \mathrm{C}$, slightly above the $280^{\circ} \mathrm{C}$ melting temperature of eutectic Au-Sn (Figure 1.5). The cover layer is then removed, exposing the tops of the solder bumps for subsequent bonding. Details of the process are described in Appendix.

The second set of samples (Figure 2.1 (b)) came from eutectic Au-Sn solder bumps, also made on a $\mathrm{Cu}$-plated ceramic substrate (Alumina) by the Z-MAJIC ${ }^{\mathrm{TM}}$ process, that were bonded to a layer of $\mathrm{Cu}$-plated polyimide to complete the joint. In this case the joints were about $60 \mu \mathrm{m}$ in diameter and $25 \mu \mathrm{m}$ in height with a pitch size of about $150 \mu \mathrm{m}$, while the $\mathrm{Cu}$ plated layers on the top and bottom pads were about 5 $\mu \mathrm{m}$ in thickness. This second set of samples underwent a second lamination reflow $\left(10 \mathrm{~min}\right.$. above $280^{\circ} \mathrm{C}$, peak at $310^{\circ} \mathrm{C}$ ) in forming the joint.

The relatively large solder bump samples were used as a reference for the study of the smaller volume solder joints samples.

\subsubsection{Thermal Treatments and Microstructural Characterization}

The microstructure of the solder bumps (the first set of samples) was studied under following three conditions: as-solidified, after up to eight "reflow treatments" to a peak temperature of $260^{\circ} \mathrm{C}$, and after aging at $200^{\circ} \mathrm{C}$ for up to 120 days. In this case, the "reflow treatments" do not actually melt the solder; the cycle was used to 
simulate the reflow that lower melting temperature solders such as $\mathrm{Sn}-3.5 \mathrm{Ag}$ joints (melting temperature of $221^{\circ} \mathrm{C}$ ) undergo when used in the same devices as occurs in commercial practice.

The microstructure of the solder joints (the second set of samples) was studied under the following three conditions: after aging at $150^{\circ} \mathrm{C}$ for 20 days, after aging at $200^{\circ} \mathrm{C}$ for up to 50 days, and after thermal cycling from $-65^{\circ} \mathrm{C}$ to $150^{\circ} \mathrm{C}$ for 500 cycles (a ramp of 10min and a dwell of 10min.).

Microstructural characterization was performed through metallographic study and compositional analysis. Metallographic studies were done on samples that were mounted in epoxy, then polished to observe and analyze the cross-sectional microstructure using a optical microscope and a scanning electron microscope (SEM) with a back-scattered electron (BSE) detector. An energy-dispersive X-ray (EDX) analyzer was used for the compositional analysis. It was found that some $\mathrm{Cu}$ was transferred from the $\mathrm{Cu}$ pad onto the solder surface during polishing. To remove this $\mathrm{Cu}$, the samples were etched with dilute $\mathrm{HNO}_{3}$ before EDX analysis.

Additional details of the microstructure were analyzed by a transmission electron microscope (TEM).

\subsection{SOLDER BUMPS}

The microstructures of all the solder bumps studied resemble that of the assolidified bump shown in Figure 2.2. As expected from the binary phase diagram (Figure 1.5), the bulk of the solder is a eutectic mixture of the $\delta$-phase (nominally AuSn) and $\zeta$-phase (a Au-rich intermetallic with a broad composition range, from 
about 9 to almost 18 atomic percent $\mathrm{Sn}$ ). The $\mathrm{Cu}$ interface is coated with a thick, irregularly shaped intermetallic layer that is predominantly $\zeta$-phase with a significant addition of $\mathrm{Cu}$ substituting for $\mathrm{Au}$. In addition, the aged samples have a double layer of $\mathrm{Cu}$-rich intermetallic between the $\zeta$-phase and the $\mathrm{Cu}$ substrate; the inner layer is nominally $\mathrm{Cu}_{3} \mathrm{Au}$, while the outer layer is nominally $\mathrm{CuAu}$.

\subsubsection{As-Solidified Bumps}

The cross-sectional microstructure of the as-solidified bump is shown in Figure 2.2. The interior of the bump has a fine-scale eutectic microstructure. The bright constituent in the eutectic is $\zeta$-phase while the darker constituent is $\delta$-phase. $\mathrm{Cu}$ was detected throughout the bulk solder by EDX analysis, suggesting that $\mathrm{Cu}$ dissolved into the molten solder during reflow. The composition of the bulk eutectic is approximately $60 \mathrm{Au}-10 \mathrm{Cu}-30 \mathrm{Sn}$ (all compositions are in mole fraction unless stated otherwise). Since the nominal composition of eutectic $\mathrm{Au}-\mathrm{Sn}$ is 71Au-29Sn, it appears that $\mathrm{Cu}$ substitutes for $\mathrm{Au}$ in the eutectic. However, due to the very fine spacing of the lamellae it was not possible to determine how $\mathrm{Cu}$ partitions between the two phases.

The mushroom-shaped interfacial intermetallic was identified by EDX analysis as a ternary $\mathrm{CuAuSn}$ that has a composition of (66-70) $\mathrm{Au}(16-20) \mathrm{Cu}(13-15) \mathrm{Sn}$, with the $\mathrm{Cu}$ content increasing slightly toward the interface. If we assume that the $\mathrm{Cu}$ substitutes for $\mathrm{Au}$, this phase is $\zeta$-phase in its ternary, approximately $(\mathrm{AuCu})_{5} \mathrm{Sn}$ form. This conclusion is consistent with the proposed ternary phase diagram shown in Figureure 2.3,[36] which suggests that the $\zeta$-phase can incorporate up to about $20 \mathrm{Cu}$. 

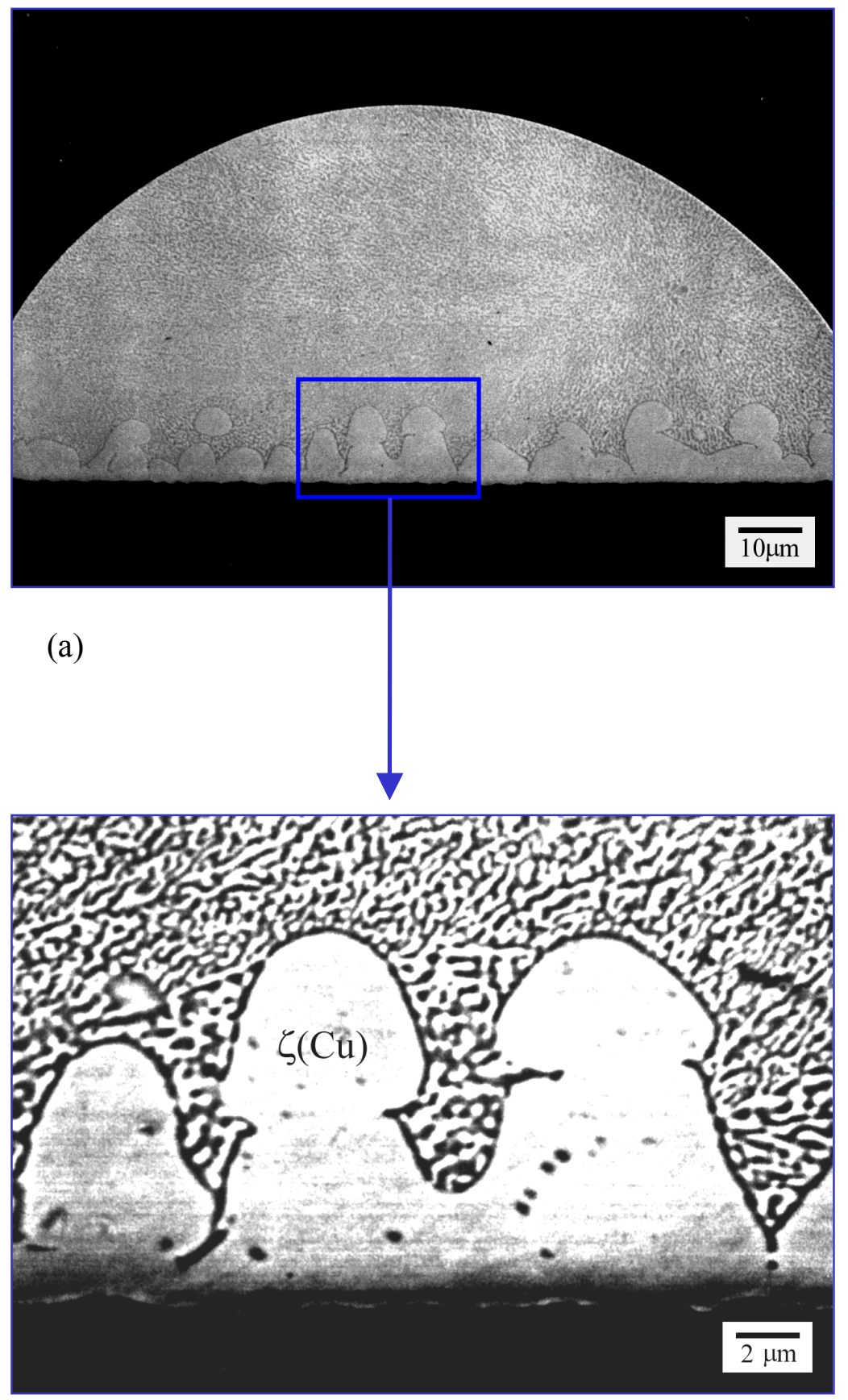

(b)

Figure 2.2. Cross-sectional micrographs of as-solidified solder bump (a) SEM image at low magnification (b) BSE image at high magnification. 


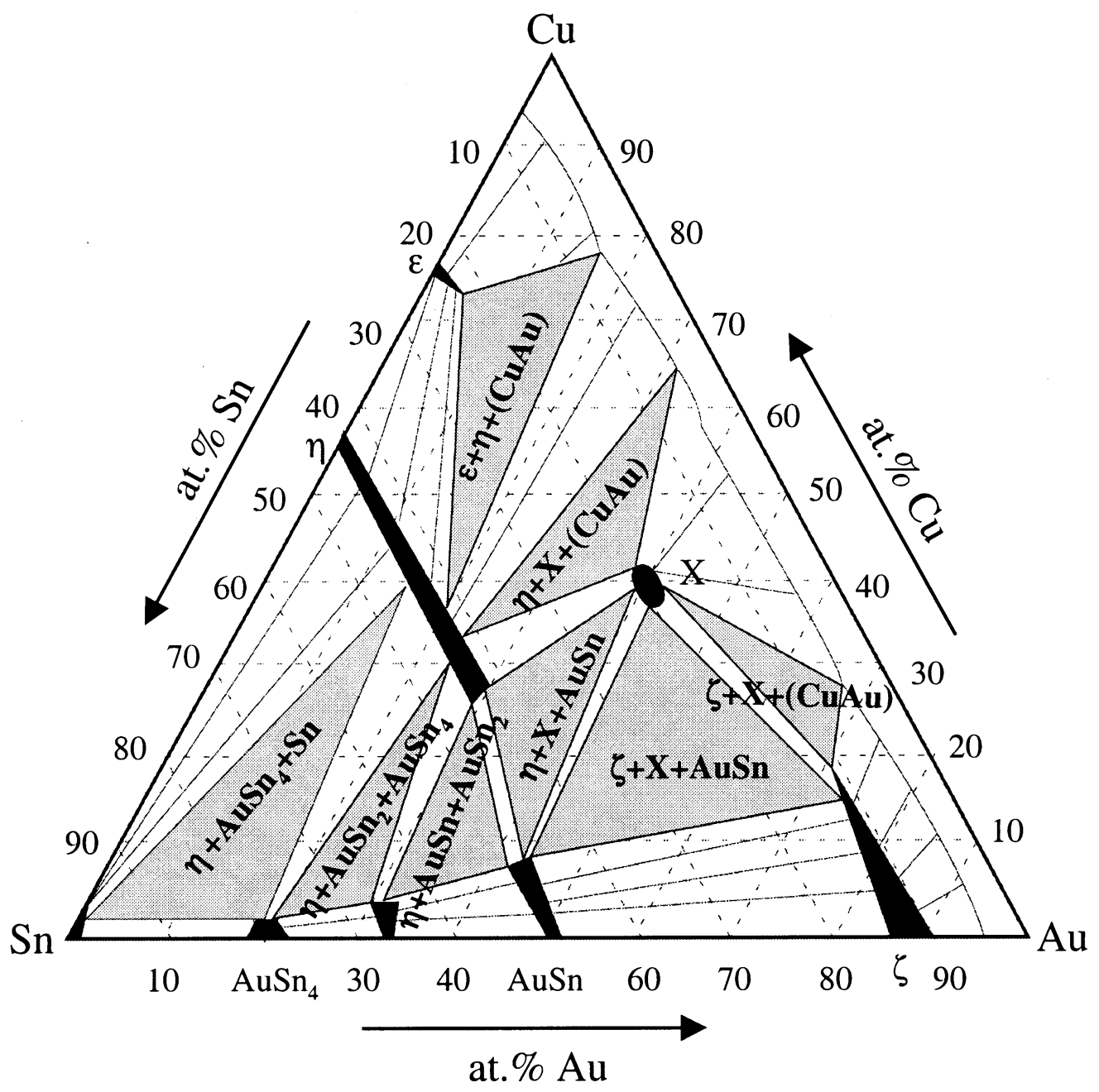

Figure 2.3. Isothermal cross section of the ternary Au-Cu-Sn system at $190^{\circ} \mathrm{C} .[36]$ 
A close examination of BSE images shows that there is a thin layer of a third phase at the $\mathrm{Cu}-\zeta$ interface. EDX analysis revealed that this phase is relatively rich in $\mathrm{Cu}$, but, since the layer is no more than $0.5 \mu \mathrm{m}$ thick, its composition could not be measured precisely.

The incorporation of $\mathrm{Cu}$ into the high Au-content eutectic Au-Sn system can be inferred from the binary Au-Cu system.[43] Since well established criteria by Hume-Rothery for the extensive solid solubility are satisfied,[44] $\mathrm{Au}$ and $\mathrm{Cu}$ form a continuous solid solution above $410^{\circ} \mathrm{C}$. That is, the size difference between $\mathrm{Au}$ and $\mathrm{Cu}$, although not negligible, is well within the $15 \%$ criterion. Additionally their valences are equal in metallic phases, and small distinction in electronegativity certainly does not by itself remove compatibility.[45] Therefore, $\mathrm{Cu}$ can replace Au in the eutectic Au-Sn solder.

The overall microstructure of the bump is relatively easy to understand, based on the solid-liquid reaction between molten eutectic $\mathrm{Au}-\mathrm{Sn}$ solder and the $\mathrm{Cu}$ substrate. When the solder is molten, between $280^{\circ} \mathrm{C}$ and $315^{\circ} \mathrm{C}, \mathrm{Cu}$ dissolves and gradually accumulates in the liquid solder. Since the $\mathrm{Cu}$ acts basically like $\mathrm{Au}$, we can infer from the binary phase diagram (Figure 1.5) that the $\mathrm{Cu}$ addition produces a hypoeutectic composition, from which a $\mathrm{Cu}$-containing $\zeta$-phase precipitates along the $\mathrm{Cu}$ interface. Since $\mathrm{Cu}$ is believed to be the most mobile species in the $\mathrm{Au}-\mathrm{Cu}-\mathrm{Sn}$ system, $[19,27,46-53]$ the rate of growth of this intermetallic is determined by the rate of $\mathrm{Cu}$ diffusion through it to the interface between the intermetallic and the residual molten solder. Since the temperature is only slightly above the eutectic temperature, 
the residual liquid retains at near-eutectic composition, and solidifies into the eutectic constituent upon cooling.

One important observation is that mushroom-shaped phases are considerably large with respect to the bump size. In addition, they each appear to consist of a couple of large grains. Since these are far from the eutectic mixture and occupy a large portion of the bump, it may alter the expected behavior of eutectic Au-Sn. The rationale for the large mushroom shape of these phases is not obvious. However, considering their size and morphologies, their formations may be attributed to the short-circuit channels for $\mathrm{Cu}$ diffusion into the molten solder which are used to explain the fast formation of $\mathrm{Cu}-\mathrm{Sn}$ intermetallics.[54-57] If $\mathrm{Cu}$ diffused through the $\zeta$-phase, the solid state diffusion would lead to much slower $\mathrm{Cu}$ dissolution and a planar intermetallic interface, i.e. a thin flat intermetallic layer would be formed. A possible formation mechanism of the mushroom shaped phases is illustrated in Figure 2.4.

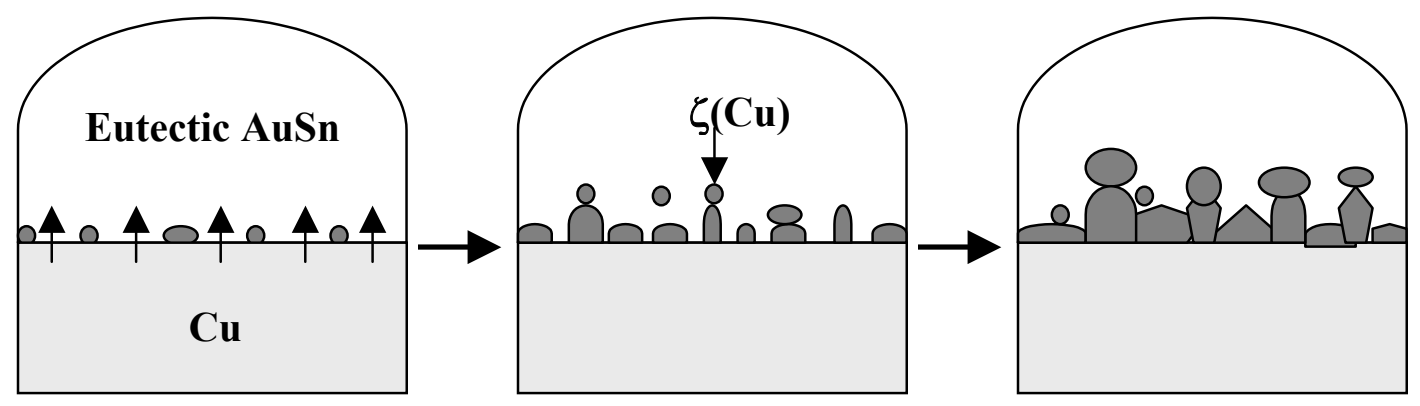

Figure 2.4. Schematic illustration of possible formation mechanism of mushroomshaped phases. 
The $\mathrm{Cu}$ containing $\zeta$-phases are isolated in an early period of their growth and between them provided the channels through which $\mathrm{Cu}$ can contact the molten solder and dissolve continuously. The fast $\mathrm{Cu}$ dissolution increases the local concentration of $\mathrm{Cu}$ near the $\zeta$-phases so that they may nucleate and grow there. As these phases grow, the channels become closed and mushroom-shaped intermetallics can be formed

Figure 2.5 shows details of the microstructure near the mushroom-shaped phase. Diffraction pattern analysis combined with TEM EDX analysis confirms that the mushroom-shaped phase is a $\zeta$-based $(\mathrm{Au}, \mathrm{Cu})_{5} \mathrm{Sn}$ phase. Furthermore, the diffraction pattern reveals that it is a single crystalline, with size that is not comparable to the grains of eutectic constituents.

\subsection{2 "Reflow Treated" Bumps}

Figure 2.6(a) shows a cross-section of a bump that was given eight "reflow" cycles with a peak temperature of $260^{\circ} \mathrm{C}$. This treatment causes an obvious coarsening of the lamellae within the eutectic constituent, making them large enough for EDX analysis. The measured composition of the $\zeta$-phase is (73-76)Au(912) $\mathrm{Cu}(14-15) \mathrm{Sn}$, which is consistent with a straightforward substitution of $\mathrm{Cu}$ for $\mathrm{Au}$. The measured composition of the $\delta$-phase was (46-47)Au(50-52)Sn with less than $2 \mathrm{Cu}$. It appears that the $\mathrm{Cu}$ in the eutectic segregates almost completely to the $\zeta_{-}$ phase. This result disagrees slightly with the proposed ternary phases diagram (Figure 2.3), which does show a preferential segregation to $\zeta$, but suggests a partition that leaves the $\delta$-phase with a more significant $\mathrm{Cu}$ content. 

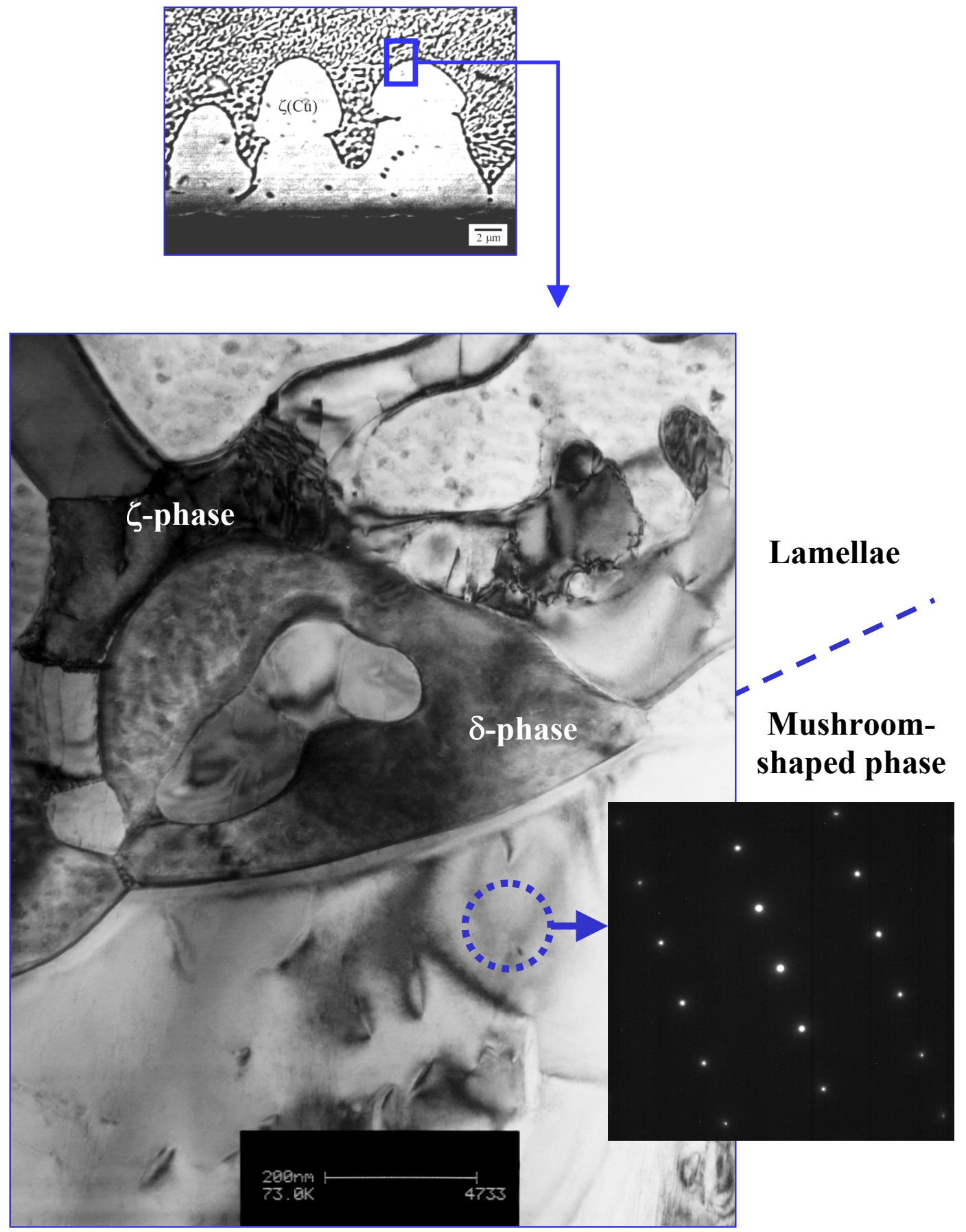

Figure 2.5. TEM bright filed image of as-solidified solder bump. Diffraction pattern analysis shows that the mushroom-shaped phase is a $\zeta$-based single crystalline. 


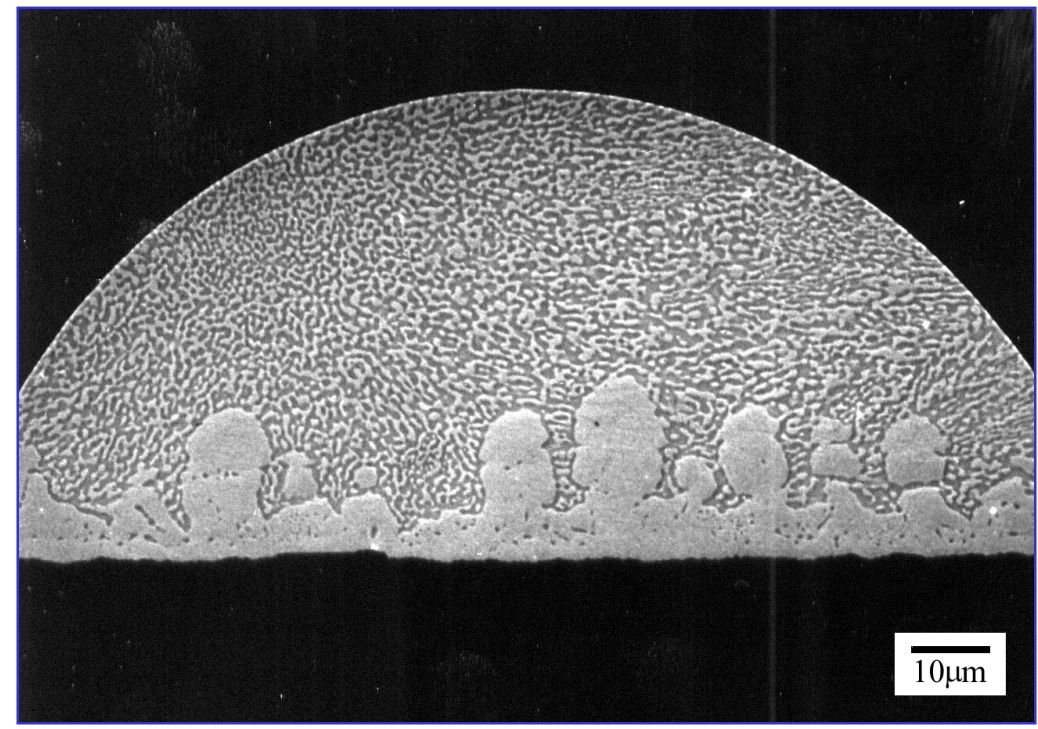

(a)

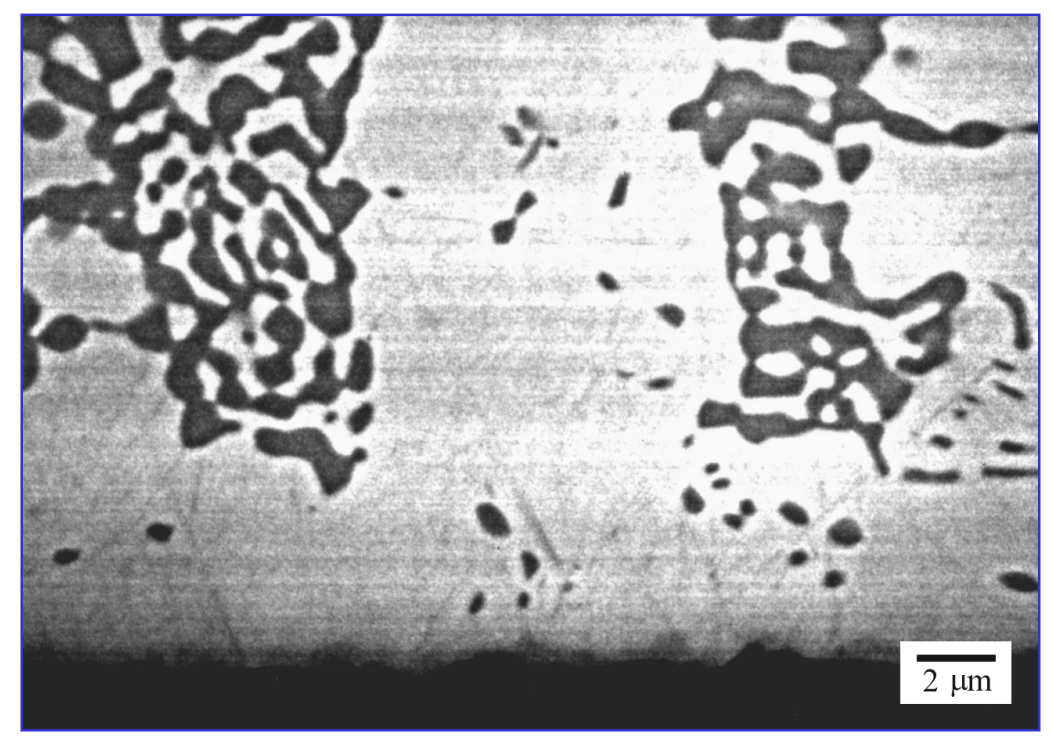

(b)

Figure 2.6. Cross-sectional micrographs of 8 times-reflowed (peak temperature of $260^{\circ} \mathrm{C}$ ) solder bump (a) SEM image at low magnification (b) BSE image at high magnification. 
The $\zeta$-phase layer at the interface grows very little, if at all, during these "reflows", which do not actually melt the solder. However, its composition is enriched in $\mathrm{Cu}$. EDX analysis of the $\zeta$-phase at the interface shows the composition is (64-70) $\mathrm{Au}(16-25) \mathrm{Cu}(12-15) \mathrm{Sn}$. Moreover, the layer has become decorated with a

distribution of precipitates that were identified as $\delta$-phase (AuSn). The $190^{\circ} \mathrm{C}$ isothermal section of the proposed phase diagram (Figure 2.3) suggests that the system enters a three-phase region, $\zeta+\delta+$ "X", when the $\mathrm{Cu}$ content of $\zeta$ increases above 20 atomic percent and the Sn content is greater than about 15\%. Therefore, it was expected that precipitates of X-phase (40Au40Cu20Sn) would be found within the $\zeta$ layer, however none were found. It follows that the $\zeta$-phase is simply rich in $\mathrm{Cu}$.

The intermetallic layer along the $\zeta-\mathrm{Cu}$ interface (Figure 2.6(b)), also grows during this thermal cycle. Isolated regions of it were thick enough for EDX analysis, and the composition was $(46-48) \mathrm{Cu}(45-47) \mathrm{Au}(7-8) \mathrm{Sn}$. The film is $\mathrm{CuAu}$ with a bit of entrapped Sn.

\subsubsection{Isothermally Aged Bumps}

When the solder bump is aged at $200^{\circ} \mathrm{C}$ the eutectic Au-Sn lamellae coarsen and become globular, while the $\zeta$-layer at the interface accumulates $\mathrm{Cu}$ and new copper-rich intermetallics develop at the $\zeta-\mathrm{Cu}$ interface. Since $\mathrm{Cu}$ forms $\mathrm{Cu}$-rich intermetallics with both $\mathrm{Au}$ and $\mathrm{Sn}$, it is not surprising to find an additional intermetallic at the $\mathrm{Cu}$ interface. 
The early-stage evolution of the microstructure is illustrated in Figure 2.7, which includes BSE images of bumps aged at $200^{\circ} \mathrm{C}$ for 1 and 4 days. The $\zeta$-phase layer at the interface does not appear to grow, but the $\delta$-phase precipitates that are within it grow and become more distinct. The $\mathrm{CuAu}$ layer at the $\mathrm{Cu}$ interface grows noticeably. EDX analysis suggests that this compound is slightly $\mathrm{Cu}$-rich, with a composition near $55 \mathrm{Cu} 45 \mathrm{Au}$, while gradually losing $\mathrm{Sn}$, going from 1-2Sn after 1 day to below 1 Sn after 2 days.

Figure 2.8 shows the microstructure after 80 days at $200^{\circ} \mathrm{C}$. The eutectic has now become quite coarse, and the interfacial $\zeta$-layer has gradually thickened, primarily by filling in the troughs between the mushroom-shaped protrusions. The $\mathrm{CuAu}$ layer has thickened at a nearly constant composition. A third intermetallic layer has appeared on the $\mathrm{Cu}$ side. This layer, which is not clearly seen until after about 50 days aging, has a composition (78-80) $\mathrm{Cu}(17-20) \mathrm{Au}(1-2) \mathrm{Sn}$, showing that it is $\mathrm{Cu}_{3} \mathrm{Au}$ with a possible enrichment of $\mathrm{Cu}$ and a small addition of $\mathrm{Sn}$. Since the $\mathrm{CuAu}$ and $\mathrm{Cu}_{3} \mathrm{Au}$ layers are formed by solid-solid reaction between the $\zeta$ layer and the $\mathrm{Cu}$ substrate and since the Sn source is the $\zeta$ layer, it is interesting that a small amount of Sn was entrapped on the $\mathrm{Cu}$ side in the $\mathrm{Cu}_{3} \mathrm{Sn}$ layer, even though the $\mathrm{CuAu}$ layer was nearly free from $\mathrm{Sn}$. Considering the gradual loss of $\mathrm{Sn}$ from the initial $\mathrm{CuAu}$ layer during aging and assuming the $\mathrm{Sn}$ solubility in $\mathrm{CuAu}$ at $200^{\circ} \mathrm{C}$ is small, $\mathrm{Sn}$ may move out from the $\mathrm{CuAu}$ layer into the $\mathrm{Cu}_{3} \mathrm{Au}$ layer. 


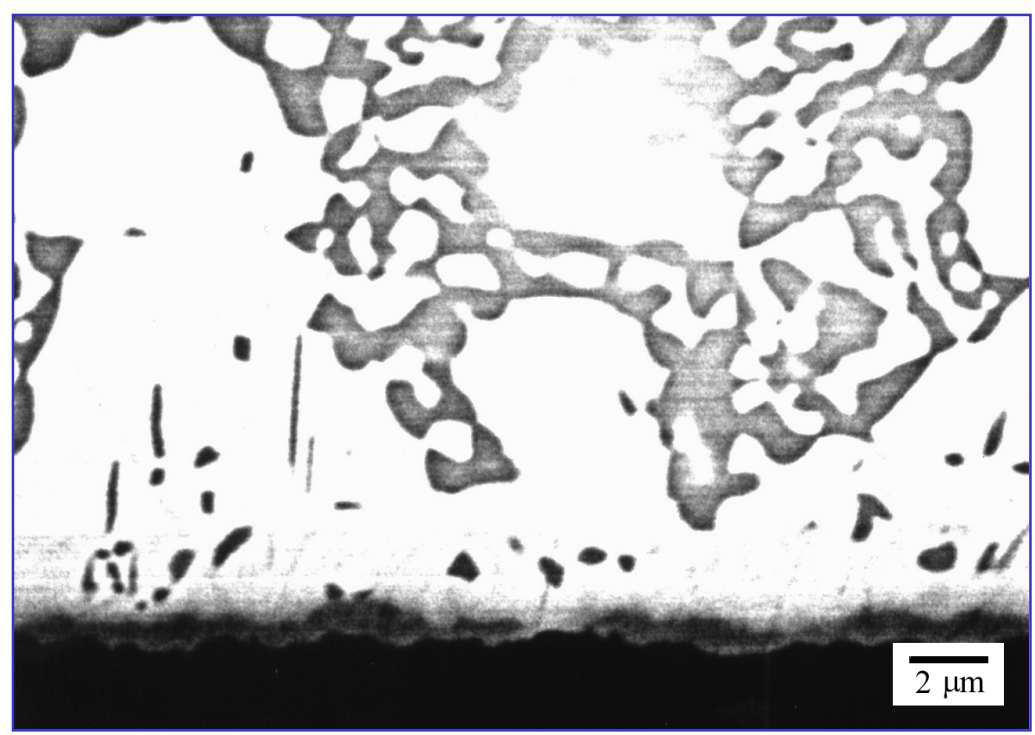

(a)

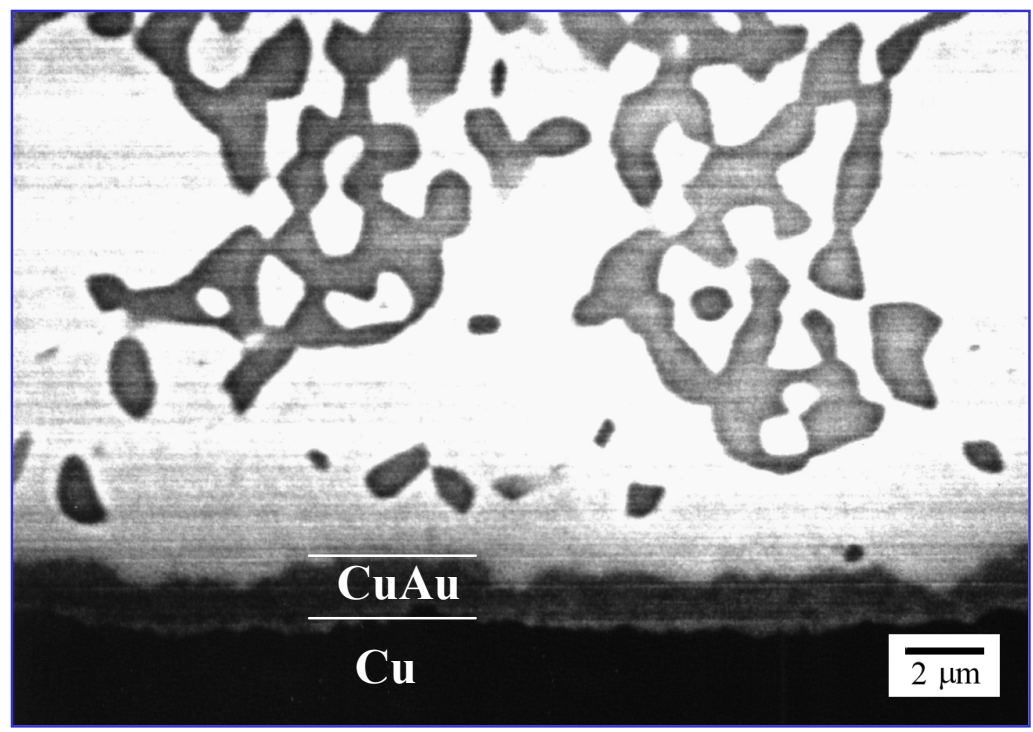

(b)

Figure 2.7. Cross sectional BSE images of solder bumps aged at $200^{\circ} \mathrm{C}$ for (a) 1 day, and (b) 4 days. 

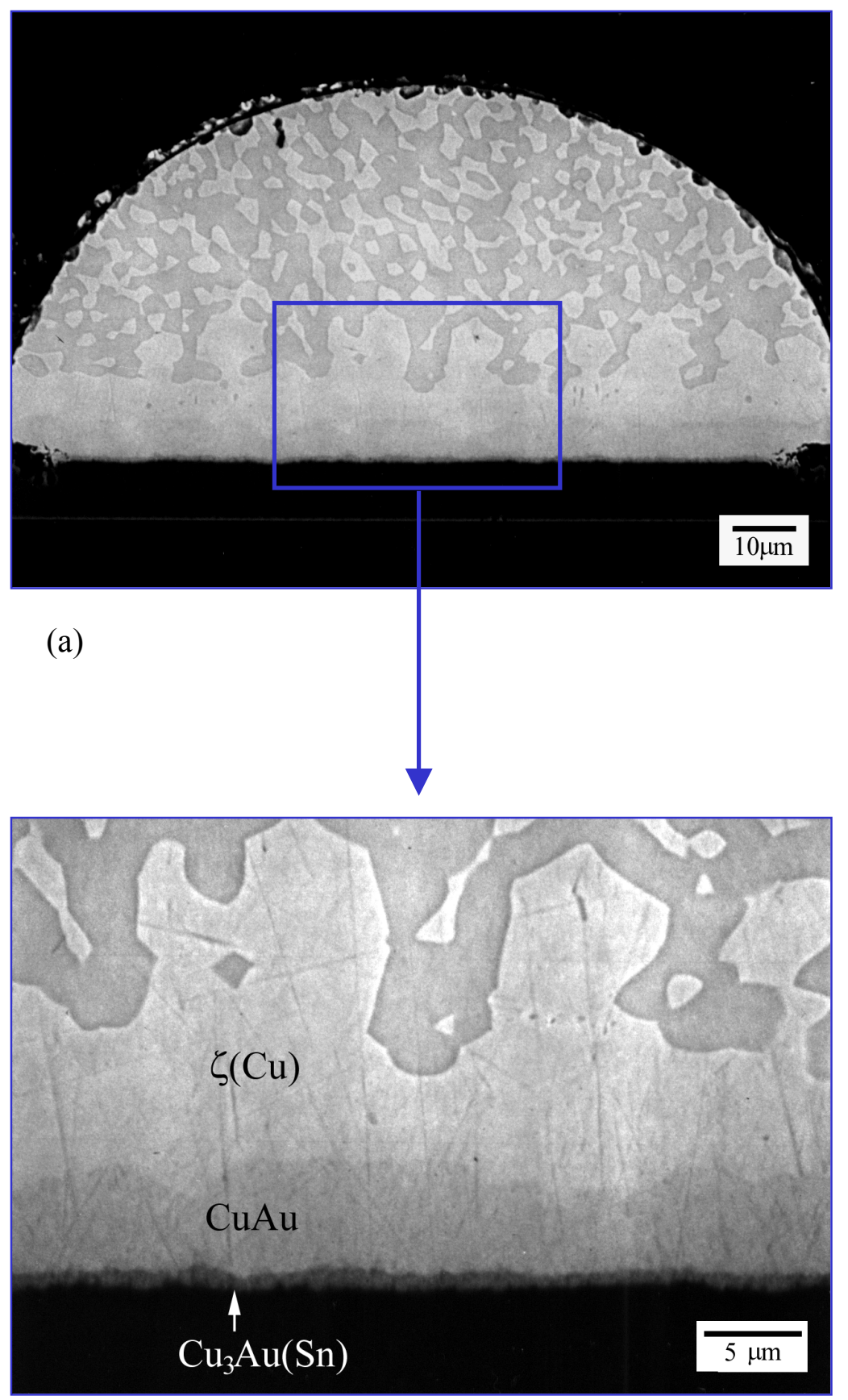

(b)

Figure 2.8. Cross-sectional SEM micrographs of solder bump aged at $200^{\circ} \mathrm{C}$ for 80 days (a) at low magnification (b) at high magnification. 
The $\mathrm{Cu}$ content of the phases within the eutectic has also increased. The $\zeta$ phase composition is (61-63) $\mathrm{Au}(25-29) \mathrm{Cu}(10-12) \mathrm{Sn}$, and the $\delta$-phase (AuSn) now contains a measurable amount of $\mathrm{Cu}($ about $7 \mathrm{Cu})$. No X-phase is found.

Upon further aging the eutectic continues to coarsen, the interfacial $\zeta$-phase layer gradually becomes more enriched in $\mathrm{Cu}$ without significant thickening or $\mathrm{X}$ phase precipitation, and the $\mathrm{CuAu}$ and $\mathrm{Cu}_{3} \mathrm{Au}$ intermetallic layers grow at essentially constant composition.

The growth of the $\mathrm{CuAu}$ and $\mathrm{Cu}_{3} \mathrm{Au}$ layers is plotted in Figure 2.9. While the data is limited, both layers show normal diffusion-controlled growth kinetics and thicken as $\mathrm{t}^{1 / 2} \cdot[25,26,58,59]$ The development of the compound intermetallic layer hence resembles that of the $\mathrm{Cu}-\mathrm{Sn}$ case analyzed by Mei et al.,[27] where the intermetallic grows by consuming the underlying $\mathrm{Cu}$ and the overlying layer of $\zeta$ phase. Once both intermetallic layers have formed, they maintain a constant thickness ratio during growth. Since the $\mathrm{CuAu}$ layer is initially thicker, it also thickens more rapidly.

\subsection{SOLDER JOINTS}

The solder joints studied here differ from the solder bumps in that they are smaller $(60 \mu \mathrm{m}$ diameter, $25 \mu \mathrm{m}$ height vs. $140 \mu \mathrm{m}$ diameter, $60 \mu \mathrm{m}$ height), they contact $\mathrm{Cu}$ on both sides, and they have undergone a second lamination reflow (10 min. above $280^{\circ} \mathrm{C}$, peak at $310^{\circ} \mathrm{C}$ ) in forming the joint. 


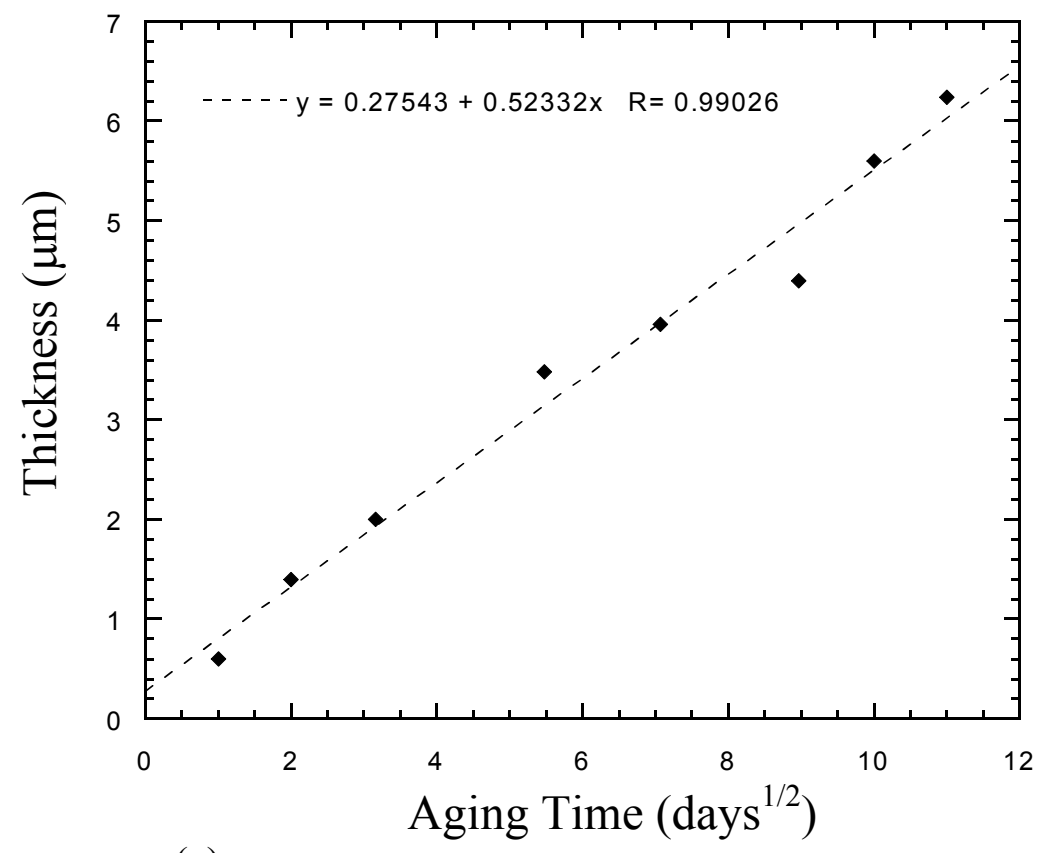

(a)

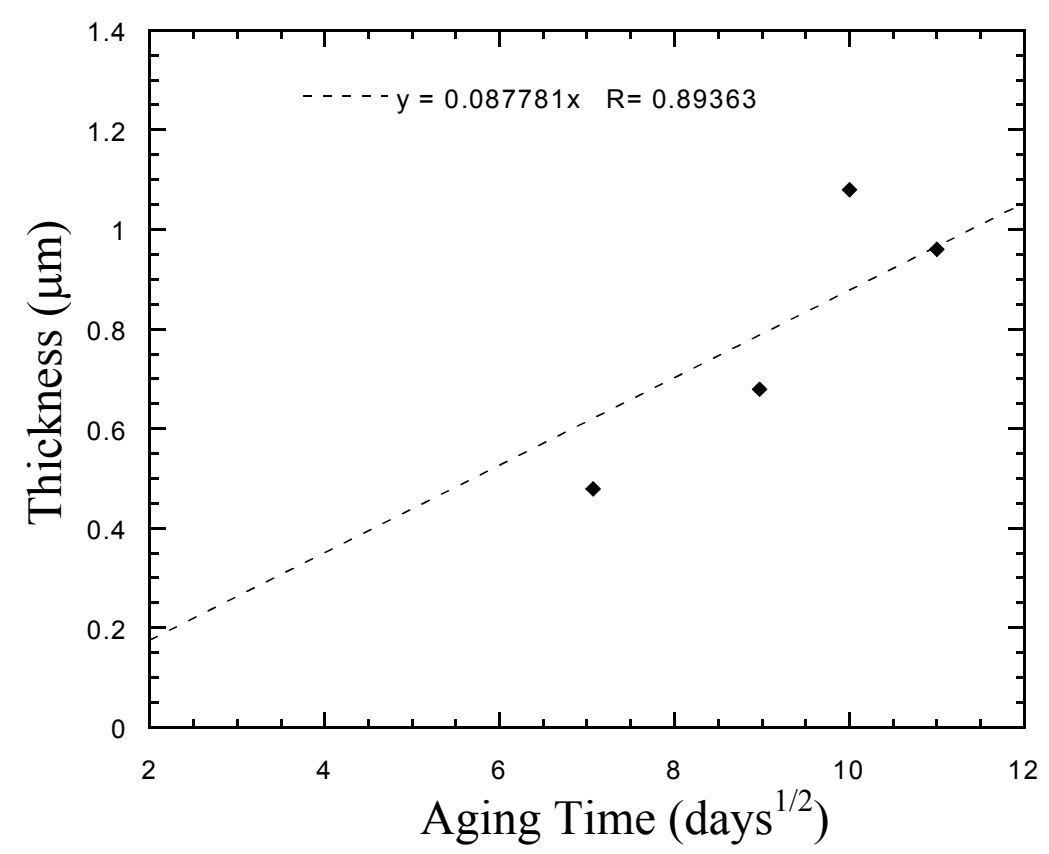

(b)

Figure 2.9. Thickness of (a) the $\mathrm{CuAu}$ layer, and (b) the $\mathrm{Cu}_{3} \mathrm{Au}$ layer in solder bumps with the square root of aging time at $200^{\circ} \mathrm{C}$. 
Moreover, the fact that the joints are enclosed between the bonded layers suggests that the cooling rate after the final lamination reflow is significantly slower than that of the exposed solder bumps described above.

\subsubsection{As-Solidified Joints}

The consequence of changes in the joint geometry and in the process is to produce a joint microstructure that is dramatically different from that of the solder bumps. The substantial majority of the joints examined have the microstructure illustrated in Figure 2.10, with thick intermetallic coatings at both interfaces and a coarse, two-phase structure in the center of the joint. The two phases in the center of the joint are $\delta$-phase, which appears dark in the SEM micrograph, and $\zeta$-phase, which appears relatively light. The $\delta$-phase is almost stochiometric AuSn with very little $\mathrm{Cu}$. The $\zeta$-phase has the measured composition (65-68)Au(19-22) $\mathrm{Cu}(13-14) \mathrm{Sn}$. The thick intermetallic layers at the interfaces are nominally $\zeta$-phase. However, they are highly enriched in $\mathrm{Cu}$, with composition (57-59) $\mathrm{Au}(29-31) \mathrm{Cu}(10-12) \mathrm{Sn}$. This composition is outside the $\zeta$-field of the proposed phase diagram (Figure 2.3), which suggests that the intermetallic contains precipitates. While these are difficult to resolve in the SEM, they become evident upon aging, as discussed below. A single $\mathrm{Cu}$-rich intermetallic layer can also be resolved at the $\mathrm{Cu}$ interface. Its nominal composition is (5659) $\mathrm{Cu}(36-39) \mathrm{Au}(4-6) \mathrm{Sn}$, which is a $\mathrm{Cu}$-rich $\mathrm{CuAu}$ with some entrapped $\mathrm{Sn}$. 


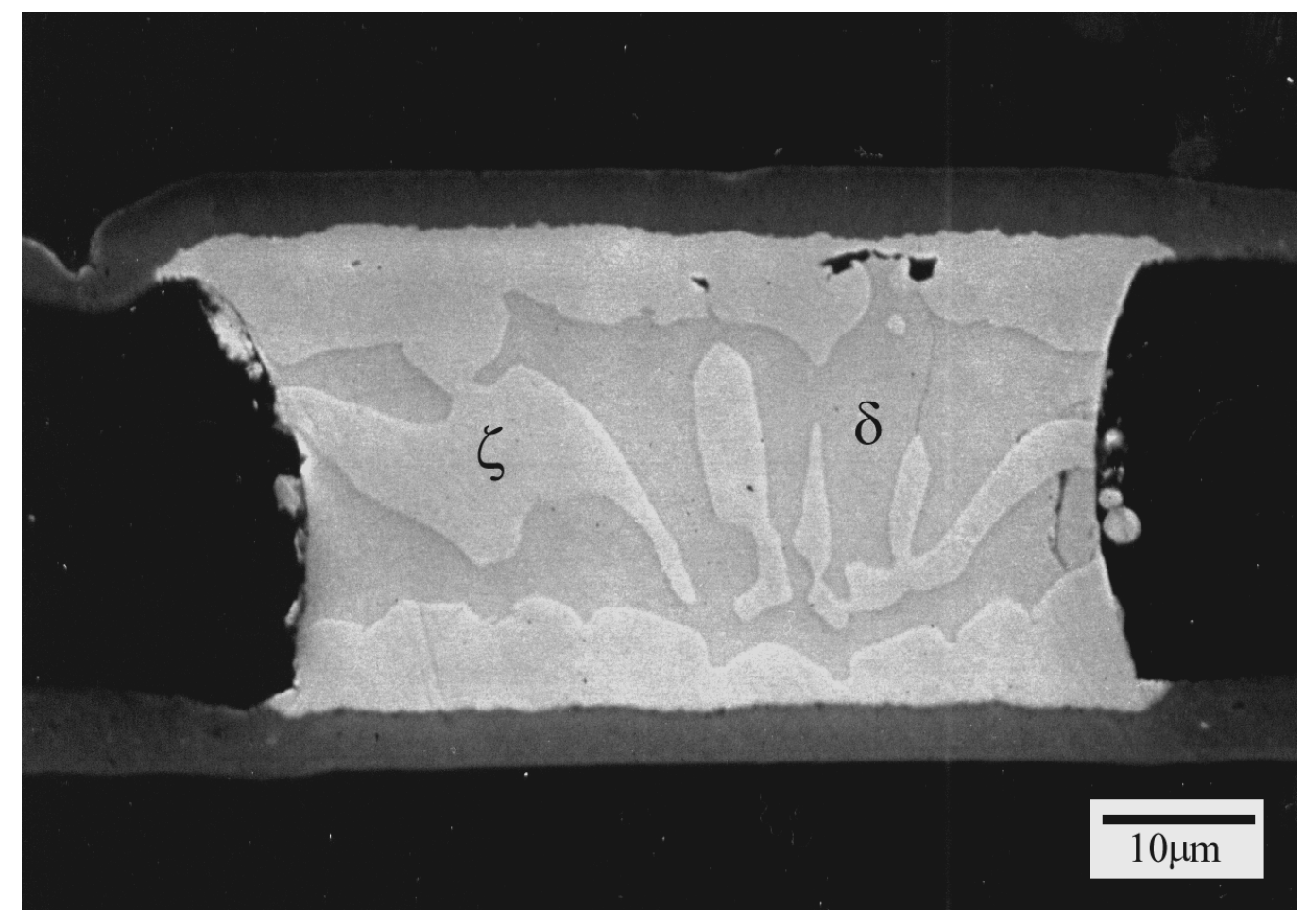

Figure 2.10. Cross-sectional SEM micrographs of as-solidified joint with typical microstructure. 
The microstructure observed in the ultrafine joint is obviously different from the microstructure of large joints or typical bulk solders. This supports our hypothesis that the microstructure and hence the mechanical behaviors of ultrafine joints cannot be inferred from that of large joints.

For the joint samples, it was not possible to examine the microstructure using TEM due to its geometry. Specifically, the polyimide surrounding the joint is nonconductive and damaged by electron beam. However, considering that each big mushroom-shaped phase (also Cu-enriched $\zeta$-phase) in the solder bump was confirmed to be one large grain, which was often more than $20 \mu \mathrm{m}$ tall, it is believed that the microstructure of the ultrafine joint in Figure 2.10 consists of a very small number of grains. Since the number of grains in the ultrafine joint is expected to be very small with respect to the size of the joint, it is not be obvious to predict their mechanical behavior from conventional mechanical tests as discussed in chapter 1 .

\subsubsection{Formation of Joint Microstructure}

An important question is how the microstructure of the joint as shown in Figure 2.10 is formed. Considering the fact that the nominally binary Au-Sn solder turned out to be ternary $\mathrm{Au}-\mathrm{Cu}-\mathrm{Sn}$ in actual joints, the effect of $\mathrm{Cu}$ on the microstructure of the eutectic Au-Sn needs to be evaluated.

In Figure 2.11, a schematic vertical section along 71 Au29Sn(eutectic)-Cu is shown. This diagram was constructed to examine the as-solidified joint microstructure based on Karlsen et al.'s isothermal sections near $320^{\circ} \mathrm{C}$ (Figure $2.12),[45]$ which is close to the peak temperature of the present study. 


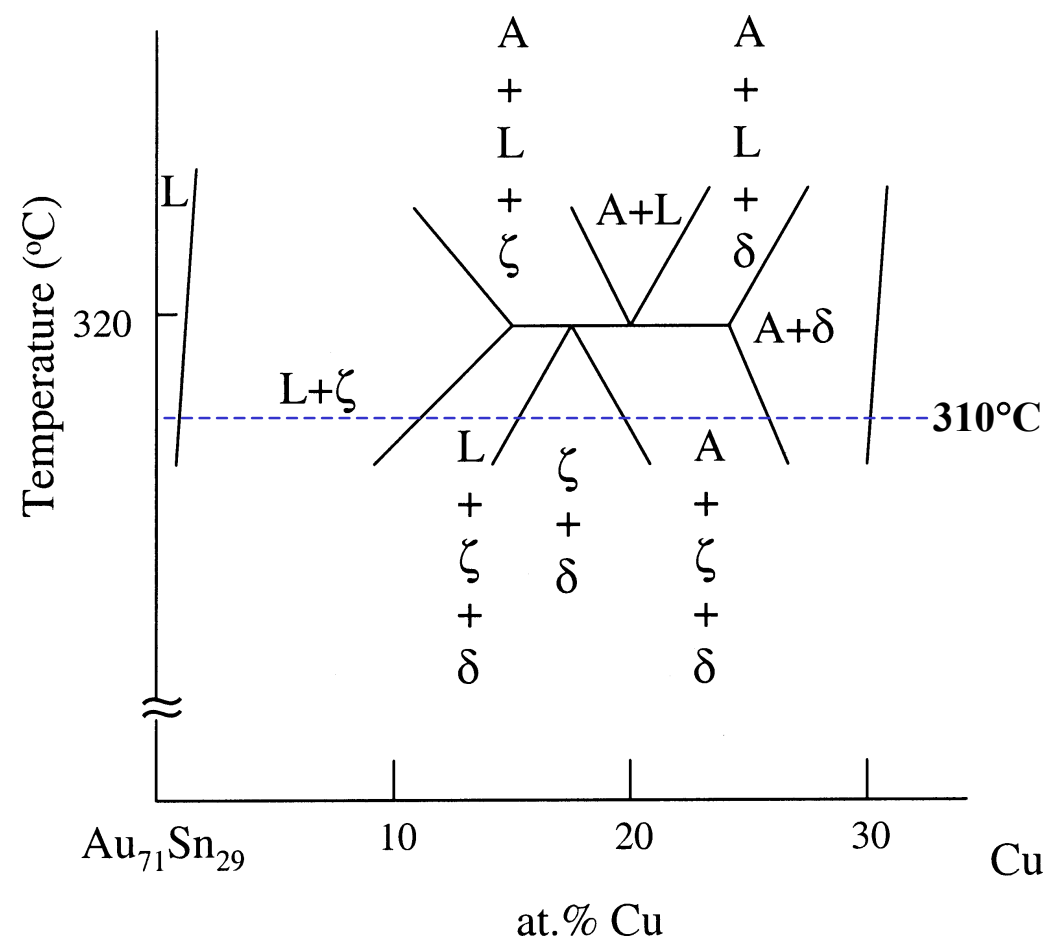

Figure 2.11. Schematic vertical section along 71 Au29Sn-Cu. 
(a)

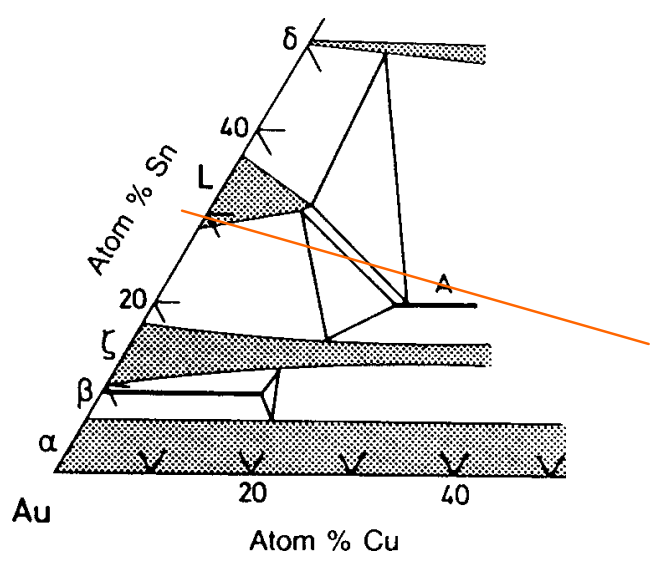

(b)

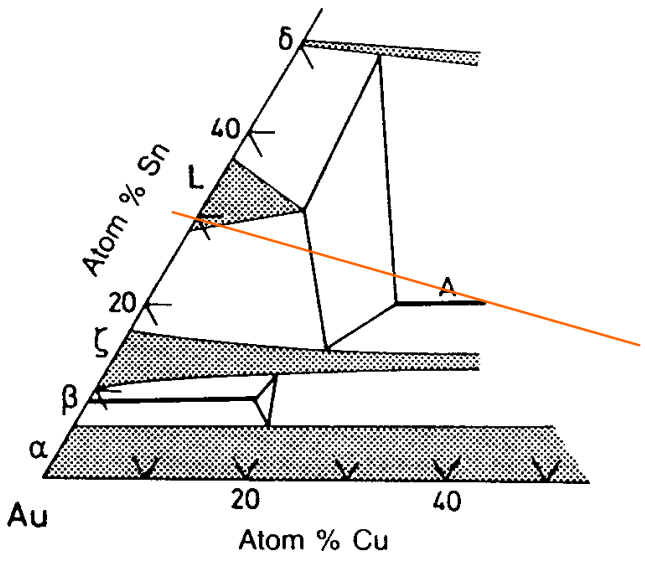

(c)

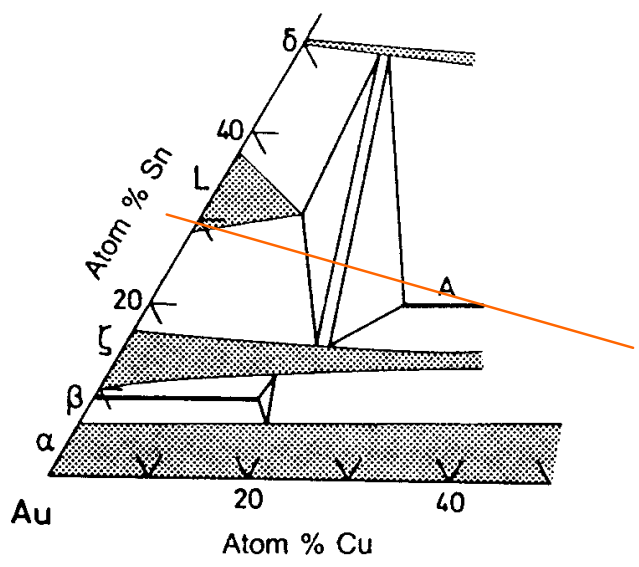

Figure 2.12. Isothermal sections of Au-rich corner of $\mathrm{Au}-\mathrm{Cu}-\mathrm{Sn}$ system near $320^{\circ} \mathrm{C}$ from ref. 42 . (a) just above $320^{\circ} \mathrm{C} \mathrm{(b)} \mathrm{at} 320^{\circ} \mathrm{C}$ (c) at just below $320^{\circ} \mathrm{C}$. The line was drawn between $\mathrm{Cu}$ and eutectic $\mathrm{Au}-\mathrm{Sn}$ on each section to measure the phase region with respect to $\mathrm{Cu}$ content. 
The line was drawn between $\mathrm{Cu}$ and eutectic $\mathrm{Au}-\mathrm{Sn}$ on each section in order to measure the phase region with respect to $\mathrm{Cu}$ content. According to Karlsen et al., phase $\mathrm{A}$ is a high temperature phase which has a nominal composition of (4247) $\mathrm{Au}(33-37) \mathrm{Cu} 20 \mathrm{Sn}$. This phase transforms into the lower temperature phase $\mathrm{X}$ shown in Figure 2.3. Since the joints have a much larger surface to volume ratio than the bumps examined earlier and because they were held above $280^{\circ} \mathrm{C}$ for much longer, more $\mathrm{Cu}$ can dissolve into the molten solder, and the melt composition can reach the $\zeta$ $+\delta$ region. Since we could not find the A phase in the as-solidified sample, the $\mathrm{Cu}$ composition during reflow is most likely in the $\zeta+\delta$ region. It follows that the joint solidifies completely during reflow; hence no liquid remains to form a eutectic on subsequent cooling, and no lamellar structure is formed. This analysis suggests that the major factor controlling the joint microstructure is the amount of $\mathrm{Cu}$ dissolution during the reflow process, which is controlled by the reflow profile and the sample geometry. If the $\mathrm{Cu}$ dissolution is sufficient to place the bulk composition within the $\zeta$ $+\delta$ two-phase region the joint solidifies into a coarse microstructure. Otherwise, liquid remains at the end of the reflow and solidifies into a lamellar eutectic.

Occasionally joints that have a fine eutectic microstructure in the interior have been found in the same set of samples. An example is shown in Figure 2.13. This microstructure appears to have two different causes. In most of these joints the upper $\mathrm{Cu}$ pad was incompletely bonded, which would cause insufficient $\mathrm{Cu}$ dissolution and eutectic solidification. In other joints it is suspected that the local temperature during reflow was low, resulting in reduced diffusion of $\mathrm{Cu}$ 


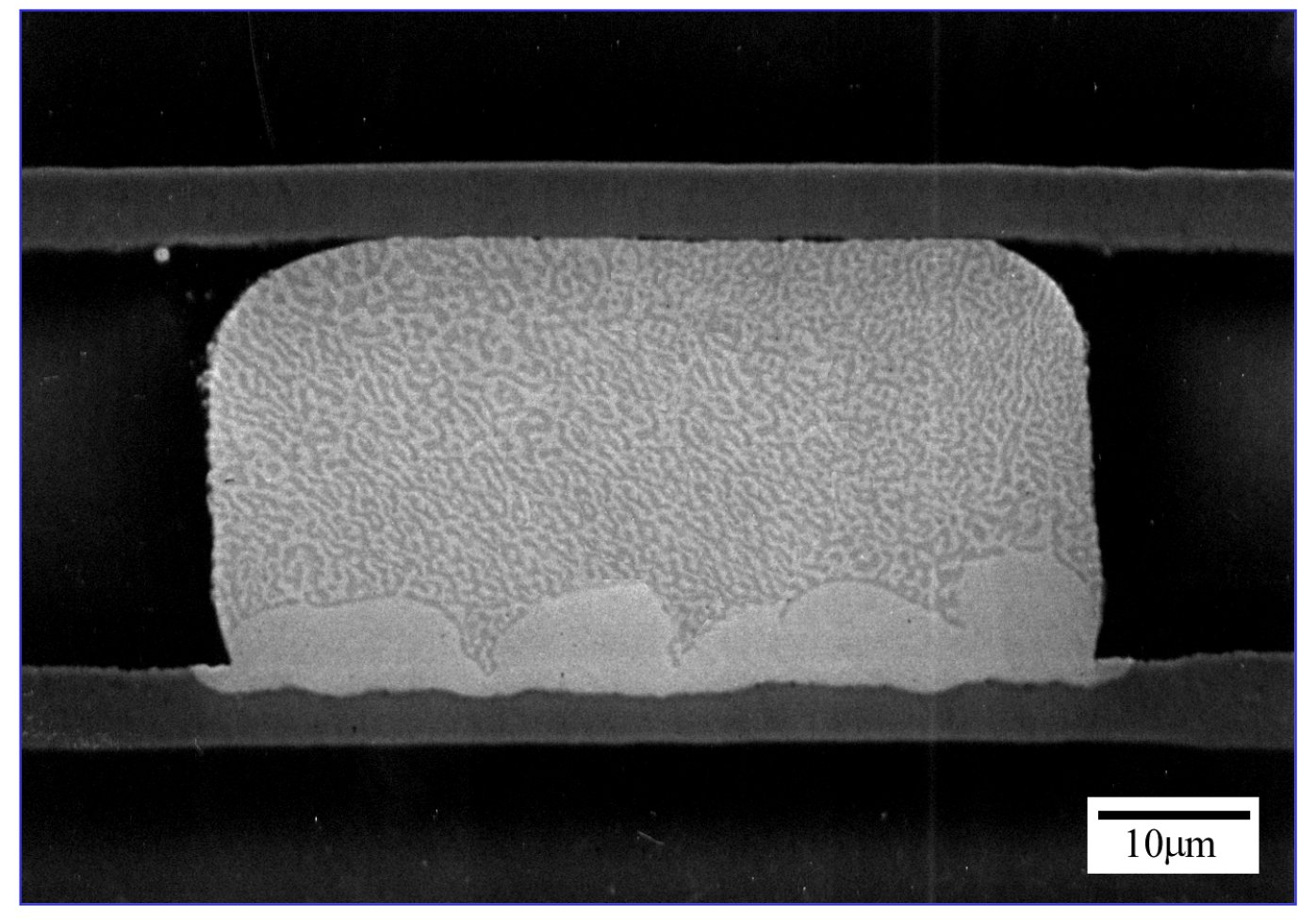

Figure 2.13. Cross-sectional SEM micrographs of as-solidified joint with less common microstructure. 


\subsubsection{Isothermally Aged Joints}

Both the microstructure and phase distribution change significantly as the solder accumulates $\mathrm{Cu}$ from the substrates during aging.

\subsubsection{Bulk Solder of the Joint}

Aging at $200^{\circ} \mathrm{C}$ results in a steady accumulation of $\mathrm{Cu}$ within the joint, causing monotonic growth of the $\mathrm{Cu}$-rich intermetallics, which eventually bridge the joint.

Figure 2.14 illustrates the microstructure after 10 days aging at $200^{\circ} \mathrm{C}$. The $\zeta$ phase layers at the interfaces have thickened, and become significantly richer in $\mathrm{Cu}$. The $\zeta$-phase in the layer has the composition (58-61) $\mathrm{Au}(28-31) \mathrm{Cu}(10-11) \mathrm{Sn}$. The $\zeta-$ phase is decorated with precipitates that prove to be $\delta$-phase (AuSn), as in the solder bumps described previously. While the $\zeta$-phase is supersaturated with respect to precipitation of the X-phase (at least, according to the phase diagram in Figure 2.3), no X-phase precipitates appear.

The microstructure and intermetallic composition are roughly similar for samples aged for 20 days, though with a further increase in $\mathrm{Cu}$ content.

Aging for 50 days, however, produces a dramatic change in the phase distribution within the joint. This microstructure is illustrated in Figure 2.15. The thick intermetallic layers have bridged the joint. They are different in appearance and have also, apparently, changed in phase. EDX analysis gives the composition (4041) $\mathrm{Au}(41-42) \mathrm{Cu}(17-19) \mathrm{Sn}$, which is very close to the reported composition of the Xphase ternary intermetallic (40Au40Cu20Sn). 

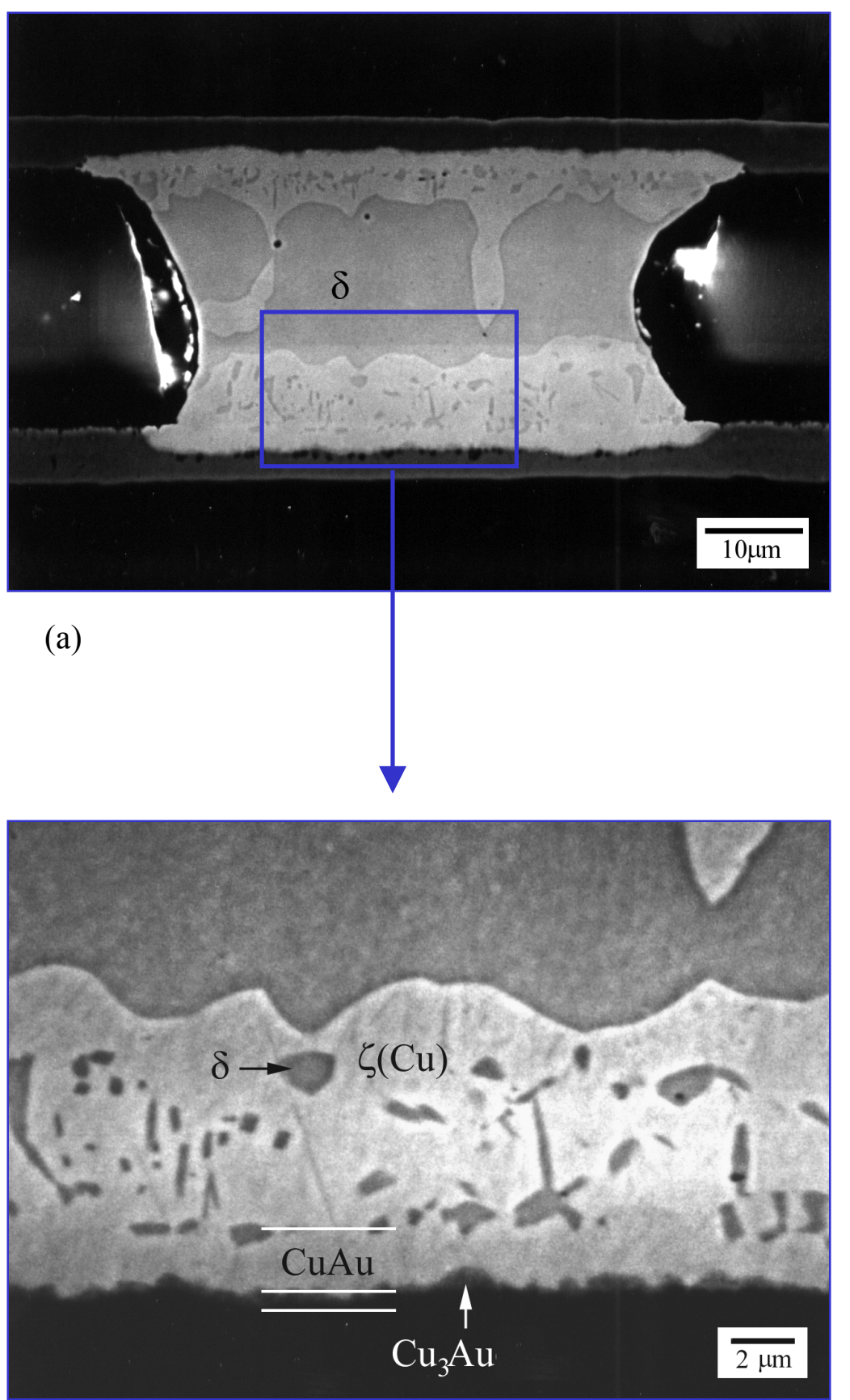

(b)

Figure 2.14. Cross-sectional SEM micrographs of a solder joint aged at $200^{\circ} \mathrm{C}$ for 10 days (a) at low magnification (b) at high magnification. 

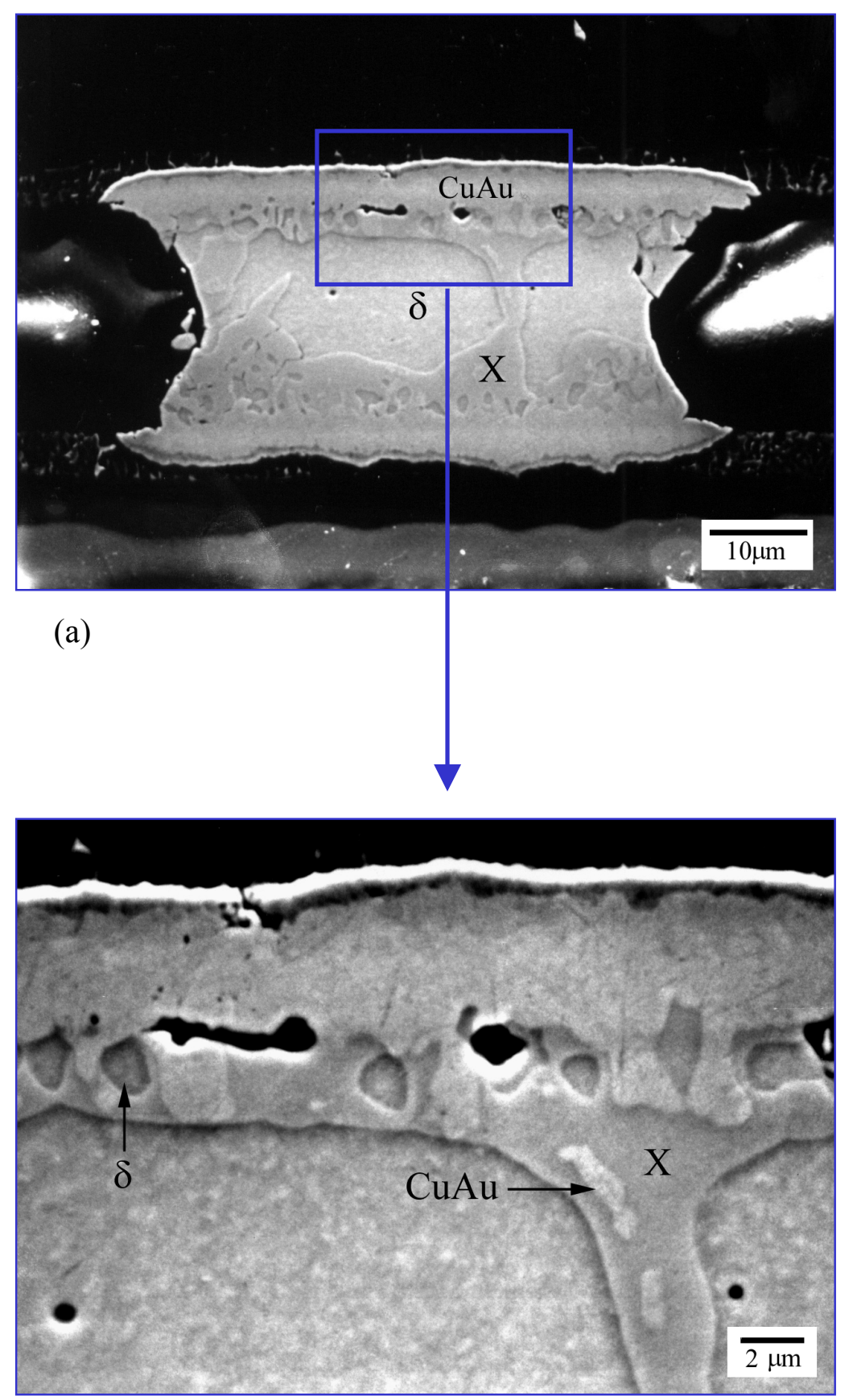

(b)

Figure 2.15. Cross-sectional SEM micrographs of a solder joint aged at $200^{\circ} \mathrm{C}$ for 50 days (a) at low magnification (b) at high magnification. 
As shown in Figure 2.15(b), the X-phase is decorated with small precipitates. EDX analysis shows that the larger and darker of these are $\delta$-phase (AuSn). The smaller, lighter precipitates prove to be $\mathrm{CuAu}$. No $\zeta$-phase was found. These results are puzzling, since there is no $\delta+\mathrm{X}+\mathrm{CuAu}$ region in the proposed phase diagram, and the $\mathrm{X}$-phase can only be accessed by passing through compositions where $\mathrm{X}$ and $\zeta$ coexist. It appears that there may be a three phase region of $\zeta+\delta+\mathrm{CuAu}$ which moves into the $\delta+\mathrm{X}+\mathrm{CuAu}$ region with increasing $\mathrm{Cu}$ content.

\subsubsection{Interface of the Joint}

$\mathrm{Cu}$-rich intermetallic layers form at the $\mathrm{Cu}$ interface in the solder joints, as in the solder bumps. In Figure 2.14(b), the outer layer is nominally $\mathrm{CuAu}$, with almost no detectable $\mathrm{Sn}$, and the inner layer is nominally $\mathrm{Cu}_{3} \mathrm{Au}$ with about $2 \mathrm{Sn}$ included.

The $\mathrm{Cu}$-rich intermetallic layers at the interface have also coarsened as aging time increases. In Figure 2.15(b), the $\mathrm{CuAu}$ layer appears to be slightly $\mathrm{Cu}-\mathrm{rich}$, with composition (53-54) $\mathrm{Cu}(46-47) \mathrm{Au}(<1) \mathrm{Sn}$. The $\mathrm{Cu}_{3} \mathrm{Au}$ layer is also slightly $\mathrm{Cu}-\mathrm{rich}$, with composition (76-79) $\mathrm{Cu}(19-22) \mathrm{Au} 2 \mathrm{Sn}$. The growths of the two intermetallic layers are plotted as a function of time in Figure 2.16. As in the case of the solder bumps, their thicknesses increase as $\mathrm{t}^{1 / 2}$. However, the growth rates are somewhat higher in the joints than in the bumps, which is consistent with the generally higher $\mathrm{Cu}$ content of the $\zeta$-phase layer. 


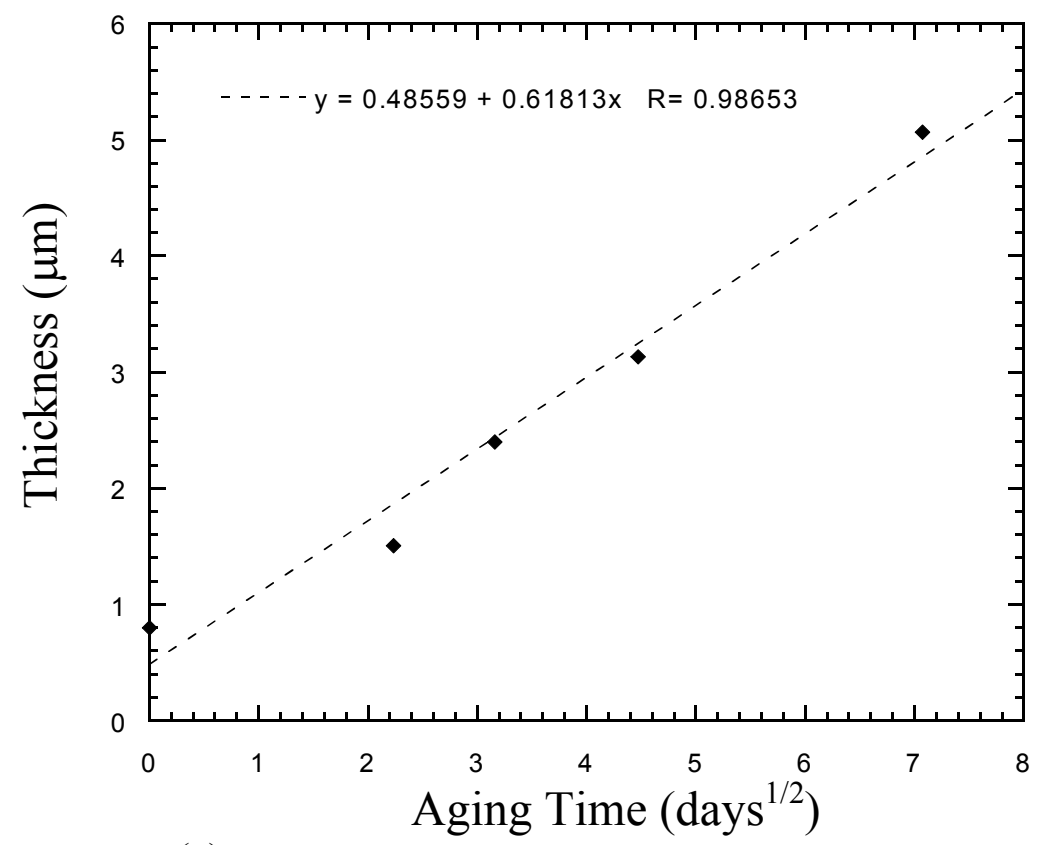

(a)

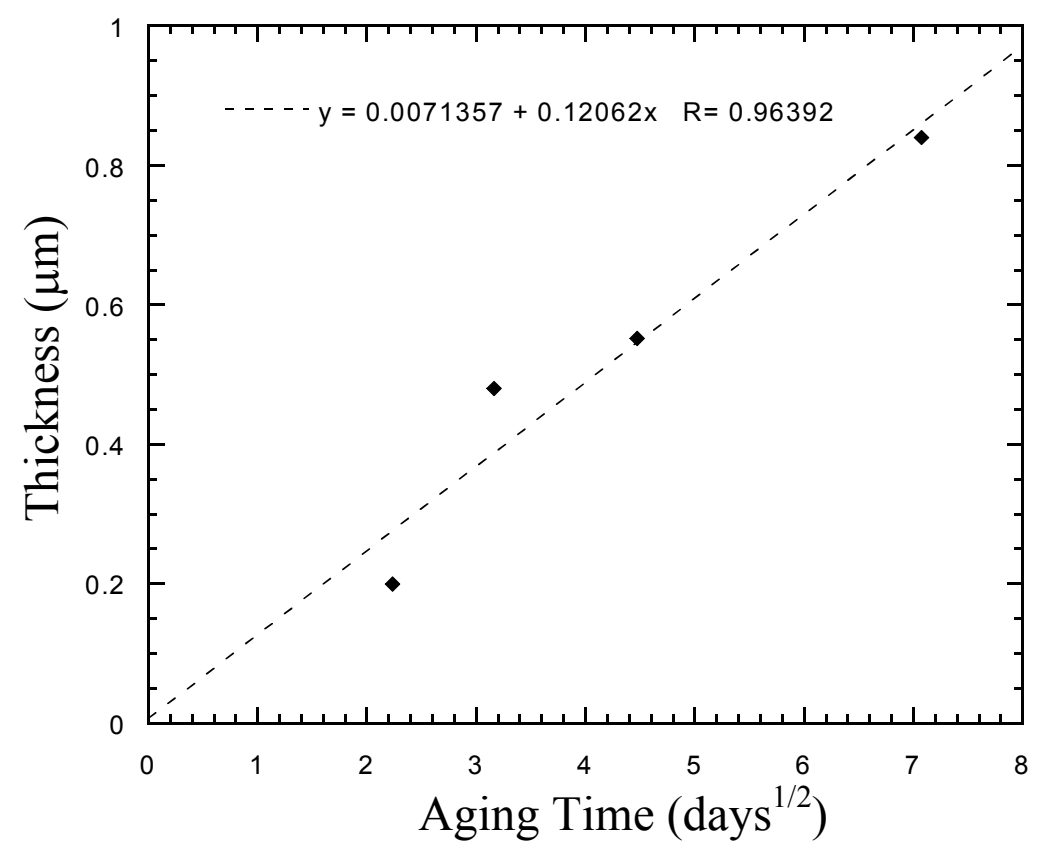

(b)

Figure 2.16. Thickness of (a) the $\mathrm{CuAu}$ layer, and (b) the $\mathrm{Cu}_{3} \mathrm{Au}$ layer in solder joints with the square root of aging time at $200^{\circ} \mathrm{C}$. 
The average consumed thickness of the $\mathrm{Cu}$ into the solder joints during aging is illustrated in Figure 2.17. The solid squares denote the measured thickness of the total consumed $\mathrm{Cu}$ and the circles represents the $\mathrm{Cu}$ consumed into interfacial $\mathrm{Cu}-\mathrm{Au}$ layers, which was calculated from the growth data of those layers. Therefore the difference between them represents the amount of $\mathrm{Cu}$ that diffused into the bulk solder through the $\mathrm{Cu}-\mathrm{Au}$ layers, which leads to phase transformations in the constituent phases in the bulk solder. This shows a characteristic of the Au-Sn on $\mathrm{Cu}$ system which is somewhat different from the conventional $\mathrm{Pb}-\mathrm{Sn}$ or $\mathrm{Sn}$-based $\mathrm{Pb}$-free solder with $\mathrm{Cu}$ pad metal. Usually in those systems, $\mathrm{Cu}-\mathrm{Sn}$ intermetallics are formed at the interface by interdiffusion between $\mathrm{Cu}$ and $\mathrm{Sn}$, and $\mathrm{Cu}$ diffusion into the bulk solder is limited by its solubility limit. However, due to the high solubility of $\mathrm{Cu}$ in $\mathrm{Au}[43]$ and the higher diffusivity of $\mathrm{Cu}$ than that of $\mathrm{Au},[50-53] \mathrm{Cu}$ diffuses unidirectionally into the bulk eutectic Au-Sn solder and directly contributes in microstructural changes of the bulk solder. Additionally $\mathrm{Cu}-\mathrm{Au}$ interfacial layers do not effectively act as a diffusion barrier against $\mathrm{Cu}$, which can be seen Figure 2.17. Since the amount of $\mathrm{Cu}$ is limited, the high consumption rate of $\mathrm{Cu}$ leads to the depletion of the $\mathrm{Cu}$ layer and thereby dewetting of the solder. From this perspective, either adjusting the thickness of the $\mathrm{Cu}$ layer or adding a diffusion barrier would improve the eutectic Au-Sn solder joints on $\mathrm{Cu}$ system. Modification of the initial solder composition from the eutectic $\mathrm{Au}-\mathrm{Sn}$ to the eutectic $\mathrm{Au}(\mathrm{Cu})-\mathrm{Sn}$ by substituting $\mathrm{Au}$ with a small amount of $\mathrm{Cu}$ will also retard $\mathrm{Cu}$ consumption in this system. 


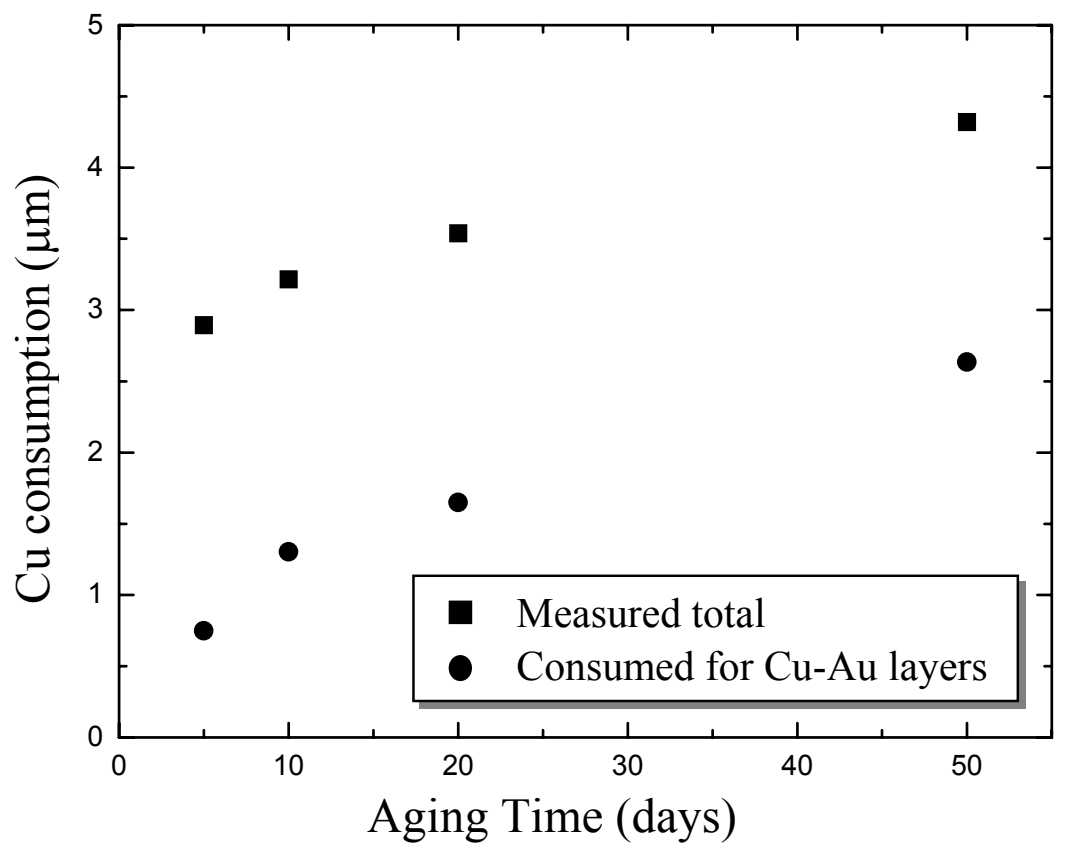

Figure 2.17. The average consumed thickness of $\mathrm{Cu}$ in solder joints with the aging time at $200^{\circ} \mathrm{C}$. 
Fast $\mathrm{Cu}$ diffusion into the eutectic $\mathrm{Au}-\mathrm{Sn}$ solder produces another important microstructural evolution at the interface. As shown in Figure 2.18(a), pores along the interface between the interfacial layer and $\mathrm{Cu}$ substrate were observed in aged joints. In order to reveal their detailed structure TEM analysis was performed with aged solder bumps. Figure 2.18(b) taken from a TEM specimen that is not fully thinned confirms the overall distribution of pores along the interface. As shown in figure 2.18(c), the pores are located on the $\mathrm{Cu}$ side of the interface between $\mathrm{Cu}$ and $\mathrm{Cu}_{3} \mathrm{Sn}$ layer. This indicates that these pores are formed by Kirkendall effect.[60-63] That is, $\mathrm{Cu}$ atoms diffuse more rapidly through interfacial layers compared with the counterdiffusion of $\mathrm{Au}$, consequently producing a counterflow of vacancies towards $\mathrm{Cu}$ which condense to form voids at the interface. This result agrees with the reported diffusional data[50-53] and other observations in $\mathrm{Cu}-\mathrm{Au}$ and $\mathrm{Cu}-\mathrm{AuSn}$ systems.[36,64-67]

According to Zakel et al.,[65-67] the $\zeta$-phase at the interface between $\mathrm{Cu}$ and the eutectic $\mathrm{Au}-\mathrm{Sn}$ in TAB inner lead contacts acts like a diffusion barrier inhibiting Kirkendall pore formation caused by $\mathrm{Cu}$ diffusion. However, in the case of the high temperature aging of the ultrafine solder joints studied in this work, the $\zeta$-phase does not effectively inhibit Kirkendall pore formation. Because the $\zeta$-phase itself has a high solubility of $\mathrm{Cu}$ (Figure 2.3) and it grows with increasing $\mathrm{Cu}$ content, they can lead to intermetallic bridging across the joint (Figure 2.15). Furthermore it can transform to the $\mathrm{Cu}$-rich $\mathrm{Au}-\mathrm{Cu}-\mathrm{Sn}$ phase with a steady accumulation of $\mathrm{Cu}$. Therefore, $\mathrm{Cu}$ diffuses steadily through into $\zeta$-phase, and together with the high dffusivity of $\mathrm{Cu}$ Kirkendall pores are formed at the interface. 


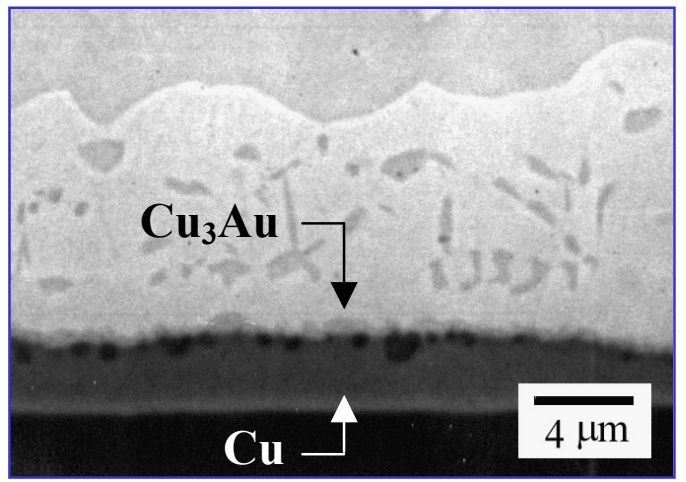

(a)

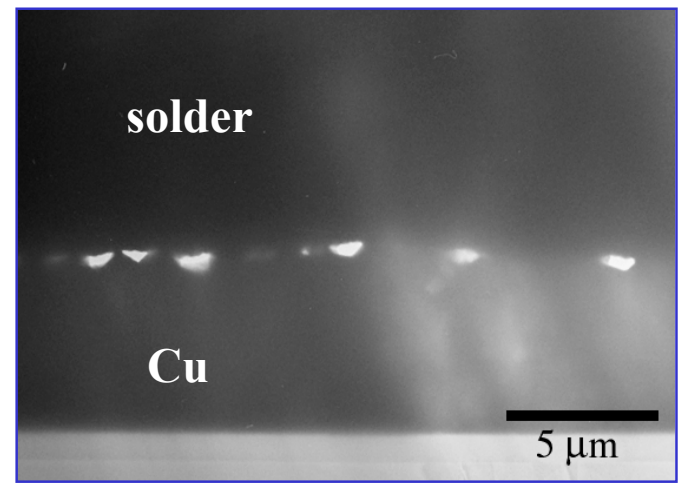

(b)

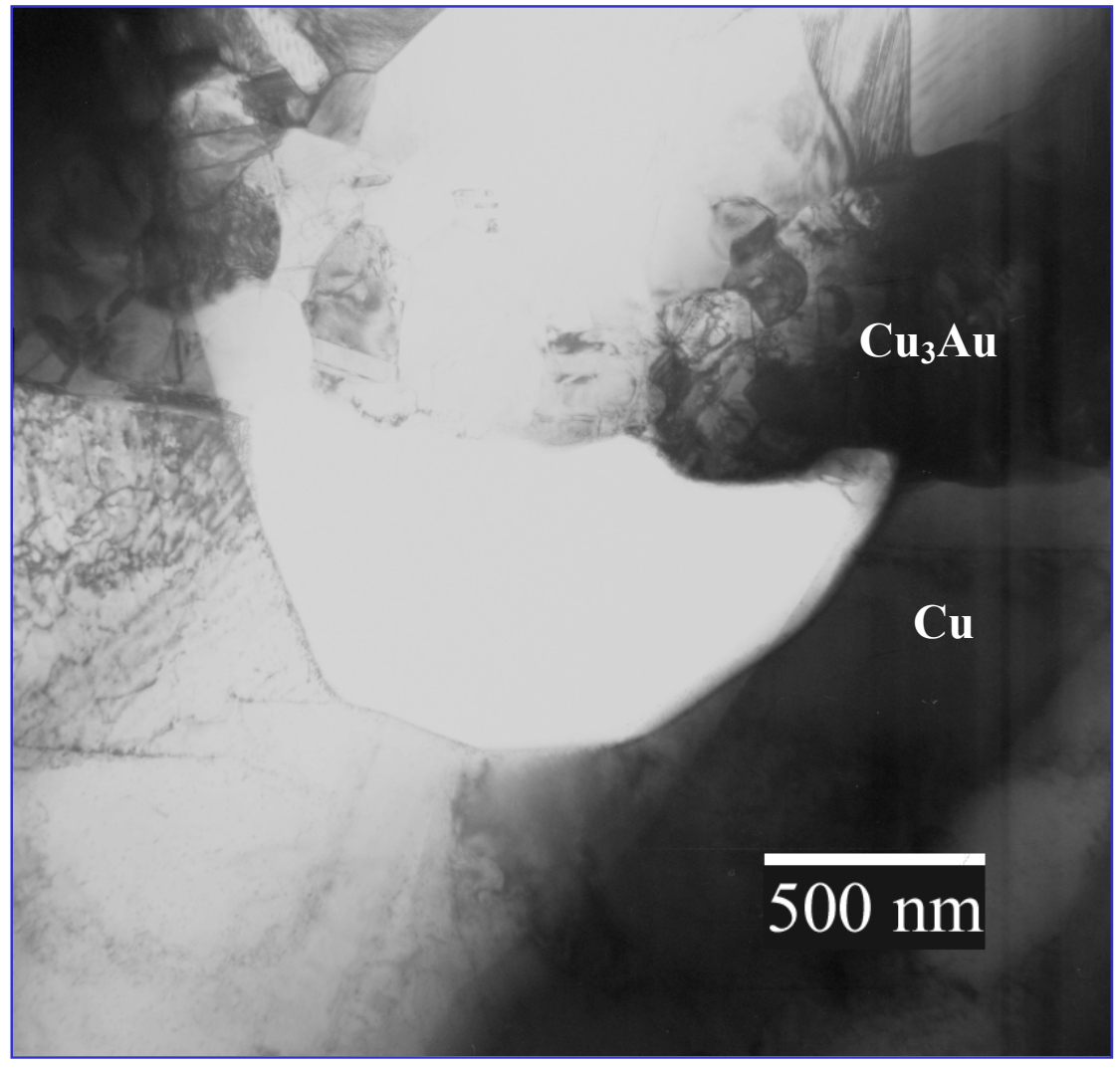

(c)

Figure 2.18. Pores observed along the interface between $\mathrm{Cu}$ and the interfacial layer. (a) SEM micrograph of aged joint at $200^{\circ} \mathrm{C}$ for 10 days. TEM micrographs of aged bump at $200^{\circ} \mathrm{C}$ for 31 days (b) before full thinning (c) after thinning. 
If a solder joint microstructure is like that found in the ultrafine joints of this study, which has a thick $\mathrm{Cu}$-containing $\zeta$ - phase, Kirkendall pores (always a serious reliability concern) can be formed at elevated temperatures. The degradation of electrical, thermal and mechanical properties of the solder joints by the Kirkendall pores has been found in microelectronic packages such as $\mathrm{Al}-\mathrm{Au}$ contacts in wire bonding, $[68,69] \mathrm{Cu}-\mathrm{Au}(\mathrm{Sn})$ inner lead contacts in tape automated bonding(TAB),[6567], and Au-Sn contacts in Lasers and LEDs.[70]

\subsubsection{Thermally Cycled Joints}

For comparison, joint samples were studied after two alternative treatments: isothermal aging for 20 days at $150^{\circ} \mathrm{C}$ and thermal cycling from $-65^{\circ} \mathrm{C}$ to $150^{\circ} \mathrm{C}$ for 500 cycles, in which the length of condition the total dwell time at $150^{\circ} \mathrm{C}$ is about 3.5 days.

Figure 2.19 shows a cross-section of a sample that was isothermally aged for 20 days at $150^{\circ} \mathrm{C}$. Thick $\zeta$-phase intermetallics coat the interfaces, and have almost bridged the joint. Their composition is (60-64) $\mathrm{Au}(23-27) \mathrm{Cu}(12-14) \mathrm{Sn}$, which is close to that found after 10 days aging at $200^{\circ} \mathrm{C}$. The layer is decorated with a distribution of fine AuSn ( $\delta$ ) precipitates. Only one Cu-rich intermetallic is found at the $\mathrm{Cu}$ interface and is very close to the composition measured in the as-solidified joint.

Figure 2.20 shows the complex microstructure of a joint that was cycled 500 times from $-65^{\circ} \mathrm{C}$ to $150^{\circ} \mathrm{C}$, beginning from the as-solidified condition. 


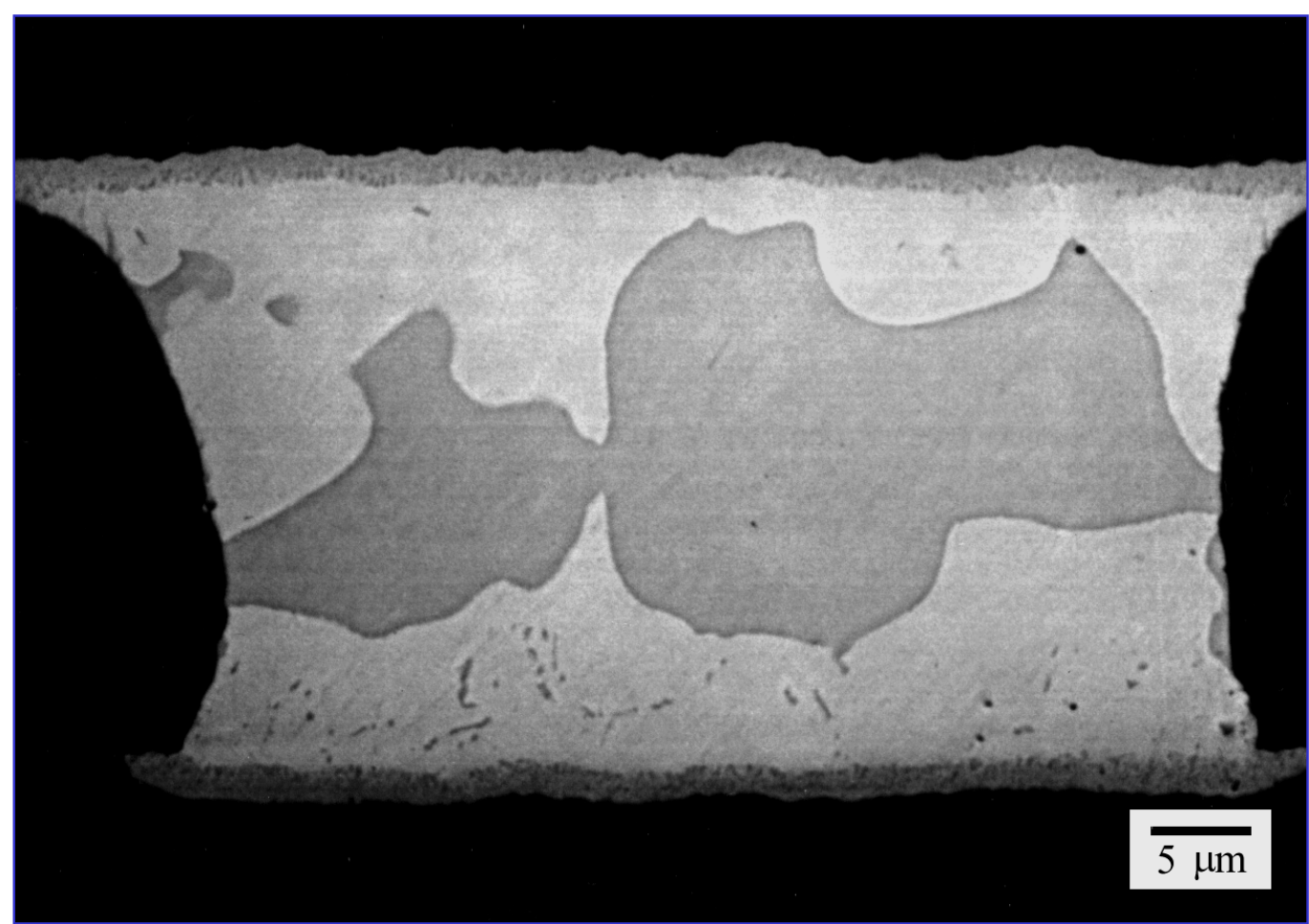

Figure 2.19. Cross-sectional BSE image of solder joint aged at $150^{\circ} \mathrm{C}$ for 20 days. 


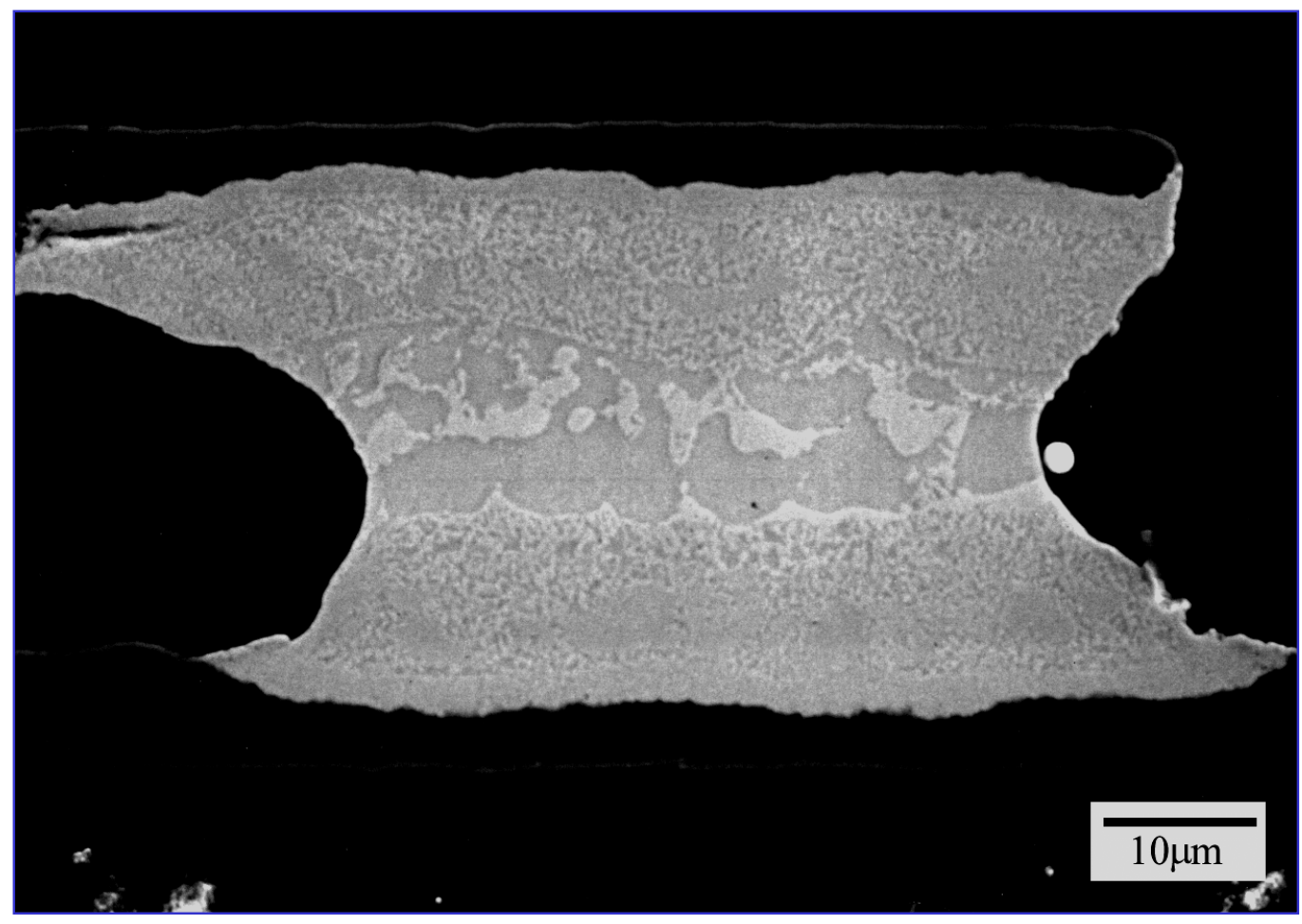

Figure 2.20. Cross-sectional SEM micrograph of solder joint thermally cycled from 65 to $150^{\circ} \mathrm{C}$ for 500 cycles. 
The overall deformation of the joint is evident. Also, a short crack has developed at the upper left-hand edge of the joint near the $\mathrm{Cu}$ interface. This crack appears to follow the $\mathrm{CuAu}-\zeta$ interface, and does not appear to be affected by the process voids (from flux or out-gassing from the substrate) which are located slightly farther beneath the interface.

The thick $\zeta$-phase layer in this cycled joint is multi-phase and is broken up into small volumes less than $1 \mu \mathrm{m}$ in diameter. Due to the fine size of precipitates, however, it was not possible to identify which phase was precipitated out. Considering the microstructural changes found during aging, they are probably precipitates of $\delta$ phase and/or $\mathrm{X}$-phase which is the $\mathrm{Cu}$-rich $\mathrm{Au}-\mathrm{Cu}-\mathrm{Sn}$ phase in Figure 2.3 .

The overall composition of the refined region is $(46-56) \mathrm{Au}(30-36) \mathrm{Cu}(14-$ 18)Sn, which would appear to place it within the three-phase $\zeta+\mathrm{X}+\mathrm{CuAu}$ field in the proposed phase diagram (Figure 2.3). Although its total dwell time at $150^{\circ} \mathrm{C}$ is much shorter than the aged joint in Figure 2.19, the $\mathrm{Cu}$ content is much higher than that in the aged joint. The high $\mathrm{Cu}$ content suggests that the mechanical work associated with the thermal cycling enhances the diffusivity of $\mathrm{Cu}$. The fine-grained structure that is present in the sample pictured here would certainly favor a high diffusivity via grain boundary diffusion.

The significance of this microstructural change during thermal cycling is in the refinement of the apparent grain size. Since it has been shown that phase coarsening occurs during thermal cycling and decreases the fatigue life in $\mathrm{Pb}-\mathrm{Sn}$ solder joints,[ $22-23,71-74]$ the result of this work is exactly opposite and may result in the increase 
in the fatigue life and improvement of mechanical properties. Considering the above observations, this is a new mechanism, which is called 'natural healing process'. In this process the very small volume solder joints with initially coarse microstructure can naturally improve their mechanical properties during service. Since the bulk solder becomes hardened by this process, the failure during thermal cycling is expected to happen at the interface as observed in Figure 2.20. Even though in this specific system the refining process was accomplished by $\mathrm{Cu}$ diffusion, which may eventually cause some problems described in 2.4 .3 .2 , this idea may be utilized by modifying the solder composition into the eutectic $\mathrm{Au}(\mathrm{Cu})$-Sn without significant $\mathrm{Cu}$ diffusion from the substrate.

\subsection{SUMmARY AND CONCLUSIONS}

As-solidified eutectic Au-Sn microbumps on $\mathrm{Cu}$ have a thick $\zeta$-phase intermetallic along the $\mathrm{Cu}$ interface with periodic mushroom-shaped protrusions, and a fine eutectic lamellar structure throughout the bulk. Isothermal aging treatments at $200^{\circ} \mathrm{C}$ coarsen the eutectic and significantly increase the $\mathrm{Cu}$ content of the intermetallic, which develops a distribution of $\delta$-phase (AuSn) precipitates. Despite the high $\mathrm{Cu}$ content of the $\zeta$-phase (>25Cu), however, no X-phase (40Au40Cu20Sn) is found. Prolonged aging at $200^{\circ} \mathrm{C}$ leads to the formation of a double layer of Cu-rich intermetallics along the $\mathrm{Cu}$ interface. The intermetallics are, nominally, $\mathrm{Cu}_{3} \mathrm{Au}$ on the $\mathrm{Cu}$-side and $\mathrm{CuAu}$ on the $\zeta$-phase side. Both intermetallics thicken with $\mathrm{t}^{1 / 2}$.

Eutectic microjoints, $60 \mu \mathrm{m}$ in diameter by $25 \mu \mathrm{m}$ height, were formed between $\mathrm{Cu}$ pads on $\mathrm{Si}$ and polyimide. The typical microstructure in the as-solidified 
condition has thick, $\mathrm{Cu}$-rich $\zeta$-phase intermetallics along the interfaces, with only a few large grains in the interior. As the joints are aged at $200^{\circ} \mathrm{C}$, the $\zeta$-phase becomes enriched in $\mathrm{Cu}$, taking in as much as $35 \mathrm{Cu}$. It is decorated by $\delta$-phase (AuSn). Between 20 and 50 days aging at $200^{\circ} \mathrm{C}$, the $\zeta$-phase fully transforms to $\mathrm{X}$-phase with a very nearly stoichiometric composition (40Au40Cu20Sn). The X-phase contains precipitates of both $\delta$-phase (AuSn) and $\mathrm{CuAu}$, but no residual $\zeta$-phase was found. Steady diffusion of $\mathrm{Cu}$ into the bulk solder resulted in significant consumption of substrate $\mathrm{Cu}$. Kirkendall pores were observed along the interface between $\mathrm{Cu}$ and $\mathrm{Cu}_{3} \mathrm{Sn}$. Thermal cycling from $65^{\circ} \mathrm{C}$ to $150^{\circ} \mathrm{C}$ caused the $\zeta$-phase interfacial layer to decompose into a very fine-grained distribution of two or more phases. Like the microbumps, the microjoints also formed a double-layer film of $\mathrm{Cu}_{3} \mathrm{Au}$ and $\mathrm{CuAu}$ along the $\mathrm{Cu}$ interface. The $\mathrm{Cu}$-rich intermetallics thickened with $\mathrm{t}^{1 / 2}$ while preserving a constant thickness ratio.

The principle conclusions are that: (1) As-solidified microjoints of eutectic AuSn on $\mathrm{Cu}$ can have microstructures that are very coarse on the scale of the joint, where the microstructure is dependent on the amount of $\mathrm{Cu}$ dissolution during the reflow process. These joints contain so few grains that one should be cautious when using macroscopic properties to predict their behavior. (2) Thick interfacial intermetallics form during soldering. These are primarily $\zeta$-phase enriched with $\mathrm{Cu}$, and their evolution is not well predicted by the ternary phase diagram that has recently been proposed for the Au-Cu-Sn system.[36] (3) In particular, after accumulating a significant $\mathrm{Cu}$ content, the $\zeta$-phase intermetallic may convert into an " $\mathrm{X}$ "-phase whose 
properties are not well known. (4) The thick $\zeta(\mathrm{Cu})$-phase can be decomposed into a fine-grained mixture of two or more phases by thermal cycling. (5) The phase relationships in the aged, $\mathrm{Cu}$-rich joints differ from those in the ternary $\mathrm{Au}-\mathrm{Cu}-\mathrm{Sn}$ phase diagram(Figure 2.3), particularly in the vicinity of the "X"-phase field. (6) Significant consumption of substrate $\mathrm{Cu}$ and formation of Kirkendall pores at the interface during aging may cause reliability problems. 6) In order to retard $\mathrm{Cu}$ consumption during both soldering and service without applying a diffusion barrier, it is suggested that the initial solder composition is modified from the eutectic Au-Sn to the eutectic $\mathrm{Au}(\mathrm{Cu})-\mathrm{Sn}$ by substituting $\mathrm{Au}$ with a small amount of $\mathrm{Cu}$. 


\title{
Chapter 3. Microstructure of Eutectic Au-Sn SOLDER JoINTS ON CU/ELECTROLESS Ni/AU
}

\author{
: Electroless Ni AS A Diffusion BarRIER FOR CU
}

\subsection{INTRODUCTION}

The microstructure of a solder joint, which governs its mechanical properties, is determined not only by its composition and thermal history, but also by the reactions that occur at the solder/substrate interface. When the joint is fine its composition can be modified significantly by diffusion from the substrate. As shown in chapter 2, the microstructure of fine eutectic Au-Sn solder joints on $\mathrm{Cu}$ depends on the amount of $\mathrm{Cu}$ dissolved during the reflow process, and are further modified by the accumulation of $\mathrm{Cu}$ during aging. Since the dissolution of the substrate may compromise the reliability of the joint through high substrate consumption or void formation, it is desirable to use substrate metallizations that minimize the interaction between the solder and the substrate.

As compared to $\mathrm{Cu}$, Ni reacts slowly with most Sn-rich solders in terms of both its dissolution in molten solder and the growth of Ni-Sn intermetallics.[75-79] Therefore, Ni can potentially reduce problems found in Cu-based UBM used with Snrich solders. Ni does not exhibit the rapid consumption that $\mathrm{Cu}$ does nor excessive growth of its Sn based intermetallics.[25-27, 80-82] In addition to the slow reaction 
between $\mathrm{Ni}$ and $\mathrm{Sn}$, low diffusion rate of $\mathrm{Cu}$ through $\mathrm{Ni}[83,84]$ allows Ni-based metallization to serve as an excellent diffusion barrier against $\mathrm{Cu}$ for most $\mathrm{Sn}$-bearing solders.[77-79]

Electroless Ni plating (Ni-P) [85] has become popular in microelectronics since it offers a low-cost alternative to relatively expensive physical vapor deposition or eletroplating processes [86-91] while providing a good interfacial diffusion barrier for most Sn-bearing solders as pure Ni metallization. Additionally, it offers good corrosion resistance,[92] maskless selective deposition,[86] strong adhesion and good solder wetting.[78,93] As a common metallization scheme for UBM, electroless $\mathrm{Ni}$ metallization is usually combined in a structure with $\mathrm{Au}$, where a thin Au protective layer on the top of the electroless $\mathrm{Ni}$ to prevent $\mathrm{Ni}$ from oxidizing. This retains the wettability of the solderable layer during storage.[39-41, 91] Despite the many advantages of electroless $\mathrm{Ni}$, however, there has been some concern about the reliability of these joints, given the weak interface between the eutectic $\mathrm{Pb}-\mathrm{Sn}$ solder and the electroless $\mathrm{Ni} / \mathrm{Au}$ metallization.[94-97] This concern has motivated recent investigations of interfacial reactions [98-100] and failure mechanisms [101,102] in joints that contain electroless Ni layers.

In the case of the eutectic Au-Sn solder, which is constantly becoming more important in electronic packaging for high temperature and fluxless applications, electroless Ni plating is a promising under-bump metallization.[103,104] However, since the Au-Sn-Ni system is complex and fundamental information of its ternary phase diagram is very limited, the influence of the electroless $\mathrm{Ni} / \mathrm{Au}$ metallization on the joint and interface microstructure is only partly understood. The present work was 
undertaken in order to understand the microstructure and microstructural evolution of eutectic $\mathrm{Au}-\mathrm{Sn}$ solder on $\mathrm{Cu} /$ electroless $\mathrm{Ni} / \mathrm{Au}$ substrates, with a particular focus on the solder-substrate interface, and to provide metallurgical information of this system. By comparing the results with the eutectic $\mathrm{Au}-\mathrm{Sn}$ on $\mathrm{Cu}$ system discussed in chapter 2, the effect of substrate metallization on joint microstructure will be clarified.

\subsection{Experimental Procedure}

The work was undertaken by studying small volume solder bumps and joints samples in order to reveal the microstructural characteristics of fine joints used in industry and to compare the microstructure of the eutectic $\mathrm{Au}-\mathrm{Sn}$ on $\mathrm{Cu}$ system. In addition, due to insufficient phase information on the Au-Ni-Sn system, bulk Au-NiSn-alloys and eutectic Au-Sn/Ni couples were made and analyzed to help identify the phases that appear at the interface during aging.

\subsubsection{Test Samples}

The solder bumps were made as 20x20 arrays with eutectic $\mathrm{Au}-\mathrm{Sn}$ solder on $\mathrm{Si}$ substrates with $\mathrm{Cu}(12 \mu \mathrm{m}) /$ electroless $\mathrm{Ni}(5 \mu \mathrm{m}) / \mathrm{Au}(0.1 \mu \mathrm{m})$ metallization. The bumps were spherical caps 150-160 $\mu \mathrm{m}$ in diameter and 45-50 $\mu \mathrm{m}$ tall (Figure 3.1(a)). The samples were aged at $200^{\circ} \mathrm{C}$ for up to 365 days. Cross-sectional microstructures of both the as-solidified and aged samples were examined in a scanning electron microscope (SEM) with a back-scattered electron (BSE) detector and an energydispersive X-ray (EDX) analyzer. The detailed interfacial microstructure was analyzed by transmission electron microscope (TEM) with EDX. 


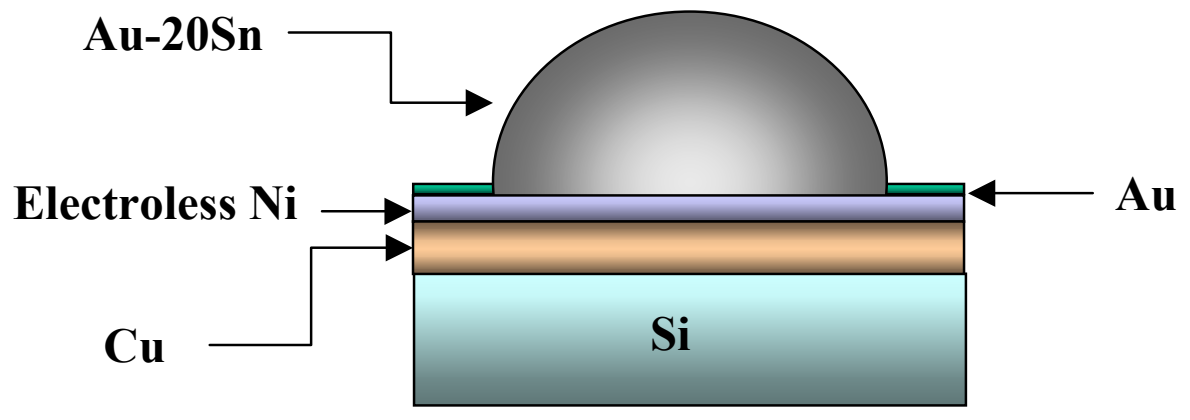

(a)

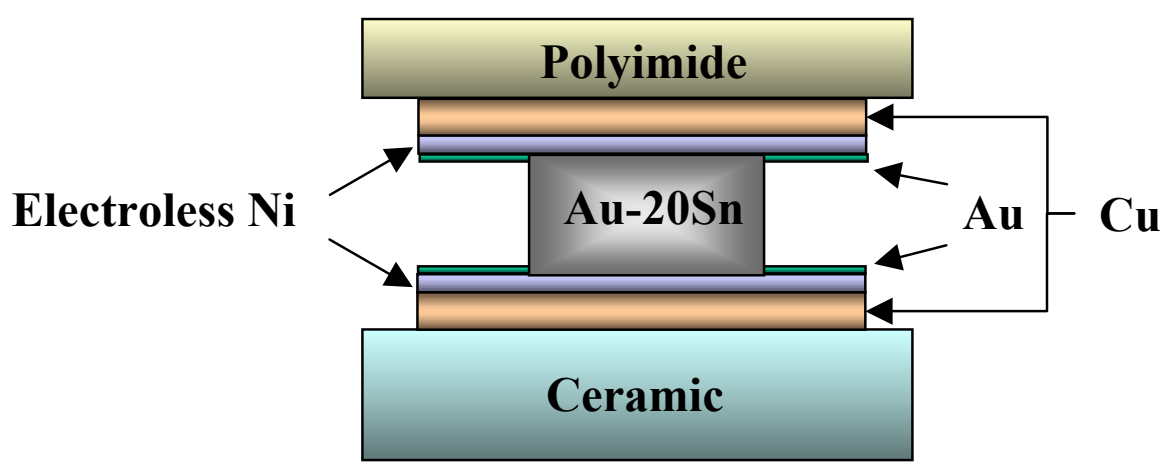

(b)

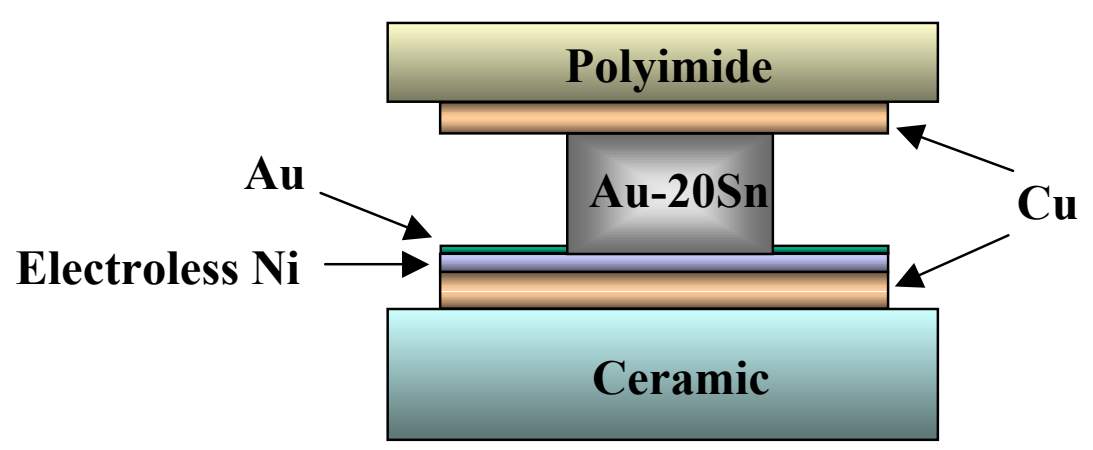

(c) 
Figure 3.1. Schematic diagrams of sample geometries used in this study. (a) solder bump: unjoined bump (b) solder joint with same metallizations on both top and bottom (c) solder joint with dissimilar metallizations.

The solder joint samples were approximately $80 \mu \mathrm{m}$ in diameter and $25 \mu \mathrm{m}$ in height with a pitch size of about $635 \mu \mathrm{m}$ (Figure 3.1(a)). The $\mathrm{Cu}(5 \mu \mathrm{m})$ /electroless $\mathrm{Ni}(20 \mu \mathrm{m}) / \mathrm{Au}(0.1 \mu \mathrm{m})$ layers were plated on top of the polyimide, and the same layer structure with relatively a thick $\mathrm{Au}(1 \mu \mathrm{m})$ layer was plated on the bottom ceramic substrate. Both bump and joint samples are slightly different than the sample sizes used in the study of eutectic $\mathrm{Au}-\mathrm{Sn}$ on $\mathrm{Cu}$ in chapter 2.

In addition, another set of joints were made between dissimilar metallizations as is common in industrial practice. The pad metallization on the top polyimide was $\mathrm{Cu}(5 \mathrm{~mm})$ while that on the bottom ceramic substrate was $\mathrm{Cu}(5 \mu \mathrm{m}) /$ electroless $\mathrm{Ni}(20$ $\mu \mathrm{m}) / \mathrm{Au}(1 \mu \mathrm{m})$ plated layers (Figure 3.1(c)). In this case the joints were about $60 \mu \mathrm{m}$ in diameter and $25 \mu \mathrm{m}$ in height with a pitch size of about $150 \mu \mathrm{m}$, which is the same size as the joints where $\mathrm{Cu}$ was used on both side in chapter 2. For the above two joint sample sets the cross-sectional microstructures in the as-solidified condition were examined and compared with each other.

All the samples used in this study were made with the same reflow and joining process conditions as the samples used in chapter 2 by the Z-MAJIC ${ }^{\text {TM }}$ process. Details of manufacturing process and conditions were described in section 2.2.1 and Appendix.

\subsubsection{Au-Ni-Sn Alloys and Eutectic Au-Sn/Electroless Ni Couples}


Three bulk Au-Ni-Sn alloys were made in order to study the intermetallic phase formation at compositions like those present at the interface of the joints in this study. The bulk alloys were made by adding Ni contents of 10, 20, and 35 mole percent to eutectic Au-Sn. The alloys were vacuum arc melted using $99.999 \%$ pure $\mathrm{Au}, \mathrm{Ni}$, and $\mathrm{Sn}$. Then the alloys were annealed at $200^{\circ} \mathrm{C}$ for 20 days and quenched in iced water. Metallographic studies and compositional analysis were performed on polished samples using SEM with BSE and EDX analyzer. X-ray diffraction analysis was performed to confirm their phase identities.

Additionally, an electroless Ni layer of about $6.5 \mu \mathrm{m}$ was deposited onto 100 $\mu \mathrm{m}$ thick eutectic Au-Sn foil (99.99\% in metallic base) to form eutectic Au$\mathrm{Sn} /$ electroless Ni couples. Small pieces of the couples were aged at $200^{\circ} \mathrm{C}$ for up to 85 days and the mophological change at the interface was examined. Since this couple was formed without a thin Au layer, it shows the direct interaction between electroless $\mathrm{Ni}$ and eutectic $\mathrm{Au}-\mathrm{Sn}$.

\subsection{SOLDER BUMPS}

The overall microstructure of the solder bumps on electroless $\mathrm{Ni} / \mathrm{Au}$ are quite different from those on just $\mathrm{Cu}$ in terms of the phase distribution at the interface, the scale of lamellae and the source of the large $\zeta$-phases in the bump. These differences are attributed mainly to the substrate metallizations, and their effects on constituent phases of the eutectic Au-Sn solder and substrate metals. Ni is shown to be an effective diffusion barrier against $\mathrm{Cu}$. 


\subsubsection{As-Solidified Bumps}

\subsubsection{Bulk Solder of the Bump}

The typical cross-sectional microstructure of an as-solidified bump is shown in Figure 3.2. The bright constituent in the eutectic microstructure is the $\zeta$-phase (nominally $\mathrm{Au}_{5} \mathrm{Sn}$ ) while the darker constituent is the $\delta$-phase (AuSn). In the assolidified eutectic Au-Sn bump on $\mathrm{Cu}$ presented in chapter 2, $\mathrm{Cu}$ was present throughout the bulk solder due to its high dissolution into the molten solder during reflow. In contrast, $\mathrm{Ni}$ was not detected outside the immediate neighborhood of the interface. This result suggests that the dissolution rate of Ni into molten Au-Sn solder is lower than that of $\mathrm{Cu}$. This is consistent with the low solubility of $\mathrm{Ni}$ in the binary $\mathrm{Au}-\mathrm{Ni}$ and Ni-Sn systems at the reflow temperature. [43]

The bulk of the bump is predominantly $\zeta$-phase. The large islands of $\zeta$ are due to the thin protective layer of $\mathrm{Au}$ on the initial substrate, which is deposited to ensure wetting by the solder. Once the solder is molten, between $280^{\circ} \mathrm{C}$ and $315^{\circ} \mathrm{C}$, the top $\mathrm{Au}$ layer dissolves and slightly increase the overall Au content of the liquid solder into a Au-rich off-eutectic composition (Figure 1.5.), resulting in the formation of proeutectic $\zeta$-phase during solidification. A similarly prominent $\zeta$-phase is found at the as-solidified interfaces of Au-Sn bumps on $\mathrm{Cu}$. However, this is not just the AuSn binary $\zeta$-phase observed in the present system, but is rather a $\zeta$-phase with a high $\mathrm{Cu}$ solubility $(\zeta(\mathrm{Cu}))$. This phase is formed by the high dissolution rate of $\mathrm{Cu}$ into the 
liquid solder and the high solubility of $\mathrm{Cu}$ in $\zeta$-phase due to the nature of between $\mathrm{Au}$ and $\mathrm{Cu}$ as discussed in chapter 2.
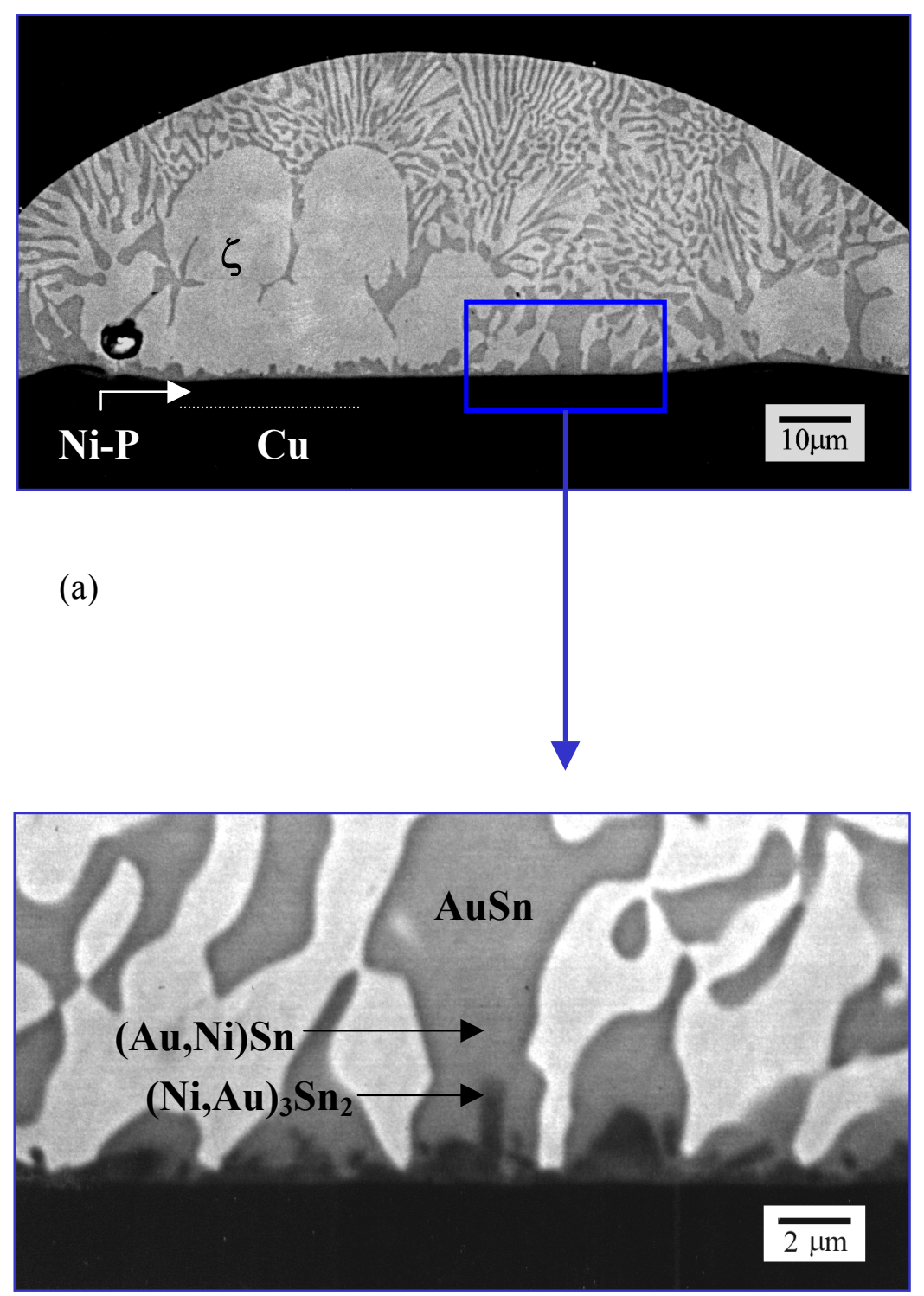

(b) 
Figure 3.2. Cross-sectional micrographs of as-solidified solder bump on $\mathrm{Cu}$ /electroless $\mathrm{Ni} / \mathrm{Au}$. (a) SEM image at low magnification (b) BSE image at high magnification.

The eutectic lamellae in the Au-Sn solder bumps on $\mathrm{Ni}$ are much coarser than those found in the as-solidified eutectic $\mathrm{Au}-\mathrm{Sn}$ bumps on $\mathrm{Cu}$ (Figure 2.2) which had the same geometry and thermal history. The reason is unclear, but most likely is a result of the $\mathrm{Cu}$ dissolution into the solder.

The $\mathrm{Au}$ in $\mathrm{Ni} / \mathrm{Au}$ layer is well known to rapidly dissolve into most $\mathrm{Sn}$-bearing solders during soldering, and precipitates out as needle-shaped (or plate-shaped) $\mathrm{AuSn}_{4}$ intermetallics. Although the precipitates do not significantly influence the overall microstructures of Sn-bearing solders, the amount of $\mathrm{Au}$ within the solder should be limited in order to avoid the deleterious effect on the joint reliability that a large amount of $\mathrm{AuSn}_{4}$ intermetallics within the bulk can have.[3-5] In the case of eutectic $\mathrm{Au}-\mathrm{Sn}$ solder, the precipitation of $\mathrm{AuSn}_{4}$ is not a concern since it does not occur. However, the amount of Au dissolved into eutectic Au-Sn should be still carefully controlled since it modifies the nominal eutectic composition and thereby the microstructure as shown in Figure 3.2(a). Therefore, in order to attain the desired properties of eutectic $\mathrm{Au}-\mathrm{Sn}$ come from its composition and microstructure, it is suggested to use an initial Au-Sn composition slightly off-eutectic on the Sn-side depending on thickness of $\mathrm{Au}$ layer, when $\mathrm{Au}$ is used as a top protective layer in substrate metallization scheme.

\subsubsection{Interface Structure of the Bumps}


An irregular-shaped intermetallic phase was observed at the interface between the solder and the electroless $\mathrm{Ni}$ metallization as shown in Figure 3.2(b). High magnification BSE imaging was used to clarify the morphology of this phase. The average thickness of this intermetallic phase was about $0.7 \mu \mathrm{m}$. Compositional analysis by EDX from this intermetallics larger than $1 \mu \mathrm{m}$ shows that it is a Au-Ni-Sn compound of the measured composition (22-25) $\mathrm{Au}(35-38) \mathrm{Ni}(38-41) \mathrm{Sn}$ (all compositions are in mole fraction unless stated otherwise), which corresponds to the $\mathrm{Ni}_{3} \mathrm{Sn}_{2}$ phase with a high $\mathrm{Au}$ solubility, $(\mathrm{Ni}, \mathrm{Au})_{3} \mathrm{Sn}_{2}$. While no other interfacial phases were noticed in the SEM micrographs, an additional Au-Ni-Sn phase was found by EDX. It forms a layer between the $(\mathrm{Ni}, \mathrm{Au})_{3} \mathrm{Sn}_{2}$ and the $\mathrm{Au}-\mathrm{Sn}$ binary phases in the bulk solder, and is identified as a $\delta$-phase with $\mathrm{Ni}$, specifically (Au,Ni)Sn, with composition (42-45)Au(5-8) Ni(46-49) Sn.

\subsubsection{Verification of Interface Phases}

The phase information found on the Au-Ni-Sn system is limited to ternary isothermal sections at room temperature [105] and $400^{\circ} \mathrm{C},[106]$ as shown in Figure 3.3. Although these two isothermal sections are concerned with different temperatures, both the Au-rich and Sn-rich corners of each show large differences in the solubility limit of $\mathrm{Au}$ and $\mathrm{Ni}$ in both $\mathrm{Ni}-\mathrm{Sn}$ and $\mathrm{Au}-\mathrm{Sn}$ intermetallic phases. Considering the Sn-rich corner recently determined at $150^{\circ} \mathrm{C},[107]$ we need to examine the phase relations and solubility limits at temperatures and compositions used in this study, which is necessary to completely understand the microstructural evolution of the solder joints during aging. 
Figure 3.4 shows the microstructures of three bulk Au-Ni-Sn alloys that were made by adding Ni contents of 10, 20, and 35 at.\% to eutectic Au-Sn.

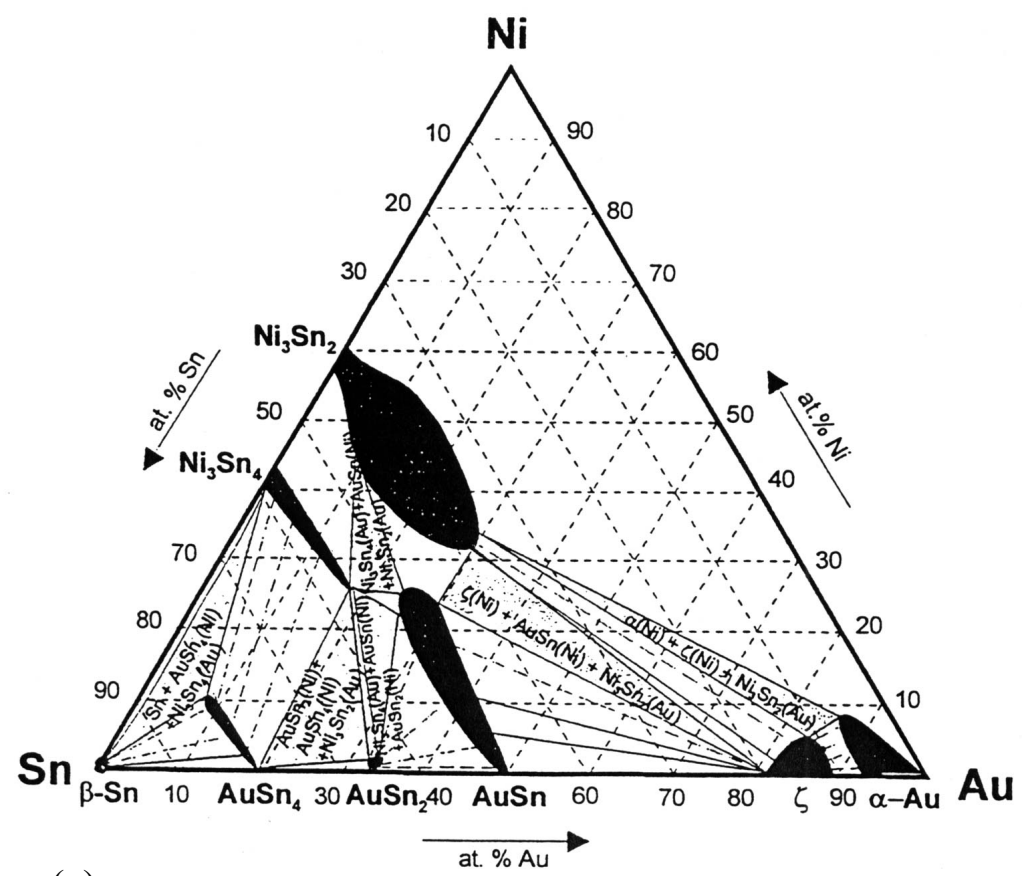

(a)

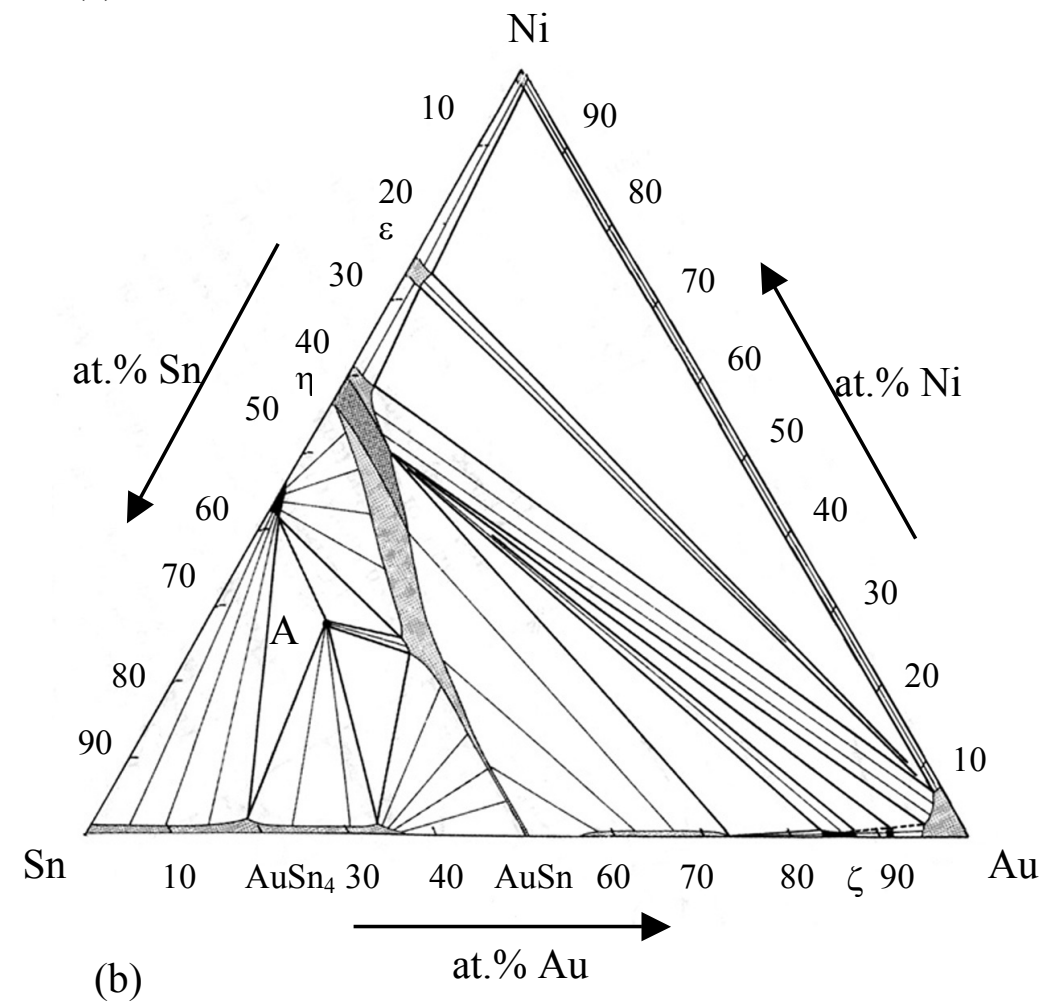


Figure 3.3. Isothermal cross section of the ternary Au-Ni-Sn system (a) at room temperature, [105] (b) $400^{\circ} \mathrm{C}$, [106].

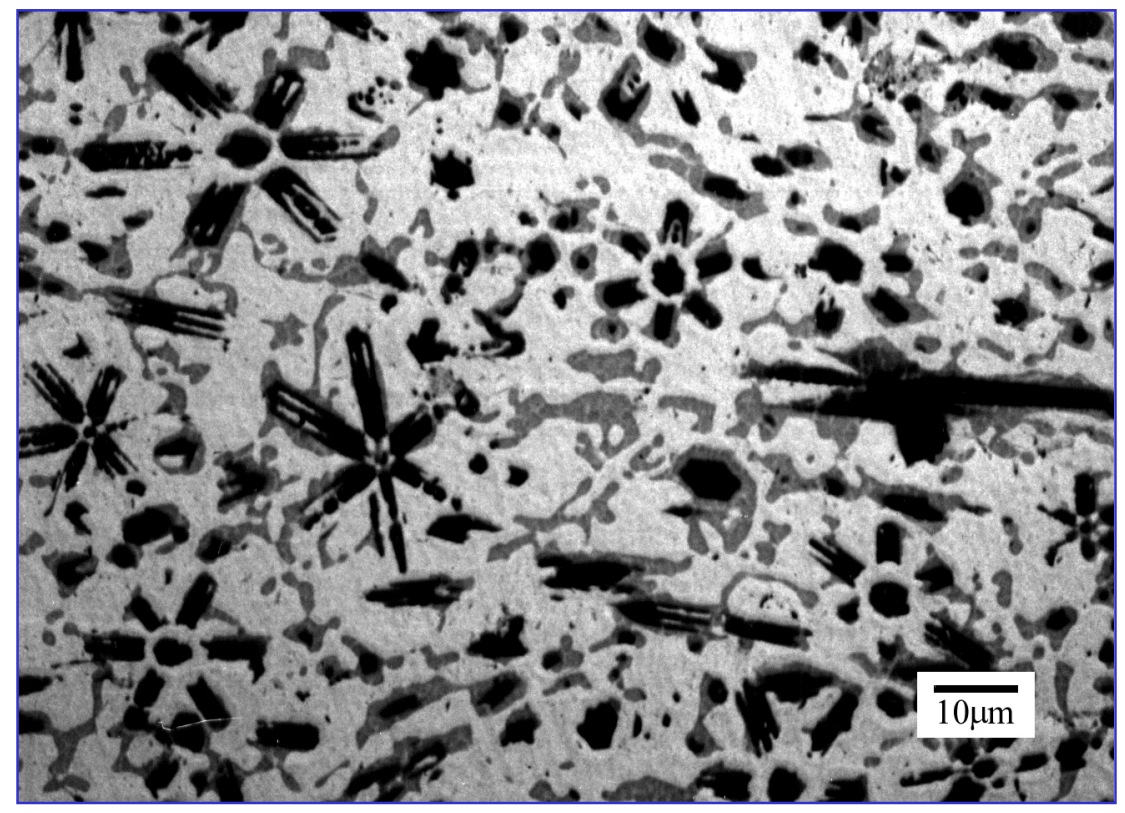

(a)

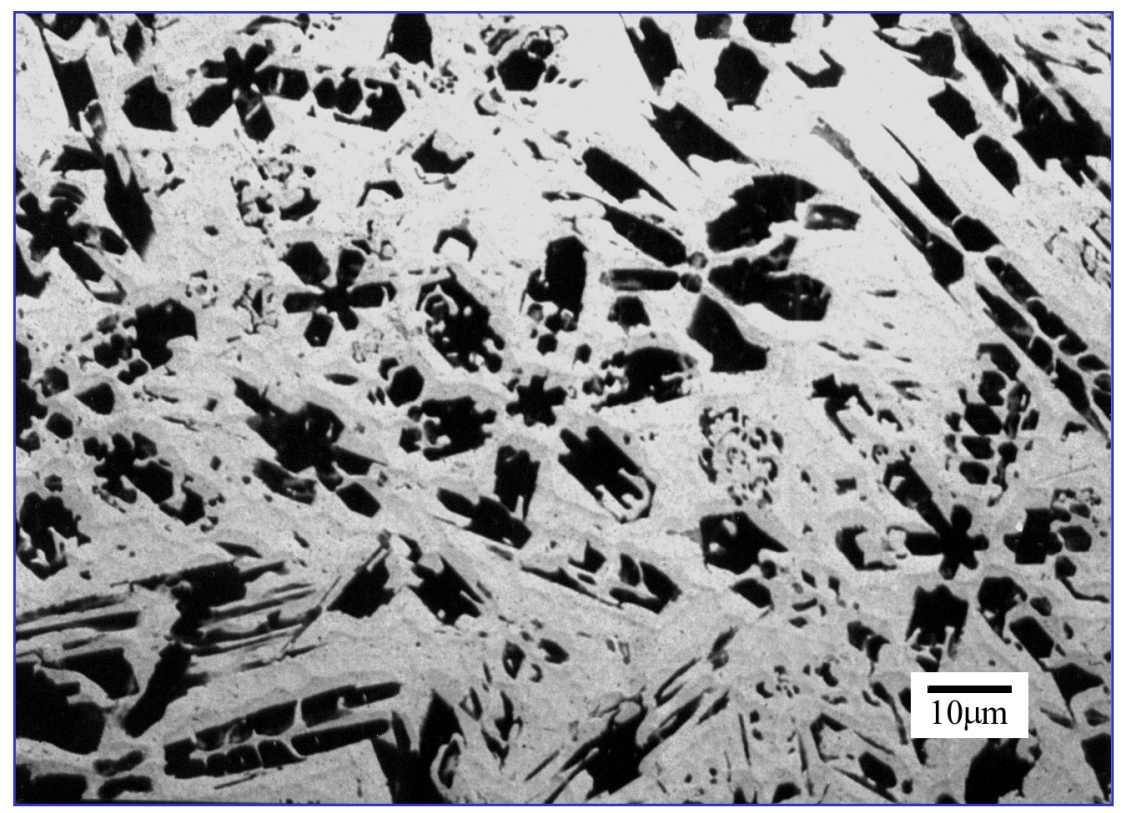

(b) 
Figure 3.4. Continued on the next page.

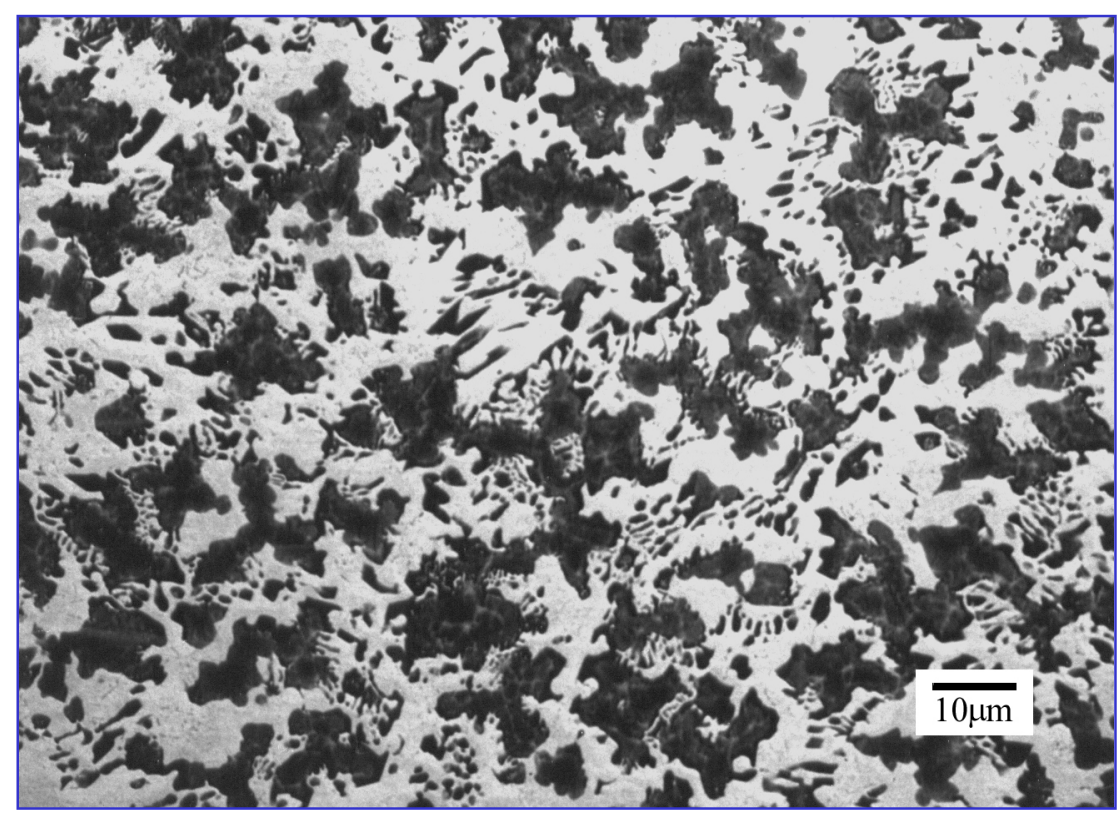

(c)

Figure 3.4. BSE micrographs of bulk Au-Ni-Sn alloys. (a) 90 (eutecitc Au-Sn)-10Ni (at.\%): $\zeta$ (matrix), $\delta(\mathrm{Ni}$ )(gray phase) (b) 80 (eutecitc Au-Sn)-20Ni (at.\%): $\zeta$ (matrix), $\mathrm{Ni}_{3} \mathrm{Sn}_{2}(\mathrm{Au})$ (dark phase) (c) 65(eutecitc Au-Sn)-35Ni (at.\%): $\mathrm{Au}(\mathrm{Ni}, \mathrm{Sn})($ matrix), $\mathrm{Ni}_{3} \mathrm{Sn}(\mathrm{Au})$ (gray phase), $\mathrm{Ni}_{3} \mathrm{Sn}_{2}(\mathrm{Au})$ (dark phase).

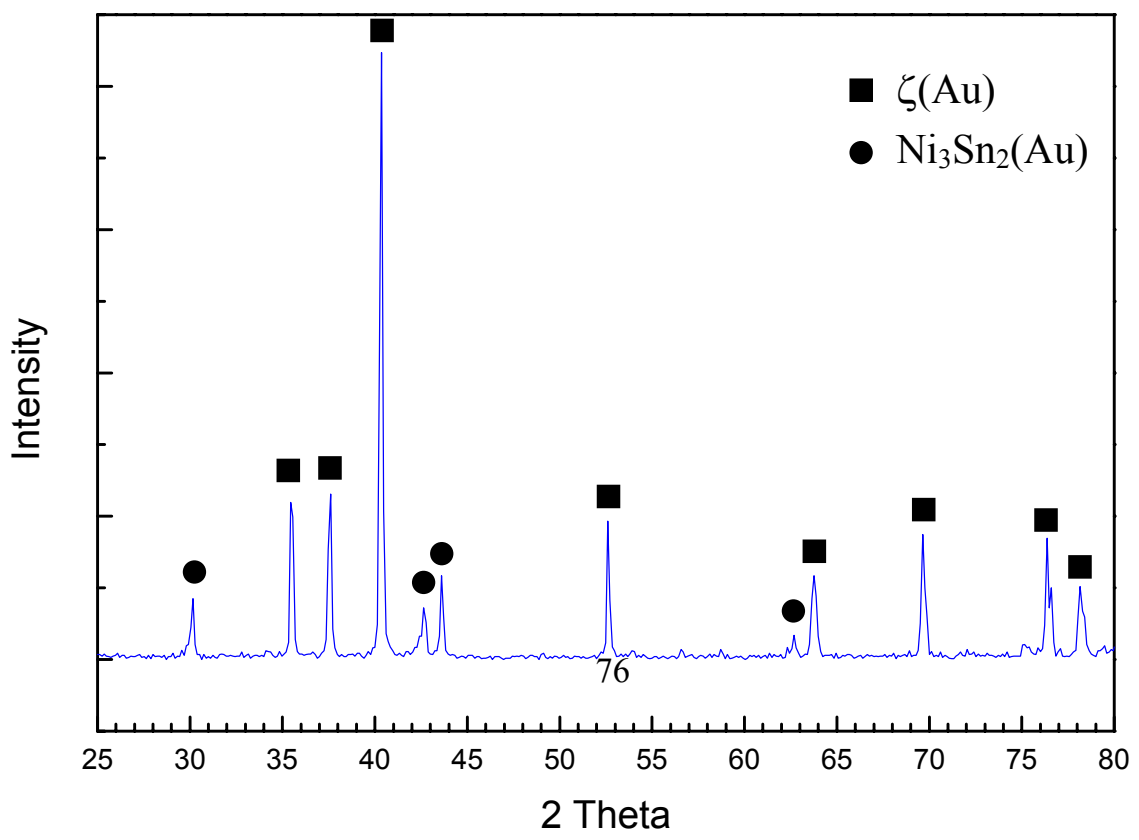


Figure 3.5. X-ray diffraction pattern of 80(eutecitc $\mathrm{Au}-\mathrm{Sn})-20 \mathrm{Ni}$ (at.\%) alloy.

The same binary phases with the solubility of a third element that were found at the interface of the solder bumps were identified in the bulk Au-Ni-Sn alloys. The phase analysis was completed through metallographic compositional analysis and confirmed by X-ray diffraction analysis, one of diffraction patterns is shown in Figure 3.5. The results are summarized in Table 3.1 and compared to those inferred from the reported isothermal sections of the ternary phase diagram at room temperature and $400^{\circ} \mathrm{C}$.

Table 3.1. Comparison of constituent phases in different isothermal sections.

\begin{tabular}{c|c|c|c}
\hline & $\begin{array}{c}\text { Eutectic } \mathrm{AuSn} \\
\text { with } 10 \text { at.\% Ni }\end{array}$ & $\begin{array}{c}\text { Eutectic } \mathrm{AuSn} \\
\text { with } 20 \text { at.\% Ni }\end{array}$ & $\begin{array}{c}\text { Eutectic } \mathrm{AuSn} \\
\text { with } 35 \text { at.\% Ni }\end{array}$ \\
\hline $\begin{array}{c}\text { Room } \\
\text { Temperature }\end{array}$ & $\begin{array}{c}\zeta+\delta(\mathrm{Ni})+ \\
\mathrm{Ni}_{3} \mathrm{Sn}_{2}(\mathrm{Au})\end{array}$ & $\begin{array}{c}\mathrm{Au}(\mathrm{Ni}, \mathrm{Sn})+\zeta(\mathrm{Ni}) \\
+\mathrm{Ni}_{3} \mathrm{Sn}_{2}(\mathrm{Au})\end{array}$ & $\mathrm{N} / \mathrm{A}$ \\
\hline $200^{\circ} \mathrm{C}$ & $\zeta+\delta(\mathrm{Ni})+$ & $\zeta(\mathrm{Ni})+\mathrm{Ni}_{3} \mathrm{Sn}_{2}(\mathrm{Au})$ & $\begin{array}{c}\mathrm{Au}(\mathrm{Ni}, \mathrm{Sn})+ \\
\mathrm{Ni}_{3} \mathrm{Sn}(\mathrm{Au})+ \\
\mathrm{Ni}_{3} \mathrm{Sn}{ }_{2}(\mathrm{Au})\end{array}$ \\
\hline & $\mathrm{Ni}_{3} \mathrm{Sn}_{2}(\mathrm{Au})$ & & $\begin{array}{c}\mathrm{Au}(\mathrm{Ni}, \mathrm{Sn})+ \\
\mathrm{Ni}_{3} \mathrm{Sn}(\mathrm{Au})+ \\
\mathrm{Ni}_{3} \mathrm{Sn}(\mathrm{Au})\end{array}$ \\
\hline
\end{tabular}


The phase distributions examined with respect to $\mathrm{Ni}$ content generally corresponds to those reported in the isothermal sections. Also it was confirmed that $\mathrm{Ni}$ is much more soluble in the $\delta$-phase than in the $\zeta$-phase, which is a known as the feature of Au-Ni-Sn system reported by Neumann et al.[106] Unlike the $\mathrm{Au}-\mathrm{Cu}$ system discussed in section 2.3.1, the Au-Ni system has an inherent lack of mutual solid solubility due to well established criteria for the occurrence of solid solubility not being satisfied. Neumann et al. reported that this is reflected in the Au-Ni-Sn system through the small solubility of Au and Ni in both the binary Ni-Sn and Au-Sn phases, but there is a large solubility between $\delta$ and $\mathrm{Ni}_{3} \mathrm{Sn}_{2}$ due to their similar crystal structural type(NiAs-type hexagonal).[106]

The determined maximum solubility of $\mathrm{Ni}$ in $\zeta$ was about 1 at. $\%$ at $200^{\circ} \mathrm{C}$, while the $\delta$-phase dissolved more than 20 at.\% Ni. It follows that $\mathrm{Ni}$ reacts primarily with the $\delta$-phase rather than $\zeta$-phase in solder joints, as is confirmed by compositional analyses of the two phases at the interface of aged solder bumps, reported in the following section.

\subsubsection{Aged Solder Bumps}

Figure 3.6 shows the microstructure of eutectic Au-Sn on electroless Ni after aging at $200^{\circ} \mathrm{C}$. As the joint ages, the eutectic lamellae in the bulk solder coarsen and become globular (Figure 3.6(a), (c)). As Ni gradually diffuses into the solder, the irregular $(\mathrm{Ni}, \mathrm{Au})_{3} \mathrm{Sn}_{2}$ intermetallic layer at the interface becomes flat and the $\delta$-based 
$(\mathrm{Au}, \mathrm{Ni}) \mathrm{Sn}$ becomes more distinct (Figure 3.6(e)). The measured compositions of the $(\mathrm{Ni}, \mathrm{Au})_{3} \mathrm{Sn}_{2}$ and $(\mathrm{Au}, \mathrm{Ni}) \mathrm{Sn}$ layers in Figure 3.6(e) are (22-26) $\mathrm{Au}(34-38) \mathrm{Ni}(40-41) \mathrm{Sn}$ and (32-35) $\mathrm{Au}(21-24) \mathrm{Ni}(44-46) \mathrm{Sn}$, respectively. The composition varies across each layer with the $\mathrm{Au}$ content slightly higher on the solder side and Ni content higher toward the substrate.

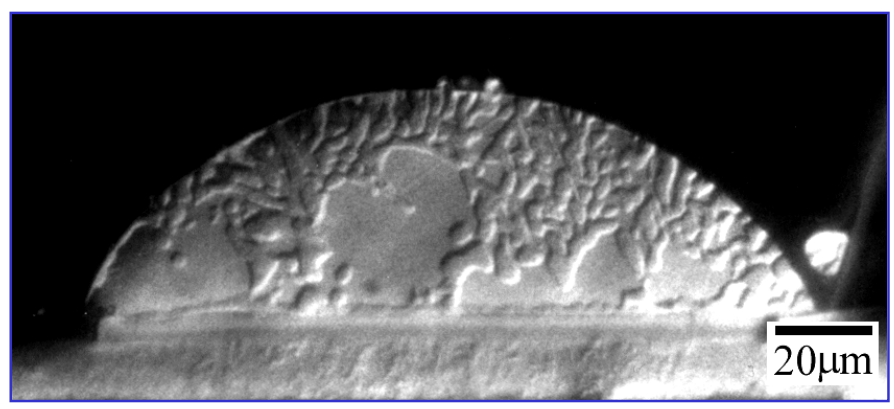

(a)

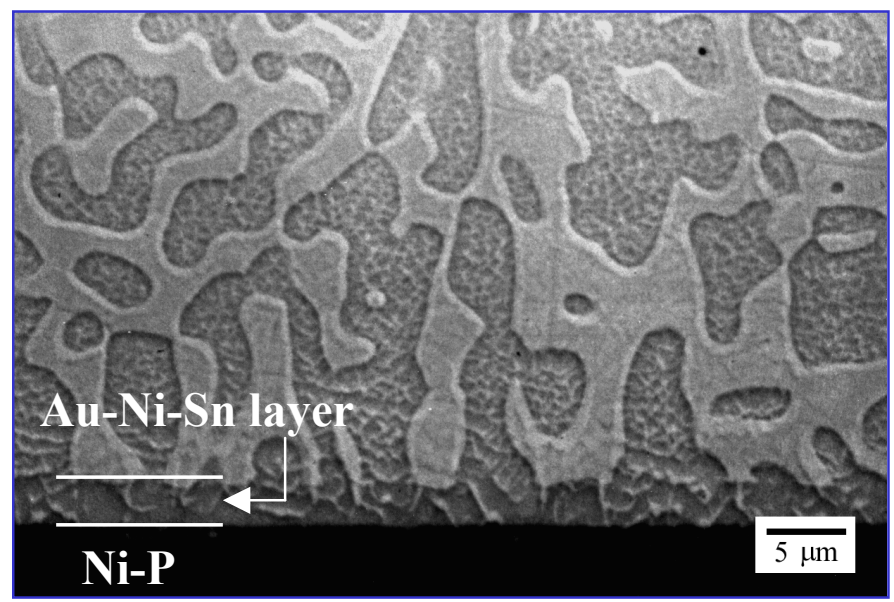

(b) 
Figure 3.6. Continued on the next page.

(c)

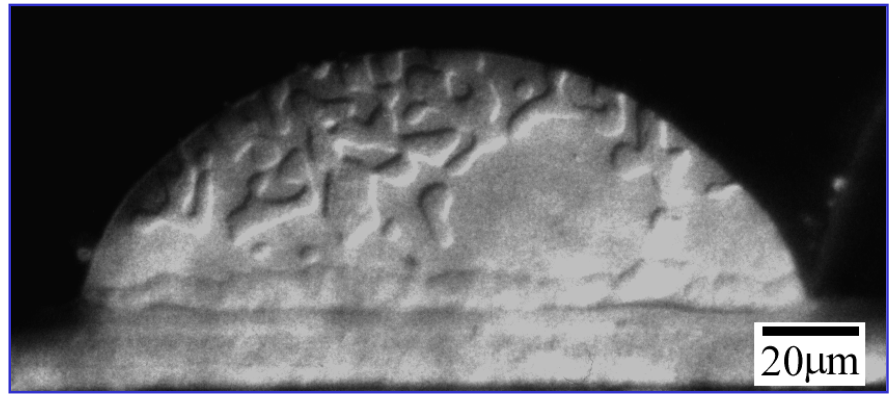

(d)

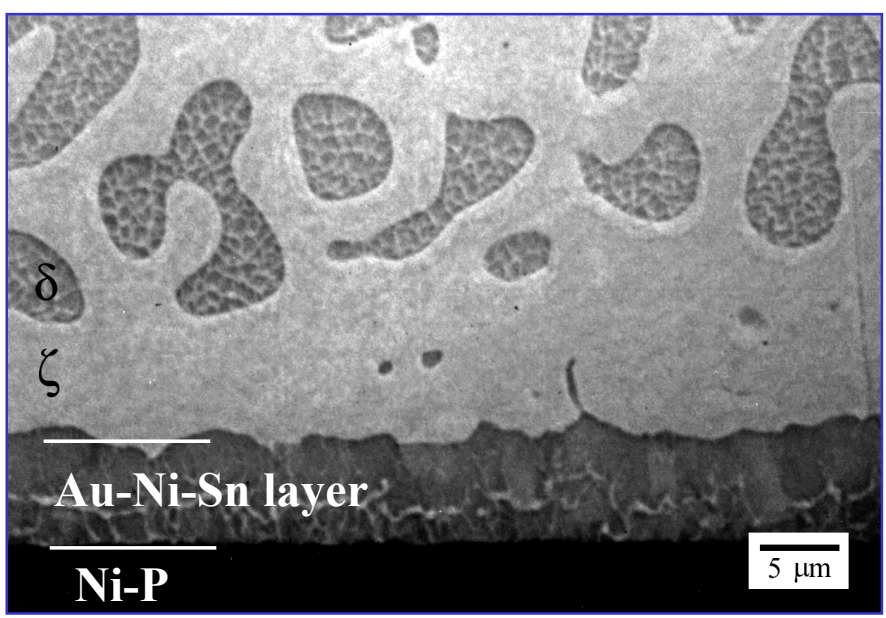

(Au, Ni)Sn

$(\mathrm{Ni}, \mathrm{Au})_{3} \mathrm{Sn}_{2}$

(e)

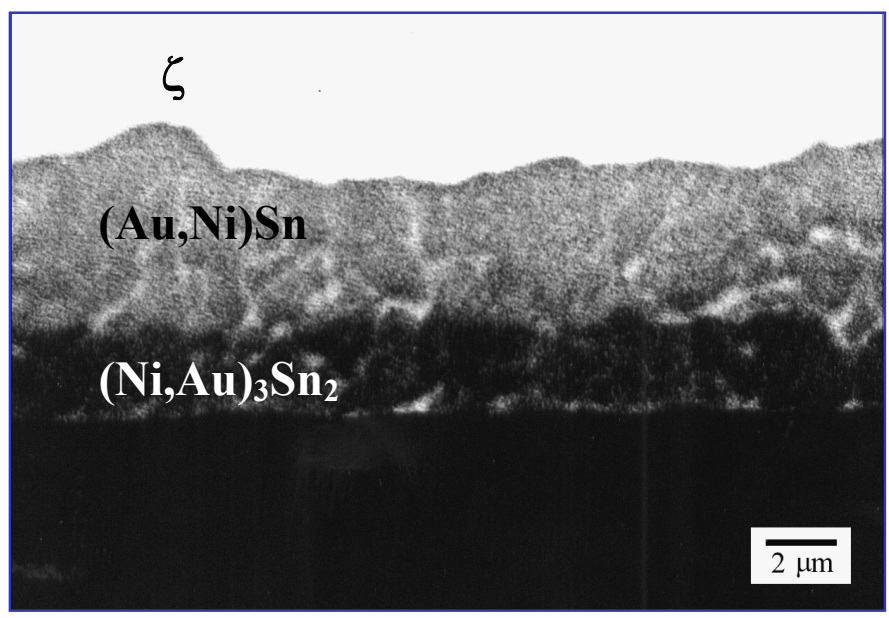


Figure 3.6. Cross-sectional micrographs of solder bumps aged at $200^{\circ} \mathrm{C}$ (a) optical micrograph for 50 days, (b) SEM micrograph near interface for 50 days, (c) optical micrograph for 365 days, (d) SEM micrograph near interface for 365 days, and (e) BSE micrograph image near interface for 365 days.

The thickness of the total interfacial intermetallic layer is plotted as a function of time in Figure 3.7. The layer thickens with $\mathrm{t}^{1 / 2}$, as is normal for diffusion-controlled growth.[25,26] The growth rate of the interfacial layer in this system is only about half the growth rate of the total interfacial layer in eutectic $\mathrm{Au}-\mathrm{Sn}$ bumps on $\mathrm{Cu}$, which is the sum of the growth rates of both $\mathrm{CuAu}$ and $\mathrm{Cu}_{3} \mathrm{Au}$ as shown Figure 3.8.

The phase distribution at the interface changes qualitatively on aging. The $\delta$ phase adjacent to the interfacial layer is gradually replaced by the $\zeta$-phase, which eventually covers the interfacial layer as shown in Figure 3.6(d). These changes are clearly observed from the eutectic $\mathrm{Au}-\mathrm{Sn} / \mathrm{electroless}$ couples aged at $200^{\circ} \mathrm{C}$ in Figure 3.9. This microstructural change results from the difference in Ni solubility in the $\zeta$ and $\delta$-phases. Since Ni solubility in the $\zeta$-phase is below 1 at.\%, $\mathrm{Ni}$ is not incorporated into the $\zeta$-phase. Instead, the $\zeta$ near the interface acts as a source of $\mathrm{Au}$ and $\mathrm{Sn}$ for the interfacial phases which are relatively rich in Sn. As the interfacial layers grow, $\mathrm{Au}$ is obtained by consuming the $\zeta$-phase. On the solder side, the $\delta$ phase, which has a high Ni solubility, incorporates $\mathrm{Ni}$ and releases $\mathrm{Au}$ as it converts into the $(\mathrm{Au}, \mathrm{Ni}) \mathrm{Sn}$ phase. The Au that is released causes lateral growth of the $\zeta$-phase 
and increases its volume fraction at the interface. The islands of $\zeta$-phases spread along the interface and contact to form a continuous layer. Once the $\zeta$-phase covers the interfacial layer, it acts as a diffusion barrier to inhibit the flow of $\mathrm{Ni}$ into the bulk solder. In fact, the Ni content in the bulk solder is small even after aging for 365 days at $200^{\circ} \mathrm{C}$.

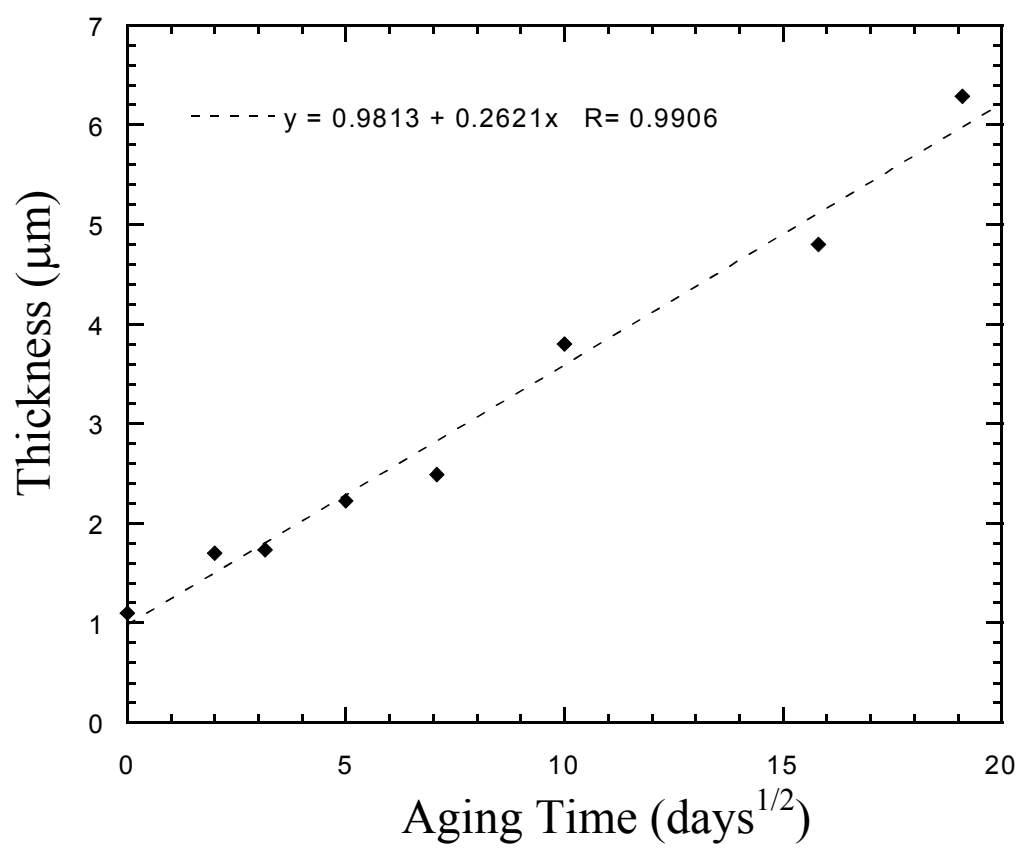


Figure 3.7. Thickness of total Au-Ni-Sn interfacial intermetallic layers with the square root of aging time at $200^{\circ} \mathrm{C}$. 


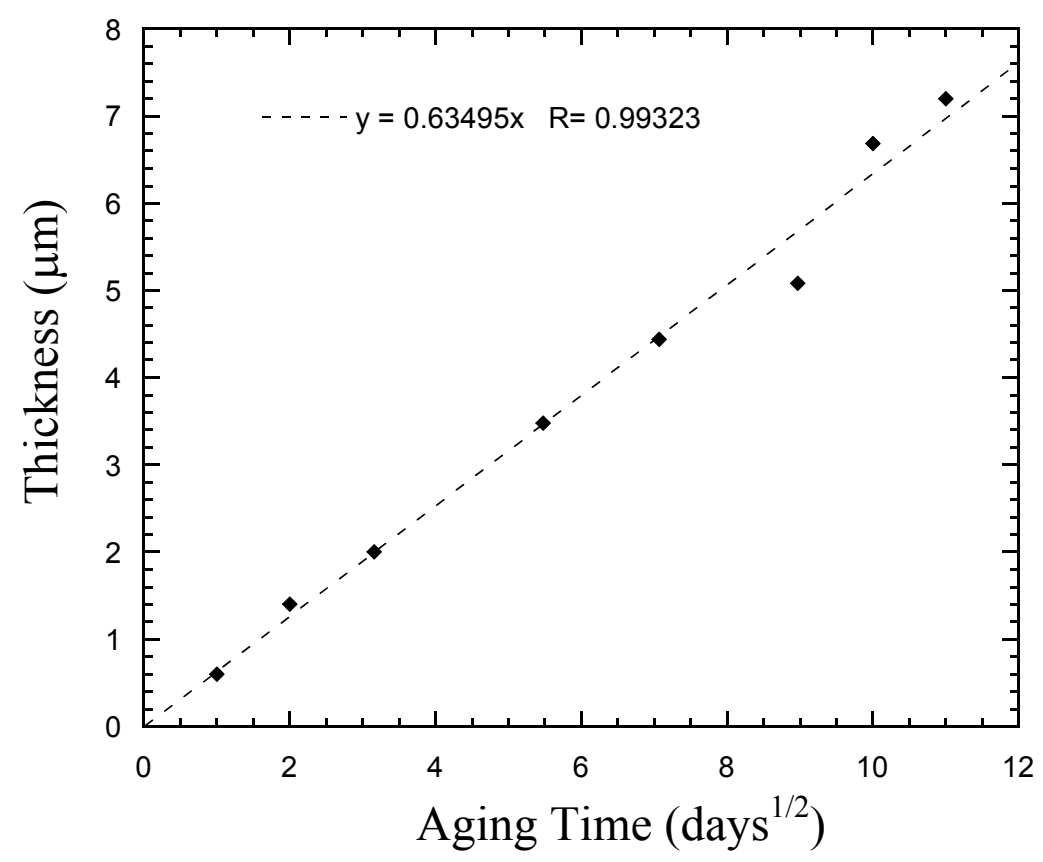

Figure 3.8. Thickness of total $\mathrm{Cu}-\mathrm{Au}$ interfacial intermetallic layers with the square root of aging time at $200^{\circ} \mathrm{C}$ that are observed in eutectic Au-Sn solder bump on $\mathrm{Cu}$. 


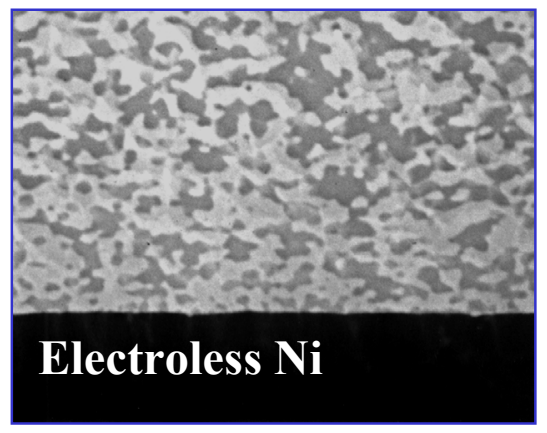

(a)

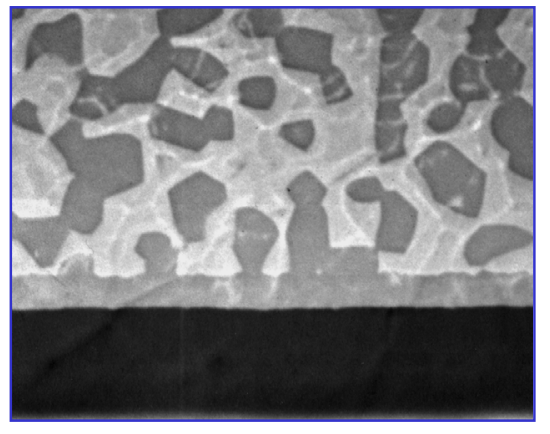

(b)

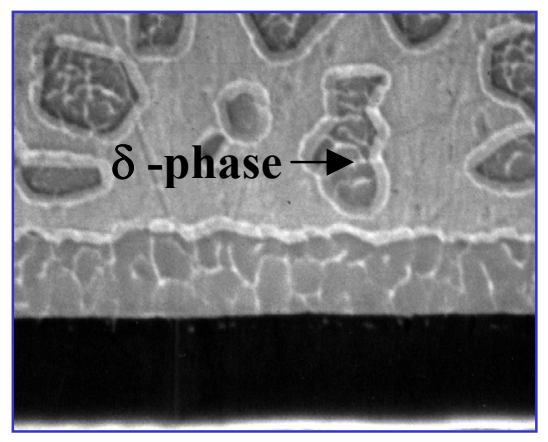

(d)

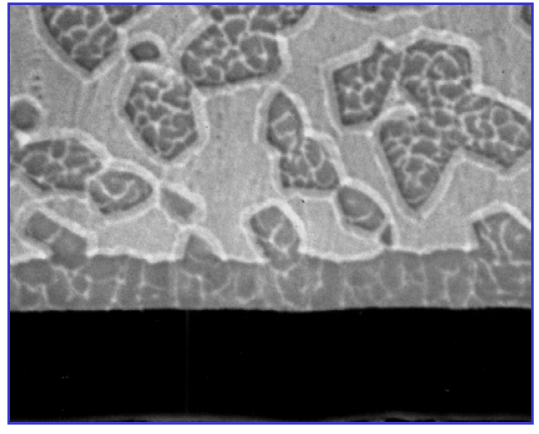

(c)

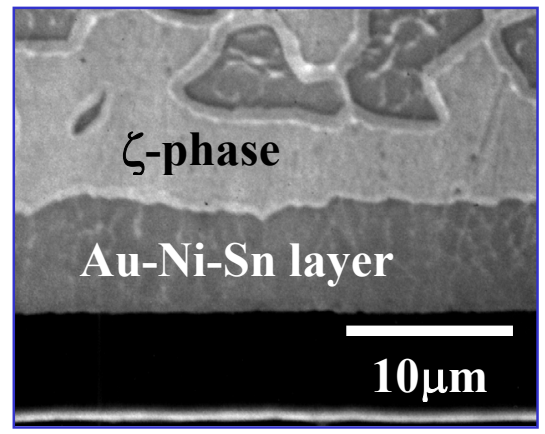

(e)

Figure 3.9. SEM micrographs showing changes of phase distribution at the interface of the eutectgic $\mathrm{Au}-\mathrm{Sn} / \mathrm{electroless} \mathrm{Ni}$ couples during aging at $200^{\circ} \mathrm{C}$ for (a) 0 day (asplated), (b) 10 days, (c) 25 days, (d) 50 days, and (e) 85 days. 


\subsection{SOLdER JOINTS}

In Figure 3.10, the typical microstructures of as-solidified joints which have electroless $\mathrm{Ni} / \mathrm{Au}$ metallizations on both the top and the bottom substrates is shown. The schematic geometry of these joints is shown in Figure 3.1(b). Considering the fact that the bulk of the solder bump is predominantly $\zeta$-phase due to the protective layer of $\mathrm{Au}$ that dissolves into molten solder, it is not surprising to find the $\zeta$-dominant coarse microstructure in this joint. Since Au layers were both on the top and bottom of the joint, more $\mathrm{Au}$ dissolves during the process and changes the nominal composition of the solder into a greater Au-rich off-eutectic.

The overall microstructure looks similar to that of the joints with $\mathrm{Cu}$ examined in chapter 2 as far as the microstructural scale. However, the constituent phases of this joint are separated into two regions of each phase rather than a two-phase mixture. The middle of joint is occupied by a binary $\zeta$-phase (with no Ni content) while the region near interface by $\delta$-based $(\mathrm{Au}, \mathrm{Ni}) \mathrm{Sn}$ phase. This is somewhat opposite to the phase distribution of the joint with $\mathrm{Cu}$ that has a thick $\zeta(\mathrm{Cu})$ phase on both interface sides. This difference in the phase distribution results from the characteristics of $\mathrm{Ni}$ and $\mathrm{Cu}$ solubility in $\zeta$ and $\delta$-phase of the eutectic $\mathrm{Au}-\mathrm{Sn}$, which have originated from the intrinsic characteristics between $\mathrm{Cu}$ and $\mathrm{Au}$, and $\mathrm{Ni}$ and $\mathrm{Au}$ as discussed previously. That is, the $\zeta$-phase has a high solubility of $\mathrm{Cu}$ but very little of Ni, while the $\delta$-phase has a high solubility of $\mathrm{Ni}$ but not of $\mathrm{Cu}$. 

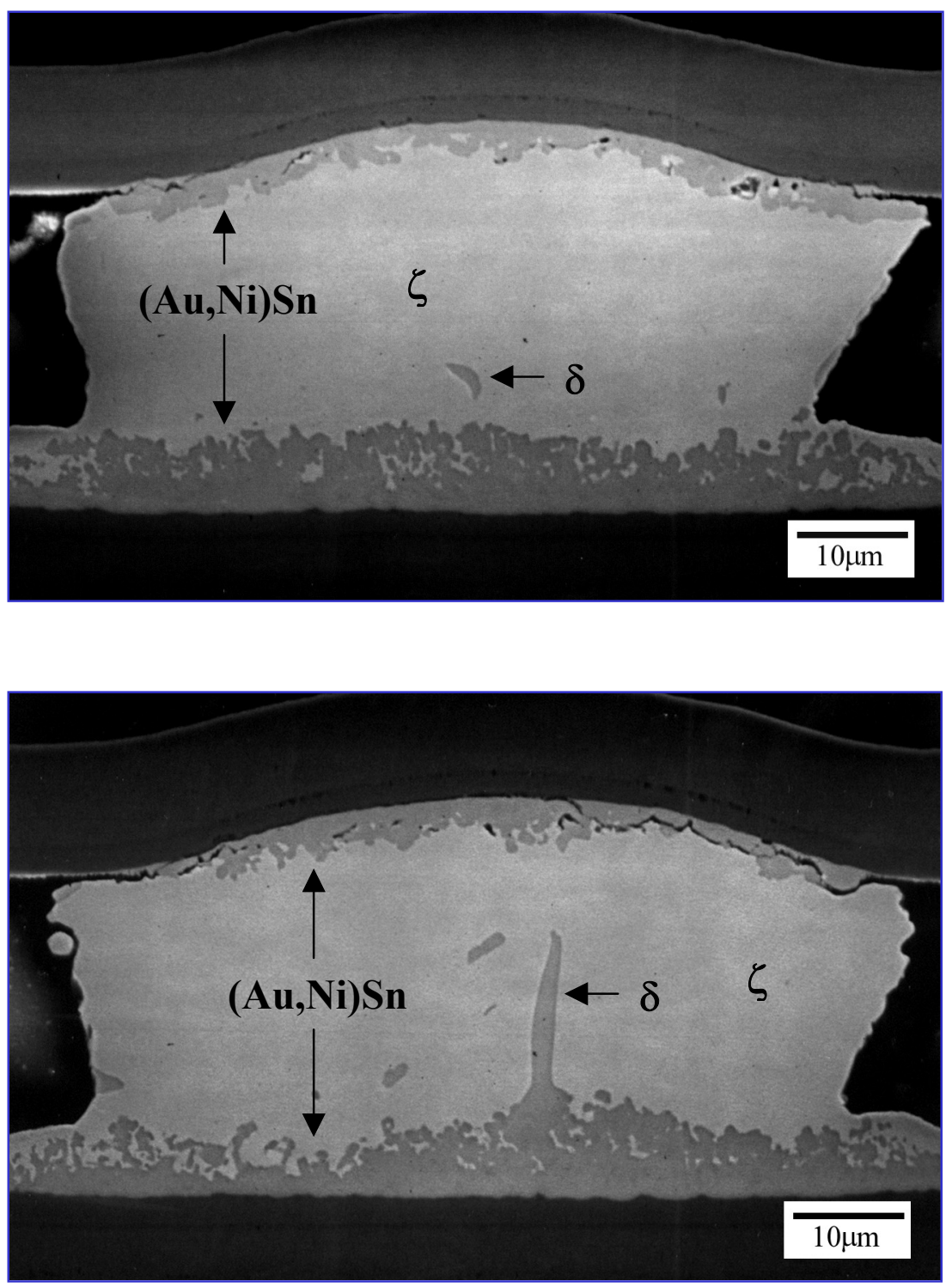

Figure 3.10. Cross-sectional SEM micrographs of as-solidified joints that have electroless $\mathrm{Ni} / \mathrm{Au}$ metallizations on both the top and the bottom substrates. 
Due to the large difference in Ni solubility in each phase, the $\delta$-phase covers the region near the interface of the joint, reacting with Ni. Likewise, $\zeta$-phase is located in the middle of the joints without incorporating Ni. Thus, it is expected that the mechanical behaviors of this type of joints will be governed by the properties of each constituent phase rather than a mixture of these.

While the cross-sectional SEM micrograph did not show it, a thin $(\mathrm{Ni}, \mathrm{Au})_{3} \mathrm{Sn}_{2}$ intermetallic layer was observed by EDX near interface right above the electroless $\mathrm{Ni}$, as in the solder bump samples.

The crack observed in the joint in Figure 3.10 was formed during sample preparation and seems to be weaker than the other kinds of joint samples due to its much larger pitch size. Although the crack was inadvertently formed, most cracks went through the $\delta$-phase or the interface between electroless $\mathrm{Ni}$ and the $\delta$, indicating that these are the weakest parts of this joints with this specific geometry.

Figure 3.11 shows representative microstructures from the joints with dissimilar metallizations, which is often seen in industrial applications. $\mathrm{Cu}$ was on the top pad of the joint and electroless $\mathrm{Ni} / \mathrm{Au}$ was on the bottom pad, as shown in Figure 3.1(c). As can be expected throughout the study, the microstructural features of this joint exactly reflect those found in the joints that have the same kind of pad metallization. The $\mathrm{Cu}$ interface is coated with the thick $\mathrm{Cu}$-containing $\zeta$-phase and thin $\mathrm{CuAu}$ compound with a small amount of $\mathrm{Sn}$ is between them. The Ni interface has a thin $(\mathrm{Ni}, \mathrm{Au})_{3} \mathrm{Sn}_{2}$ layer and $\delta$-based $(\mathrm{Au}, \mathrm{Ni}) \mathrm{Sn}$ below the bulk $\zeta$ phase. 

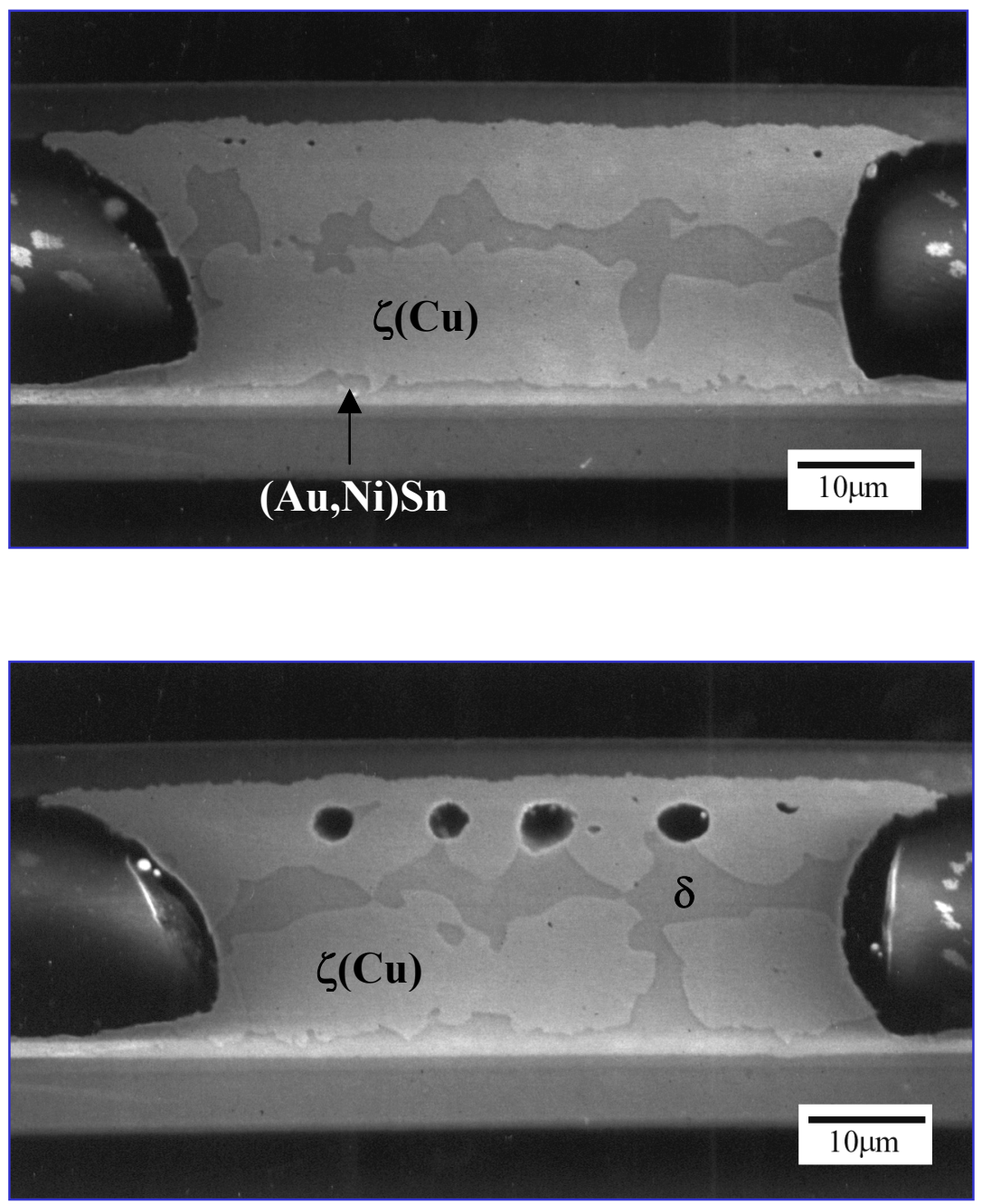

Figure 3.11. Cross-sectional SEM micrographs of as-solidified joints that have $\mathrm{Cu}$ on the top pad and electroless $\mathrm{Ni} / \mathrm{Au}$ on the bottom pad. 
$\mathrm{Cu}$ distributes throughout the joint, particularly in the $\zeta$-phase, increasing its content towards the $\mathrm{Cu}$ interface while $\mathrm{Ni}$ is localized in the $\delta$-phase at the $\mathrm{Ni}$ interface. Therefore the ni is demonstrably less dissolved into the joint despite the fact that the electroless $\mathrm{Ni}$ experienced a high temperature for much longer due in the joining process. This is partly because of the lager fraction of $\zeta$-phase caused by the dissolution of the $\mathrm{Au}$ layer, which inhibits $\mathrm{Ni}$ and accommodates $\mathrm{Cu}$. In addition, it indicates that the dissolution and diffusion rates of $\mathrm{Ni}$ are lower than those of $\mathrm{Cu}$ in the eutectic $\mathrm{Au}-\mathrm{Sn}$ solder. This is a result of the characteristics between $\mathrm{Au}$ and $\mathrm{Cu} / \mathrm{Ni}$, rather than between $\mathrm{Sn}$ and $\mathrm{Cu} / \mathrm{Ni}$. This effect is separate than the faster reaction rate of $\mathrm{Cu}$ than that of $\mathrm{Ni}$ with most other Sn-bearing solders.

\subsection{Detailed Interface Microstructure Of Solder Bump}

Unlike electolytic $\mathrm{Ni}$ plating, the typical electroless $\mathrm{Ni}$ plating used in electronic packaging involves phosphorus (P) because hypophosphite is used in the reduction of $\mathrm{Ni}$ ions.[85] It has been found that the $\mathrm{P}$ content and the thermal history determine the structure and properties of the electroless Ni layer. [108-115] In general, as-plated electroless $\mathrm{Ni}(\mathrm{Ni}-\mathrm{P})$ layer is amorphous at high $\mathrm{P}$ contents ( $\mathrm{P}$ greater than about 10 at.\%) and tends to undergo self (or thermal)-crystallization on annealing. There are no significant compositional changes during crystallization.[113]

\subsubsection{Interface in As-Solidified Bump}


Solder bumps on electroless Ni were used to analyze details of the interfacial microstructure using TEM. The P content of the electroless Ni layer used in this work was measured to be $10-12$ at.\% in the very fine-grain region near the $\mathrm{Cu}$ substrate, which is assumed to not be involved in interfacial reactions as discussed below. Figure 3.12(a) is a cross-sectional TEM micrograph of the interface between the eutectic Au-Sn solder and the electroless $\mathrm{Ni}$ in the as-solidified bump. Its structure is schematically illustrated in Figure 3.12(b). Regions of the Ni layer differ in grain size, but all of the regions are crystalline except for a thin layer immediately beneath the $(\mathrm{Ni}, \mathrm{Au})_{3} \mathrm{Sn}_{2}$ compound. This suggests that the as-plated amorphous electroless $\mathrm{Ni}$ in this system crystallized during the reflow process.

The microstructure of the $\mathrm{Ni}$ layer varies with distance beneath the $(\mathrm{Ni}, \mathrm{Au})_{3} \mathrm{Sn}_{2}$ intermetallic at the interface. The sequence of microstructures begins with a thin amorphous reaction layer $(0.16-0.18 \mu \mathrm{m}$ thick), followed by a fine-grained P-rich region $(0.15-0.2 \mu \mathrm{m}$ thick), then a relatively coarse-grained Ni-P region within which the grain size gradually decreases into a fine-grained Ni-P( $\sim 1.28 \mu \mathrm{m}$ thick $)$, and finally a uniformly very fine-grained Ni-P that borders the $\mathrm{Cu}$ substrate. The interfacial reaction for the formation of the $(\mathrm{Ni}, \mathrm{Au})_{3} \mathrm{Sn}_{2}$ intermetallic compounds involves either Ni diffusion towards the solder side or P diffusion backwards in the electroless Ni layer, which results in the compositional variation of the Ni-P layer near the interface. Considering the fact that the grain size of the electroless Ni-P is known to be related to the $\mathrm{P}$ content, $[108,116]$ it appears that about one-third of the electroless Ni layer participated in the interfacial reaction during the reflow process. These distinct microstructures are discussed in detail below. 


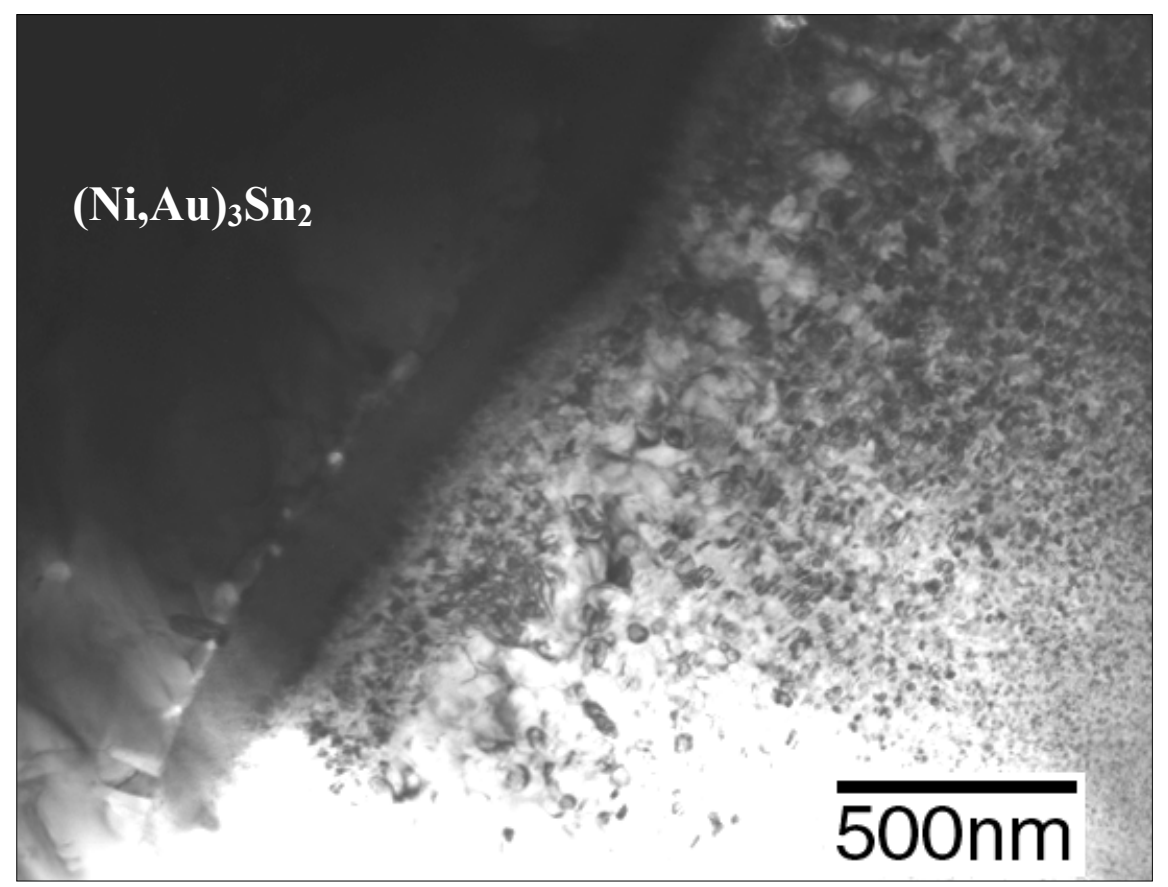

(a)

(b)

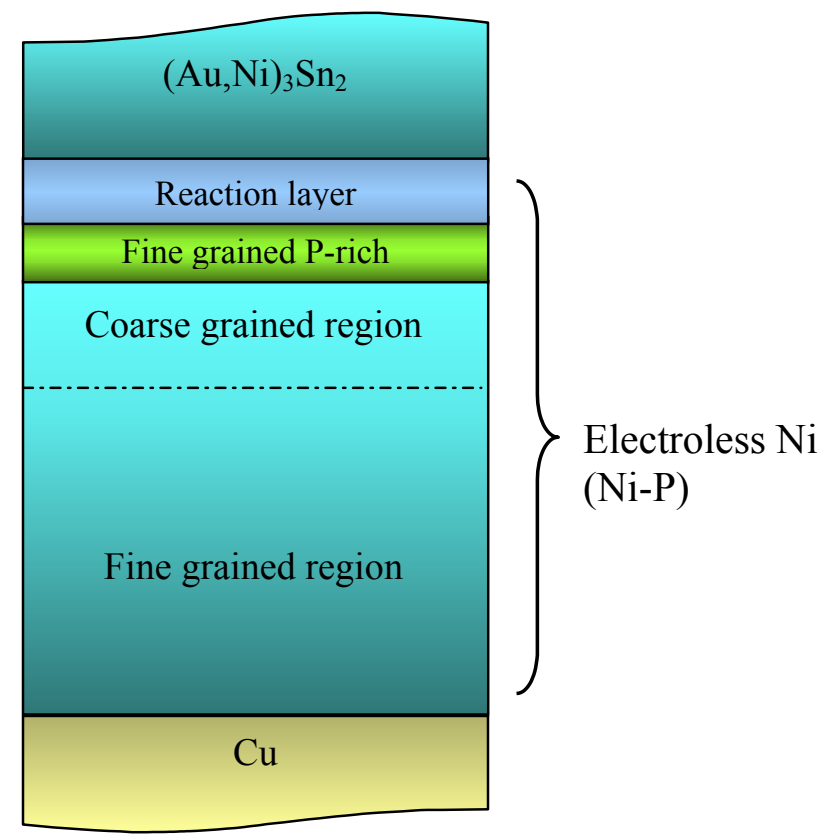

Figure 3.12. Illustration of the interface between the solder and the electroless Ni in the as-solidified bump. (a) bright field TEM micrograph, and (b) schematic diagram of the interface microstructure. 
The interlayer between the interfacial compound and $\mathrm{Ni}_{3} \mathrm{P}$ has a relatively smooth interface with the $(\mathrm{Ni}, \mathrm{Au})_{3} \mathrm{Sn}_{2}$ compound, but an indistinct interface with the lower P-rich layer. All four of the chemical species in the system are involved in this layer; its overall composition is (7-10) $\mathrm{Au}(60-65) \mathrm{Ni}(13-20) \mathrm{Sn}(9-13) \mathrm{P}$. A selectivearea diffraction pattern (SADP) of this layer (Figure 3.13(a)) shows diffuse ring patterns with weak spots of $\mathrm{Ni}_{3} \mathrm{P}$, suggesting that this layer has an amorphous character with some fine crystalline $\mathrm{Ni}_{3} \mathrm{P}$. While the formation of this amorphous reaction layer is not well understood, it may be partially attributed to the solid-state amorphization found in metal/metal and metal/Si systems.[117,118] The presence of $\mathrm{Au}$ may contribute to the formation of this interlayer, since no amorphous layer was observed at the interface between eutectic $\mathrm{Pb}-\mathrm{Sn}$ and electroless Ni.[98,99] Since an amorphous thin layer is metastable, it is expected that the layer found here will transform into stable crystalline phases, $(\mathrm{Ni}, \mathrm{Au})_{3} \mathrm{Sn}_{2}$ and $\mathrm{Ni}_{3} \mathrm{P}$, during aging.

The material immediately beneath the amorphous layer is a P-rich region with the composition (22-23)P and with a grain size of about 20nm. SADP analysis shows that this region is a mixture of pure $\mathrm{Ni}$ and the $\mathrm{Ni}_{3} \mathrm{P}$ phase (Figure 3.13(b)). This microstructure apparently forms by crystallization combined with an interfacial reaction during reflow as described above.

The coarse-grained layer beneath the P-rich layer has an average grain size of about $60 \mathrm{~nm}$ and a $\mathrm{P}$ content of $5 \sim 8$ at.\%. This layer was not observed in the assolidified $\mathrm{Pb}-\mathrm{Sn}$ system on Ni-P which has a much lower reflow temperature than that of the current system[98,99] The grain size gradually decreases across this layer towards the $\mathrm{Cu}$ side with an associated increase in the $\mathrm{P}$ content. 


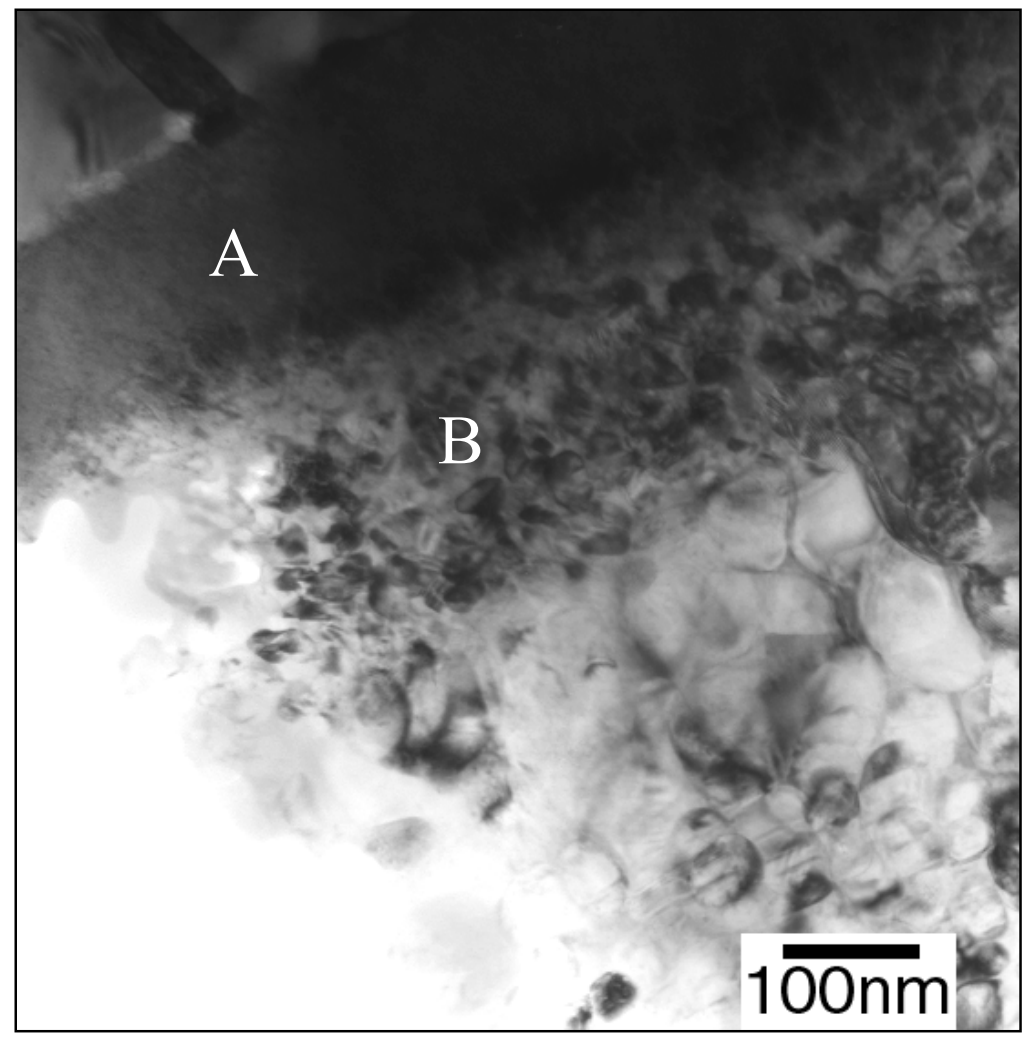

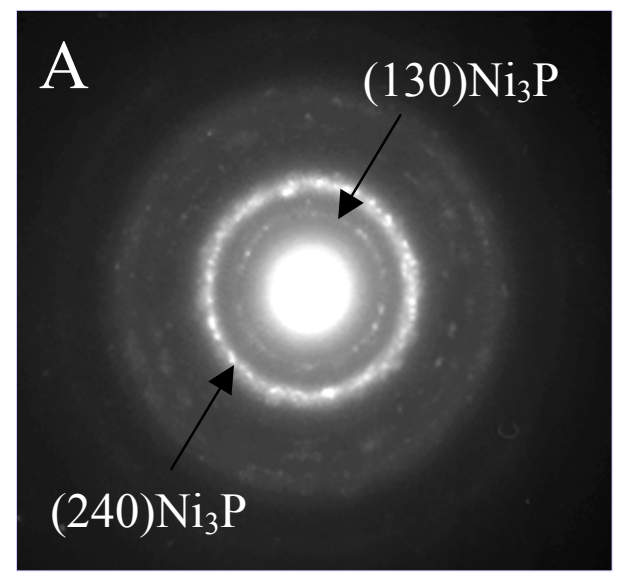

(a)

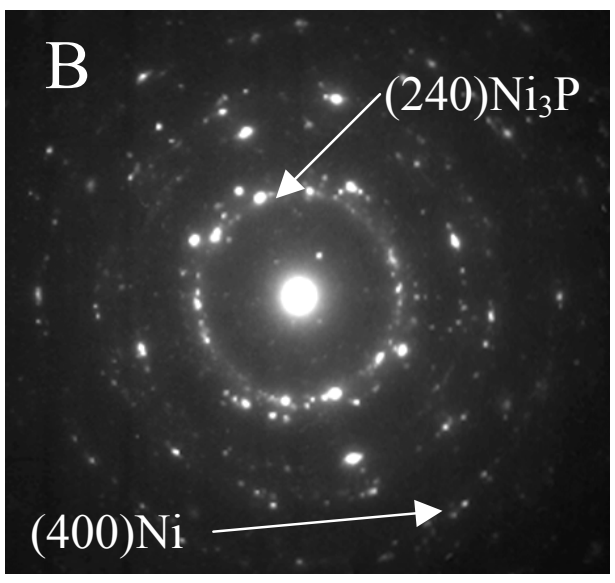

(b)

Figure 3.13. Selective area diffraction patterns of interface layers. (a) reaction layer (b) P-rich layer. 
The innermost Ni-P layer has a uniform composition and grain size (about 2-7

$\mathrm{nm})$. The formation of this coarse-grained layer appears to be related to the diffusion of $\mathrm{P}$ due to the fact that there exists a deficiency of $\mathrm{P}$. The uniform grain size and $\mathrm{P}$ content of the layer below this suggests that $\mathrm{P}$ diffuses into the upper P-rich layer which contributes to the formation and growth of stable $\mathrm{Ni}_{3} \mathrm{P}$ phases.

The overall interfacial structure is more complex than that found in eutectic $\mathrm{Pb}-\mathrm{Sn}$ on electroless Ni.[98,99] $\mathrm{Ni}$ in this system is involved in the formation of both $(\mathrm{Ni}, \mathrm{Au})_{3} \mathrm{Sn}_{2}$ and $(\mathrm{Au}, \mathrm{Ni}) \mathrm{Sn}$ phases, while $\mathrm{Ni}$ in eutectic $\mathrm{Pb}-\mathrm{Sn}$ contributes only to the interfacial reaction product $\mathrm{Ni}_{3} \mathrm{Sn}_{4}$. This is due to its extremely low solubility in eutectic $\mathrm{Pb}-\mathrm{Sn} .[107]$ In addition, the high reflow temperature of eutectic Au-Sn system, which also induces self-crystallization of as-plated Ni-P, causes more evolution of the microstructure as compared to as-solidified eutectic $\mathrm{Pb}-\mathrm{Sn}$ system where only reaction-assisted crystallization of amorphous Ni-P occurs near the interface (due to its low reflow temperature).[99]

\subsubsection{Interface in Aged Bump}

Figure 3.14 shows interfacial microstructure aged at $200^{\circ} \mathrm{C}$ for 31 days. The overall interfacial structure was unchanged. The region that was not involved in the interfacial reaction in as-solidified bump remained as fine nanocrstallines without significant coarsening. The reaction layer between the $(\mathrm{Ni}, \mathrm{Au})_{3} \mathrm{Sn}_{2}$ and the $\mathrm{P}$-rich layer appears to crystallize as a fine grain structure since its diffraction ring patterns shows fine spots rather than diffused patterns. However, the composition varies within this layer. 


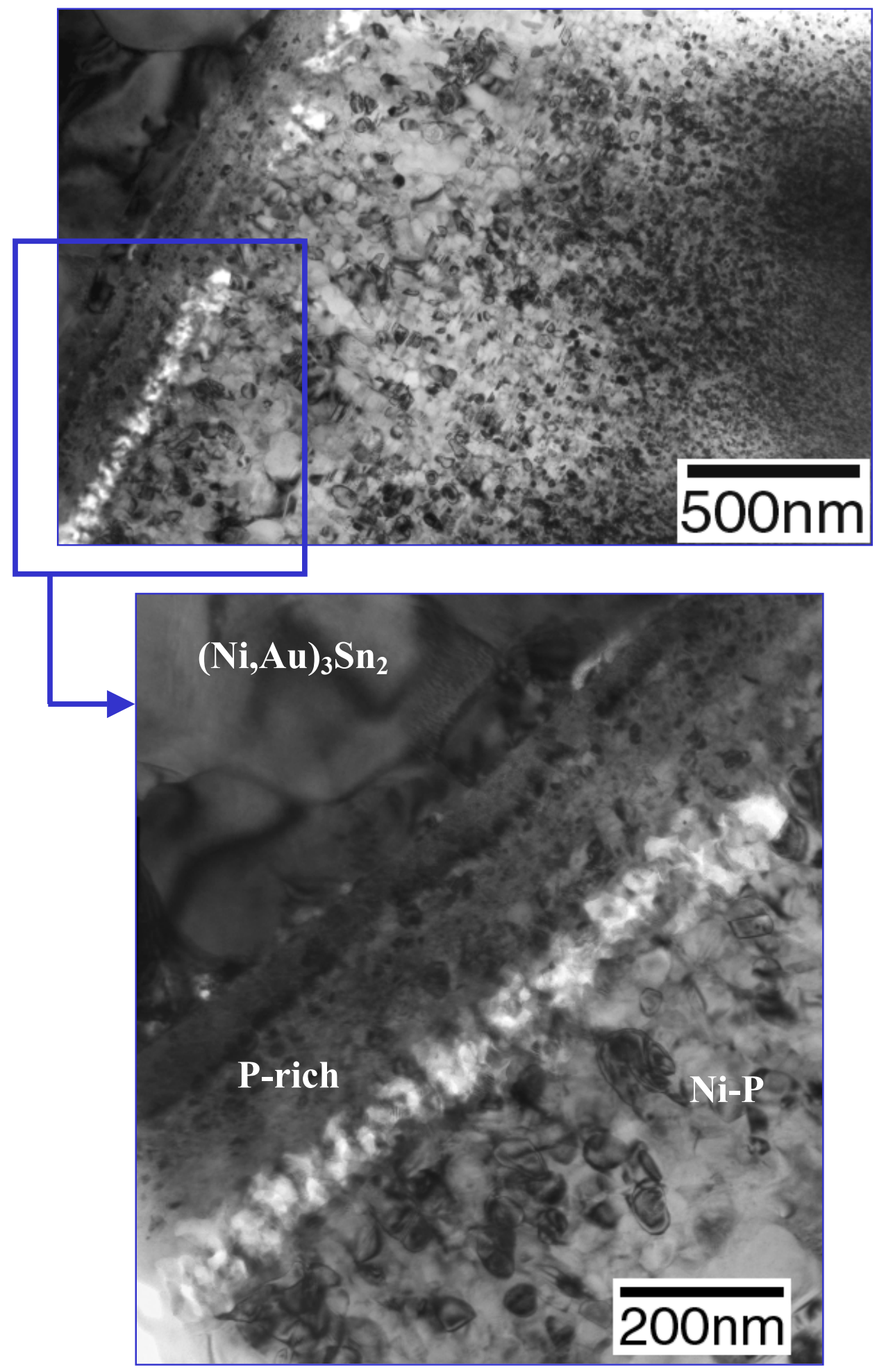

Figure 3.14. TEM micrographs showing interface microstructure of aged solder bump at $200^{\circ} \mathrm{C}$ for 31 days. 
The most notable difference was the pores at the interface between the P-rich layer and the coarse-grained Ni-P region that is deficient in P content. Similar pores were also recently found at the interface of the aged eutectic $\mathrm{Pb}-\mathrm{Sn}$ on electroless Ni. $[99,100]$ Considering the location of the pores and the fine grain structure of the Prich layer, which can provide a fast diffusion path through the grain boundary, it is hypothesized that the formation of pores results from the fast diffusion of $\mathrm{Ni}$ through the fine grained P-rich layer. If $\mathrm{Ni}$ diffusion towards the $(\mathrm{Ni}, \mathrm{Au})_{3} \mathrm{Sn}_{2}$ intermetallics is faster than the backwards diffusion of $\mathrm{P}$ that contributes to form $\mathrm{Ni}_{3} \mathrm{P}$ in electroless $\mathrm{Ni}$, pores can be formed by the Kirkendall effect near the interface in electroless Ni. Due to a lack of diffusional information on this system, however, a diffusion marker experiment is necessary to clarify this phenomenon.

\subsection{SUMmary AND CONCLUSIONS}

The typical microstructure of a eutectic Au-Sn solder bump on a $\mathrm{Cu} /$ electroless $\mathrm{Ni} / \mathrm{Au}$ substrate contains large proeutectic $\zeta$-phases due to the dissolution of the $\mathrm{Au}$ protective layer during soldering, together with a $\zeta-\delta$ lamellar eutectic constituent. Electroless Ni plays an effective role as a diffusion barrier for $\mathrm{Cu}$ such that only the electroless $\mathrm{Ni} / \mathrm{Au}$ reacts with the bulk solder to influence the microstructure of the solder bumps. At the interface, two different Au-Ni-Sn compounds form as an interfacial intermetallic layer that grows at about half the growth rate of $\mathrm{Cu}-\mathrm{Au}$ compounds at the interface of eutectic $\mathrm{Au}-\mathrm{Sn} / \mathrm{Cu}$. The maximum solubility of $\mathrm{Ni}$ in the $\zeta$-phase is about 1 at. $\%$ at $200^{\circ} \mathrm{C}$, while $\mathrm{Ni}$ solubility in the $\delta$-phase is more than 20 at.\%. It follows that $\mathrm{Ni}$ reacts primarily with the $\delta$-phase rather than the $\zeta$-phase. 
As a result, the constituent phases near the interface redistribute on aging by replacing the $\delta$-phase adjacent to the interfacial layer with the $\zeta$-phase, which eventually covers the interfacial layer and acts as a diffusion barrier against $\mathrm{Ni}$ to the bulk solder.

The electroless Ni-P layer is made of several sublayers with slightly different compositions and microstructures, including an amorphous interaction layer at the solder/electroless $\mathrm{Ni}$ interface. This complicated structure originates from $\mathrm{Ni}$ diffusion to form both interfacial $(\mathrm{Ni}, \mathrm{Au})_{3} \mathrm{Sn}_{2}$ compound and $\delta$-based $(\mathrm{Au}, \mathrm{Ni}) \mathrm{Sn}$ phase, which is accompanied by backwards diffusion of $\mathrm{P}$ in the electroless Ni. During aging, pores were observed near the interface in electroless Ni, which implies that $\mathrm{Ni}$ is the faster diffusional species in this specific system and structure.

The microstructure of eutectic Au-Sn microsolder joints that have $\mathrm{Cu} /$ electroless $\mathrm{Ni} / \mathrm{Au}$ metallizations on both the top and bottom pads consists of the predominant $\zeta$-phase with a small volume fraction of $\delta(\mathrm{Ni})$-phase which distributes near the interface. This microstructural feature results from the increased dissolution of $\mathrm{Au}$ from both pads and the preferential reaction of $\mathrm{Ni}$ with the $\delta$-phase. In order to ensure the characteristics of the eutectic composition, it is suggested to adjust the initial composition of the solder to an amount that is just slightly off-eutectic on the Sn-rich side. This would take into account the amount of $\mathrm{Au}$ dissolved when the eutectic Au-Sn solder joints are made by the metallization with a Au protective layer.

Eutectic $\mathrm{Au}-\mathrm{Sn}$ microjoints that were made between $\mathrm{Cu}$ and $\mathrm{Cu} /$ electroless $\mathrm{Ni} / \mathrm{Au}$ have both microstructural features that are found in joints of the same kind of metallization. The coarse microstructure of this joint reflects the characteristics of $\mathrm{Ni}$ and $\mathrm{Cu}$ such as their relative solubilities and diffusion rates in the $\zeta$ - and the $\delta$-phase 
of the eutectic $\mathrm{Au}-\mathrm{Sn}$. That is, Ni reacts predominantly with the $\delta$-phase while $\mathrm{Cu}$ reacts primarily with the $\zeta$-phase. The reaction between Ni and the eutectic Au-Sn is much slower than that between $\mathrm{Cu}$ and eutectic $\mathrm{Au}-\mathrm{Sn}$. This is basically attributed to the characteristics between $\mathrm{Au}$ and $\mathrm{Cu} / \mathrm{Ni}$, rather than those between $\mathrm{Sn}$ and $\mathrm{Cu} / \mathrm{Ni}$ which is observed in most other Sn-bearing systems. 


\section{SUMMARY AND CONCLUSIONS}

The purpose of this study was to understand the microstructural features of eutectic $\mathrm{Au}-\mathrm{Sn}$ solder joints (80Au-20Sn by weight), which gives insight into their mechanical properties and reliability. The study concentrated on the effects of joint size and type of substrate metallization on both the bulk and interface microstructures of the joints. The systems evaluated in this study were eutectic $\mathrm{Au}-\mathrm{Sn}$ on $\mathrm{Cu}$ and $\mathrm{Cu} /$ electroless $\mathrm{Ni} / \mathrm{Au}$. For each system, two sets of sample geometries were used to compare their microstructure with respect to geometry: Solder bumps (about $150 \mu \mathrm{m}$ in diameter and $50 \mu \mathrm{m}$ in height) were used as a reference to learn fundamental information for each system and solder joints ( $60 \mu \mathrm{m}$ in diameter and $25 \mu \mathrm{m}$ in height $)$ were used to study the size and configuration of microjoints used in industry.

Eutectic $\mathrm{Au}-\mathrm{Sn}$ solder joints on $\mathrm{Cu}$ have microstructures that are very coarse on the scale of the joint, where the microstructure is strongly affected by the amount of $\mathrm{Cu}$ dissolution during reflow process. These joints contain so few grains that one should be cautious when using macroscopic property data to predict their behavior. Thick intermetallics formed during soldering near the interface was identified as primarily $\zeta$-phase enriched with $\mathrm{Cu}$, but their evolution during both aging and thermal cycling is not well predicted by the currently available ternary Au-Cu-Sn phase diagram. Prolonged aging at $200^{\circ} \mathrm{C}$ leads to the formation and growth of $\mathrm{Cu}$-rich intermetallic layers along the $\mathrm{Cu}$ interface, which are, nominally, $\mathrm{Cu}_{3} \mathrm{Au}$ on the $\mathrm{Cu}$ side and $\mathrm{CuAu}$ on the $\zeta$-phase side. Both intermetallics show normal diffusion- 
controlled growth kinetics and thicken as $\mathrm{t}^{1 / 2}$. In addition, steady diffusion of $\mathrm{Cu}$ into the bulk solder during aging results in significant consumption of substrate $\mathrm{Cu}$ and formation of Kirkendall pores along the interface of $\mathrm{Cu} / \mathrm{Cu}_{3} \mathrm{Au}$, which may cause reliability problems. Thermal cycling of the joints caused decomposition of the thick $\zeta(\mathrm{Cu})$-phase into a fine-grained multiphase. All of these microstructural features originate from the high solubility of $\mathrm{Cu}$ in $\zeta$-phase and fast diffusion of $\mathrm{Cu}$ through eutectic $\mathrm{Au}-\mathrm{Sn}$. In order to retard high dissolution and diffusion of $\mathrm{Cu}$ into eutectic Au-Sn solder during soldering and service without applying a diffusion barrier, it is suggested that the initial solder composition is modified from the eutectic $\mathrm{Au}-\mathrm{Sn}$ to the eutectic $\mathrm{Au}(\mathrm{Cu})$-Sn by substituting $\mathrm{Au}$ with a small amount of $\mathrm{Cu}$.

The microstructure of eutectic Au-Sn solder joints on $\mathrm{Cu} /$ electroless $\mathrm{Ni} / \mathrm{Au}$ metallizations are also very coarse like those on just $\mathrm{Cu}$. They consist of predominantly $\zeta$-phase with a small volume fraction of $\delta(\mathrm{Ni})$-phase. The $\zeta$-phase separates to distribute in the middle of the joint while the $\delta$ phase separates near the interface. This microstructural feature is due to the dissolution of the Au which is used as a protective layer. Electroless $\mathrm{Ni}$ effectively acts as a diffusion barrier to $\mathrm{Cu}$ so that only Ni reacts with the eutectic solder. Since Ni solubility in the $\zeta$-phase is measured to be below about 1 at. $\%$ at $200^{\circ} \mathrm{C}$ while the $\delta$-phase dissolves more than 20 at.\% $\mathrm{Ni}$, the $\mathrm{Ni}$ reacts primarily with the $\delta$-phase rather than the $\zeta$-phase. During aging, Au-Ni-Sn compounds at the interface grow at about half the growth rate of $\mathrm{Cu}$ $\mathrm{Au}$ compounds in eutectic $\mathrm{Au}-\mathrm{Sn} / \mathrm{Cu}$. The electroless Ni-P layer consists of several sublayers with slightly different compositions and microstructures, including an 
amorphous interaction layer at the solder/electroless $\mathrm{Ni}$ interface. This complicated structure results from the interfacial reaction. In order to retain the superior characteristics of the eutectic composition, it is suggested that the initial composition of the solder is adjusted to a slightly off-eutectic on the Sn-rich side while taking into account the amount of Au dissolved from the Au protective layer.

The solubility characteristics and diffusional behavior of substrate metals in eutectic Au-Sn solder determine the detailed microstructure and microstructural evolution of the eutectic Au-Sn joints. Two important things to be noted from the results are as follows: First, the overall microstructures of these joints are very coarse with respect to the size of joint, and hence the properties of the joints cannot be the assume from bulk solder data. Second, despite having a nominally similar starting eutectic Au-Sn composition, the microstructural features of the joints are unique for a given substrate metallization. Both of these results should be take into consideration during the design of reliable eutectic Au-Sn solder joints. 


\section{REFERENCES}

1. J.W. Morris, Jr., "Ressearch trends in electronic solders and soldering", Proc. 2nd Pacific RIM Int. Conf. on Advanced Materials Processing (PRICM-2), (The Korean Institute of Metals and Materials, South Korea, 1995) p. 715.

2. J. Glazer, "Metallurgy of low temperature $\mathrm{Pb}$-free solders for electronic assembly", Int. Mater. Rev., 40 (1995) p. 65.

3. J. Glazer, P. Kramer and J.W. Morris, Jr., "Effect of Gold on the reliability of fine pitch surface mount solder joints", Circuit World, 18 (1992) p. 41.

4. P. Kramer, J. Glazer and J.W. Morris, Jr., "The effect of low Gold concentrations on the creep of eutectic Tin-Lead joints", Metall. Mater. Trans. A, 25A (1994) p. 1249.

5. M.E. Ferguson, C.D. Fieselman and M.A. Elkins, "Manufacturing concerns when soldering with Gold plated component leads or circuit board pads", IEEE Trans. Comp. Packag., Manuf. Technol. Part C, 20 (1997) p. 188.

6. J.S. Hwang, "Solder Materials", Surf. Mount Technol., 13 (1999) p. 68.

7. J.W. Morris, Jr. and S.H. Kang, "Miniaturization and reliability in the metallurgical elements of microelectronic packages", Proc. 3nd Pacific RIM Int. Conf. on Advanced Materials Processing (PRICM-3), (TMS, Warrendale, PA, 1998) p. 2563.

8. N.R. Green, J.A. Charles and G.C. Smith, "Solidification and microstructure of eutectic Pb-Sn microsolder bonds", Mater. Sci. Technol., 10 (1994) p. 976.

9. J.W. Morris, Jr. and H.L. Reynolds, "The influence of microstructure on the failure of eutectic solders", Design and Reliability of Solders and Solder Interconnections, ed. R.K. Mahidhara, D.R.Frear, S.M.L. Sastry, K.L. Murty, P.K. Liaw and W. Winterbottom (TMS, Warrendale, PA, 1997) p. 49.

10. J.D. Linton, “ The European Union's new environmental directives”, Circuit Assembly, 11 (2000) p. 32.

11. M. Abtew and G. Selvaduray, "Lead-free solders in microelectronics", Mater. Sci. Eng. R., 27 (2000) p. 95.

12. J.S. Hwang, Modern Solder Technology for Competitive Electronics Manufacturing (McGraw-Hill Co, New York, NY, 1996) p. 483. 
13. S. Jin, "Developing Lead-free solders: A challenge and opportunity", JOM, 45 (1993) p. 13.

14. NCMS Report 0401RE96, Lead-free solder project final report (National Center for Manufacturing Sciences, Ann Arbor, MI, 1997).

15. D. Suraski and K. Seelig, "The current status of Lead-free solder alloys", IEEE Trans. Electr. Packag. Manuf., 24 (2001) p. 244.

16. M. Ohring, Reliabilty and Failure of Electronic Materials and Devices (Academic Press, San Diego, CA, 1998) p. 5.

17. J. H. Lau, Low Cost Flip Chip Technologies (McGraw-Hill Co., New York, NY, 2000) p. 9.

18. J.W. Morris, Jr., "The microstructure and properties of solder joints", J. Korean Phys. Soc., 35 (1999) p.335.

19. K.N. Tu and R. Rosenberg, "Room temperature interaction in bimetallic thin film couples", Jpn. J. Appl. Phys., Suppl. 2, Part 1 (1974) p. 633.

20. J.S. Hwang, Modern Solder Technology for Competitive Electronics Manufacturing (McGraw-Hill Co, New York, NY, 1996) p. 418.

21. J. H. Lau, Thermal Stress and Strain in Microelectronics Packaging, (Van Nostrand Reinhold, New York, NY, 1993) p.501.

22. J.W. Morris, Jr., J.L. Freer Goldstein and Z. Mei, Ch. 2 in The Mechanics of Solder Alloy Interconnects, ed. D.R. Frear, S.N. Burchett, H.S. Morgan and J.H. Lau (Van Nostrand Reinhold, New York, NY, 1993).

23. D. Tribula, A Microstructural Study of Creep and thermal Fatigue Deformation in $60 \mathrm{Sn}-40 \mathrm{~Pb}$ Solder joints, Ph. D. Thesis, University of California at Berkeley (1990).

24. D.R. Frear, Microstructural Observations of the Sn-Pb Solder/Cu system and Thermal Fatigue of the Solder joint, Ph. D. Thesis, University of California at Berkeley (1987).

25. D.R. Frear and P.T. Vianco, "Intermetallic growth and mechanical behavior of low and high melting temperature solder alloys", Metall. Trans. A, 25A (1994) p. 1509 .

26. A.D. Romig, Jr., Y.A. Chang, J.J. Stephens, D.R. Frear, V. Marcotte and C. Lea, Ch. 2 in Solder Mechanics - A State of the Art Assessment, ed. D.R. Frear, W.B. Jones and K.R. Kinsman (TMS, Warrendale, PA, 1991). 
27. Z. Mei, A.J. Sunwoo and J.W. Morris, Jr., "Analysis of low-temperature intermetallic growth in Copper-Tin diffusion couples", Metall. Trans. A, 23A (1992) p. 857.

28. S. Bader, W. Gust and H. Hieber, "Rapid formation of intermetallic compounds by interdiffusion in the Cu-Sn and Ni-Sn systems", Acta Metall. Mater., 43 (1995) p. 329.

29. K. Suganuma and Y. Nakamura, "Microstructure and Strength of interface between Sn-Ag eutectic solder and Cu", J. Jpn. Inst. Metals, 59 (1995) p. 1299.

30. L.S. Goldmann and P.A. Totta, Ch. 5 in Chip On Board Technologies for Multichip Modules, ed. J.H. Lau (Van Nostrand Reinhold, New York, NY, 1994).

31. G.I. Lykken, J. Hustoft, B. Ziegler and B. Momcilovic, "Clean Galena, contaminated Lead, and soft errors in memory chips", J. Electr. Mater., 29 (2000) p. 1290.

32. J.S. Hwang, Ch. 3 in Modern Solder Technology for Competitive Electronics Manufacturing (McGraw-Hill Co, New York, NY, 1996).

33. J. Ciulik and M.R. Notis, "The Au-Sn phase diagram”, J. Alloys. Comp., 191 (1993) p. 71.

34. G.S. Matijasevic, C.C. Lee, and C.Y. Wang, "Au-Sn alloy phase diagram and properties related to its use as a bonding medium", Thin Solid Films, 223 (1993) p. 276.

35. G.S. Matijasevic, C.C. Lee, and C.Y. Wang, Ch. 6 in Chip On Board Technologies for Multichip Modules, ed. J.H. Lau (Van Nostrand Reinhold, New York, NY, 1994).

36. E. Zakel and H. Reichl, Ch. 15 in Flip Chip Technologies, ed. J.H. Lau (McGraw-Hill Co, New York, NY, 1995).

37. D.B. Walshak, Jr., Ch. 7 in Handbook of Tape Automated Bonding, ed. J.H. Lau (Van Nostrand Reinhold, New York, NY, 1992).

38. A.H. Kumar and B. Ozmat, Microelectronics Packaging Handbook, ed. R.R. Tummala and E.J. Rymaszewski (Van Nostrand Reinhold, New York, NY, 1989) p. 741 .

39. J. Lau, Flip Chip Technologies (McGraw-Hill Co, New York, NY, 1995) p. 26.

40. E.K. Yung and I. Turlik, "Electroplated solder joints for flip-chip applications", IEEE Trans. Comp., Hybrids, Manuf. Technol., 14 (1991) p. 549. 
41. N.G. Koopman, T.C. Reiley and P.A. Totta, Ch. 6 in Microelectronics Packaging Handbook, ed. R.R. Tummala and E.J. Rymaszewski (Van Nostrand Reinhold, New York, NY, 1989).

42. M.T. McCormack, H. Jiang, S.I. Beilin, B. Chou, and M. Peters, "Z-MAJIC'm: A novel Z-interconnect approach for multi-chip modules", Adv. Electr. Packag. EEP-Vol. 26-2 (1999) p. 1807.

43. T.B. Massalski, H, Okamoto, P.R. Subramanian and L. Kacprzak, Binary alloy phase diagrams, 2nd ed. (ASM int, Materials Parks, OH, 1990).

44. R.E. Reed-Hill and R. Abbaschian, Physical Metallurgy Principles, 3rd ed. (PWS Publishing Comp., Boston, MA, 1994) P. 278.

45. O.B. Karlsen, A. Kjekshus and E. Rost, "The ternary system Au-Cu-Sn", Acta Chem. Scan., 46 (1992) p. 147.

46. W.K. Warburton and D. Turnbull, "Fast diffusion in alloys", Thin Solid Films, 25 (1975) p. 71.

47. K.N. Tu and R.D. Thompson, "Kinetics of interfacial reaction in bimetallic CuSn thin films", Acta Metall., 30 (1982) p. 947.

48. S. Nakahara, R.J. McCoy, L. Buene and J.M. Vandenberg, "Room temperature interdiffusion studies of Au/Sn Thin firm couples", Thin Solid Films, 84 (1981) p. 185.

49. D. Gregersen, L. Buene, T. Finstad, O. Losnsjo and T. Olsen, "A diffusion marker in Au/Sn thin films", Thin Solid Films, 78 (1981) p. 95.

50. M.R. Pinnel and J.E. Bennett, "Mass diffusion in polycrystalline Copper/electroplated Gold planar couples”, Metall. Trans., 3 (1972) p. 1989.

51. A.N. Aleshin, V.K. Egorov, B.S. Bokstein and P.V. Kurkin, "Study of diffusion in thin Au-Cu films", Thin Solid Films, 223 (1993) p. 51.

52. P.M. Hall, J.M. Morabito and N.T. Panousis, "Interdiffusion in the $\mathrm{Cu}-\mathrm{Au}$ thin film system at $25^{\circ} \mathrm{C}$ to $250^{\circ} \mathrm{C}^{\prime}$, Thin Solid Films, 41 (1977) p. 341.

53. H.G. Tompkins and M.R. Pinnel, "Low-temperature diffusion of Copper through Gold”, J. Appl. Phys., .47 (1976) p. 3804.

54. F. Bartels, J.W. Morris, Jr., G. Dalke and W. Gust, "Intermetallic phase formation in thin solid-liquid diffusion couple", J. Electr. Mater., 23 (1994) p. 787. 
55. K.N. Tu, "Cu/Sn interfacial reactions: thin-film case versus bulk case", Mater. Chem. Phys., 46 (1996) p. 217.

56. R.A. Gagliano and M.E. Fine, "Growth of $\eta$ phase scallops and whiskers in liquid tin- solid copper reaction couples”, JOM, 53 (2001) p. 33.

57. H.K. Kim and K.N. Tu, "Kinetic analysis of the soldering reaction between eutectic $\mathrm{SnPb}$ alloy and $\mathrm{Cu}$ accompanied by ripening", Phys. Rev. B(Condensed Matter), 53 (1996) p. 16027.

58. J.L. Marshall, L.A. Foster and J.A. Sees, Ch. 3 in The Mechanics of Solder Alloy Interconnects, ed. D.r. Frear, S.N. Burchett, H.S. Morgan and J.H. Lau (Van Nostrand Reinhold, New York, NY, 1994).

59. P.T. Vianco, K.L. Erickson and P.L. Hopkins, "Solid state intermetallic compound growth between Copper and high temperature, Tin-rich solders", $J$. Electr. Mater., 23 (1994) p. 721.

60. H. Nakajima, "The discovery and acceptance of the Kirkendall effect: The result of a short research career", JOM, 49 (1997) p. 15.

61. P. Shewmon, Diffusion in Solid, 2nd ed. (TMS, Warrendale, PA, 1989) p. 132.

62. M.E. Glicksman, Ch. 17 in Difusion in Solids: Field Theory, Solid-State Principles and Applications (John Wiley \& Sons, Inc., New York, NY, 2000).

63. F.Seitz, "On the porosity observed in the Kirkendall effect", Acta Metall., 1 (1953) p. 355.

64. L.G. Feinstein and J.B. Bindell, " The failure of aged $\mathrm{Cu}-\mathrm{Au}$ thin films by Kirkendall porosity", Thin Solid Films, 62 (1979) p. 37.

65. E. Zakel, H. Reichl, "Investigations of failure mechanisms of TAB-bonded chips during thermal aging”, IEEE Trans. Comp., Hybrids, Manuf. Technol., 13 (1990) p. 856.

66. E. Zakel, G. Azdasht and H. Reichl, "Investigations of laser soldered TAB inner lead contacts", Proc. 41st Electr. Comp. Technol. Conf.,(IEEE, New York, NY, 1991) p. 497.

67. E. Zakel, H. Reichl, "Au-Sn bonding metallurgy of TAB contacts and its influence on the Kirkendall effect in the ternary Cu-Au-Sn", IEEE Trans. Comp., Hybrids, Manuf. Technol., 16 (1993) p. 323.

68. M. Ohring, Reliabilty and Failure of Electronic Materials and Devices (Academic Press, San Diego, CA, 1998) p. 247. 
69. P. Viswanadham and P. Singh, Failure Modes and Mechanisms in Electronic Packages (Chapman \& Hall, New York, NY, 1998) p. 188.

70. M. Fukuda, Reliability and Degradation of Semiconductor Lasers and LEDs (Artech House, Boston, MA, 1991) p. 143.

71. J.W. Morris, Jr. and Z. Mei, Ch. 6 in Solder Mechanics: A State of the Art Assessment, ed. D.R.Frear, W.B. Jones and K.R. Kinsman (TMS, Warrendale, PA, 1991).

72. P.L. Hacke, A.F. Sprecher and H. Conrad, "Computer simulation of thermomechanical fatigue of solder joints including microstructure coarsening", J. Electr. Packag., 115 (1993) p.153.

73. P.L. Hacke, A.F. Sprecher and H. Conrad, "Microstructure coarsening during thermo-mechanical fatigue of Pb-Sn solder joints", J. Electr. Mater., 26 (1997) p. 774.

74. H. Conrad, Z. Guo, Y. Fahmy and D. Yang, "Influence of microstructure size on the plastic deformation kinetics, fatigue crack growth rate, and low-cycle fatigue of solder joints", J. Electr. Mater., 28 (1999) p. 1062.

75. S.K. Kang and V. Ramachandran, "Growth kinetics of intermetallic phases at the liquid Sn and solid Ni interface”, Scripta Metall., 14 (1980) p. 421.

76. T.Y. Pan, H.D. Blair, John M. Nicholson and S.W. Oh, "Intermetallic compound formation of $\mathrm{Sn} / \mathrm{Pb}, \mathrm{Sn} / \mathrm{Ag}$, and $\mathrm{Sn}$ solders on Ni substrate from the molten stage and its growth during aging", Adv. Electr. Packag. EEP-Vol. 19-2 (1997) p. 1347.

77. P.L. Tu, T.C. Chan, K.C. Hung and J.K.L. Lai, "Growth kinetics of intermetallic compounds in chip scale package solder joint”, Scripta Mater., 44 (2001) p. 317.

78. C.Y Lee and K.L. Lin, "The interaction kinetics and compound formation between electroless Ni-P and solder", Thin Solid Films, 249 (1994) p. 201.

79. H.N. Keller, "Solder connections with a Ni barrier", Proc. 36th Electr. Comp. Conf. (IEEE, New York, NY, 1986) p. 31.

80. H. Kim and K.N. Tu, "Rate of consumption of $\mathrm{Cu}$ in soldering accompanied by ripening”, Appl. Phys. Lett. 67 (1995) p. 2002.

81. A.A. Liu, H.K. Kim, K.N. Tu and P.A. Totta, "Spalling of $\mathrm{Cu}_{6} \mathrm{Sn}_{5}$ spheroids in the soldering reaction of eutectic $\mathrm{SnPb}$ on $\mathrm{Cr} / \mathrm{Cu} / \mathrm{Au}$ thin films", J. Appl. Phys., 80 (1996) p. 2774. 
82. C.Y. Liu, C. Chen, A.K. Mai and K.N. Tu, "Direct correlation between mechanical failure and metallurgical reaction in flip chip solder joints", J. Appl. Phys., 85 (1999) p. 3882.

83. K.M.Chow, W.Y. Ng and L.K. Teung, "Barrier properties of Ni, pd and Pd-Fe for Cu diffusion", Surf. Coatings Technol., 105 (1998) p. 56.

84. R. Venos and H. Hoffmann, "Surface accumulation and monolayer coverage during grain boundary diffusion in polycrystalline $\mathrm{Cu} / \mathrm{Ni}$ bilayers", Thin Solid Films, 174 (1989) p. 99.

85. W. Reidel, Electroless Nickel Plating (ASM Int., Metals Park, OH, 1991)

86. K. Wong, K. Chi and A. Rangappan, "Application of electroless nickel plating in the semiconductor microcircuit industry", Plating Surf. Finishing, 75 (1988) p. 70 .

87. K. Yamakawa, M. Inaba and N. Iwase, "Maskless bumping by electroless plating for high pin count, thin and low cost microcircuits", Proc. Int. Symp. Microelectr., (Int. Soc. Hybrid Microelectron, Reston, VA, 1989.) p. 620.

88. J. Kloeser, A. Ostmann, J. Gwiasda, F. Bechtold, R. Aschenbrenner and H. Reichl, "Low cost flip chip technologies based on chemical nickel bumping and solder printing", Int. J. Microcircuits Electr. Packag., 20 (1997) p. 383.

89. C.C. Tsui, T.B. Lim, Y.C. Teo and C.Q. Cui, "Low cost underbump metallization by electroless Ni/Au plating for chip scale packages", Adv. Electr. Packag. EEPVol. 19-1 (1997) p. 119.

90. F. Stepniak, "Solder flip chips employing electroless nickel: An evaluation of reliability and cost", Adv. Electr. Packag. EEP-Vol. 19-1 (1997) p. 353.

91. J. H. Lau, Low Cost Flip Chip Technologies (McGraw-Hill Co., New York, NY, 2000) p. 48.

92. G. Schenzel and H. Kreye, "Improved corrosion resistance of electroless nickelphosphorus coatings", Plating Surf. Finishing, 77 (1990) p. 50.

93. K.L. Lin and J.M. Jang, "Wetting behavior between solder and electroless nickel deposits", Mater. Chem. Phys., 38 (1994) p. 33.

94. E. Bradley and K. Banerji, "Effect of PCB finish on the reliability and wettability of ball grid array packages" IEEE Trans. Comp. Pkg., Manuf. Technol., Part B, 19 (1996) p. 320. 
95. Z. Mei, M. Kaufmann, A. Eslambolchi and P. Johnson, "Brittle interfacial fracture of PBGA packages soldered on electroless nickel/immersion gold", Proc. 48th Electr. Comp. Technol. Conf., (IEEE, New York, NY, 1998) p. 952.

96. R.J. Coyle, A. Holliday, P. Mescher, P.P. Solan, S.A. Gahr, H.A.Cyker, J.K. Dorey and T.I. Ejim, "The influence of nickel/gold surface finish on the assembly quality and long term reliability of thermally enhanced BGA packages", 24nd IEEE/CPMT Int. Electr. Manuf. Technol. Symp., (IEEE, Piscataway, NJ, 1999) p. 23.

97. Z. Mei, P. Johnson, M. Kaufmann and A. Eslambolchi, "Effect of electroless $\mathrm{Ni} /$ immersion Au plating parameters on PBGA solder joint attachment reliability", Proc. 49th Electr. Comp. Technol. Conf., (IEEE, Piscataway, NJ, 1999) p. 125.

98. J.W. Jang, P.G. Kim, K.N. Tu, D.R. Frear and P. Thompson, "Solder reactionassisted crystallization of electroless Ni-P underbump metallization in low cost flip chip technology", J. Appl. Phys., 85 (1999) p. 8456.

99. P.L. Liu, Z. Xu and J.K. Shang, "Thermal stability of electroless-nickel/solder interface: Part A. Interfacial chemistry and microstructure", Metall. Mater. Trans. A, 31A (2000) p. 2857.

100. K.C. Hung, Y.C. Chan, C.W. Tang and H.C. Ong, "Correlation between $\mathrm{Ni}_{3} \mathrm{Sn}_{4}$ intermetallics and $\mathrm{Ni}_{3} \mathrm{P}$ due to solder reaction-assisted crystallization of electroless ni-P metallization in advanced packages", J. Mater. Res., 15 (2000) p. 2534.

101. J.W. Jang, C.Y. Liu, P.G. Kim, K.N. Tu, A.K. Mal and D.R. Frear, "Interfacial morphology and shear deformation of flip chip solder joints" J. Mater. Res., 15 (2000) p.1679.

102. P.L. Liu and J.K. Shang, "Thermal stability of electroless-nickel/solder interface: Part B. Interfacial fatigue resistance", Metall. Mater. Trans. A, 31A (2000) p. 2867.

103. S. Anhock, A. Ostmann, H. Oppermann, R. Aschenbrenner and H. Reichl, "Reliability of electroless nickel for high temperature applications", Proc. Int. Symp. Adv. Packag. Mater. (IMAPS, Reston, VA, 1999), p. 256.

104. E. Jung, K. Heinricht, J. Kloeser, R. Aschenbrenner and H. Reichl, "Alternative solders for flip chip applications in the automotive environment", 22nd IEEE/CPMT Int. Electr. Manuf. Technol. Symp., (IEEE, New York, NY, 1998) p. 82.

105. S. Anhock, H. Oppermann, C. Kallmayer, R. Aschenbrenner, L. Thomas, H. Reichl, "Investigations of $\mathrm{Au} / \mathrm{Sn}$ alloys on different end-metallizations for high 
temperature applications", Proc. 22th IEEE/CPMT Int. Electr. Manuf. Technol. Symp., (IEEE, New York, NY, 1998), p. 156.

106. A. Neumann, A. Kjekshus and E. Rest, "The ternary system Au-Ni-Sn", J. Solid State Chem., 123 (1996) p. 203.

107. H.G. Song, J.P.Ahn, A.M. Minor and J.W. Morris, Jr., "Au-Ni-Sn intermetallic phase relationships in eutectic $\mathrm{Pb}-\mathrm{Sn}$ solder formed on $\mathrm{Ni} / \mathrm{Au}$ metallization", $J$. Electr. Mater., 30 (2001) p. 409.

108. R. M. Allen and B. VanderSande, "The structure of electroless Ni-P films as a function of composition", Scripta Metall., 16 (1982) p. 1161.

109. M.W. Mahoney and P.J. Dynes, "The effect of thermal history and phosphorous level on the crystallization of electroless nickel", Scripta Metall., 19 (1985) p. 539.

110. M. Erming, L. Shoufu and L. Pengxing, "A transmission electron microscopy study on the crystallization of amorphous Ni-P electroless deposited coatings", Thin Solid Films, 166 (1988) p. 273.

111. Q.X. Mai, R.D. Daniels and H.B. Harpalani, "Structural changes induced by heating in electroless nickel-phosphorus alloys", Thin Solid Films, 166 (1988) p. 235.

112. S.V.S. Tyagi, S.K. barthwal, V.K. Tondon and S. Ray, "The annealing behavior of electroless noncrystalline nickel phosphorus films", Thin Solid Films, 169 (1989) p. 229.

113. H. Li, H. Chen, S. Dong, J. Yang and J. Deng, "Study on the crystallization process of Ni-P amorphous alloy”, Appl. Surf. Sci., 125 (1998) p. 115.

114. A.H. Graham, R.W. Lindsay and H.J. Read, "The structure and mechanical properties of electroless nickel”, J. Electrochem. Soc., 112 (1965) p. 401.

115. T. Osaka, M. Usuda, I. Koiwa and H. Sawai, "Effect of Phosphorous content on the magnetic and electric properties of electroless Ni-P film after heat treatment", Japan. J. Appl. Phys., 27 (1988) p. 1885.

116. E.V. Makhsoos, E.L. Thomas and L.E. Toth, "Electron microscopy of crystalline and amorphous Ni-P electrodeposited films: In-situ crystallization of an amorphous solid", Metall. Trans. A, 9 (1978) p. 1449.

117. Q. Zhang, W.S. Lai, G.W. Yang and B.X. Liu, "solid-state amorphization in $\mathrm{Ni} / \mathrm{Nb}$ multilayers studied by molecular-dynamic simulation together with experiments", J. Phys.: Condens. Matter, 12 (2000) p. 6991. 
118. L.J. Chen, "Solid state amorphization in metal/Si systems", Mater. Sci. Eng. R, R29 (2000) p. 115. 


\section{APPENDIX}

\section{$<$ Manufacturing Process for the Samples USEd in This Study $>$}

The Au-Sn joints used in this study were made by Bumped Z-MAJIC ${ }^{\text {M }}$ ( Zconnections by Metal-Adhesive Joining In Cavities) process that was developed by Fujitsu Computer Packaging Technology.[39] The fundamental Z-MAJICTM processes utilize multi-functional stencils that are patterned, formed, and left on as an integral part of the substrate. The basic steps for this technology are as follows:

An organic adhesive film or bonding sheet with removable cover layer is tacked to the substrate. The film may have performed via openings aligned to the substrate bonding pad pattern or stencil openings may be formed over the substrate bonding pads following film application. These cavities may be formed by either mechanical drilling, punching, chemical etching, laser drilling, etc. (Figure A-1 a))

Solder paste is printed in the stencil cavities (Figure A-1 b)) and the bumps are formed within the cavities by an appropriate thermal profile in a reflow furnace.

The cover layer of the stencil film is removed from the substrate (Figure A-1 c)). The remaining adhesive layer may then be used as a solder mask, surface protection or passivation.

A temperature/pressure controlled lamination step simultaneously forms adhesive and conductive metallurgical bonds over the entire surface of the exposed substrate pads (Figure A-1 d)) 
This technology enables followings:

1) Higher aspect ratio of cavities/connections and narrower stencil walls, controlling solder volume by the ratio of bonding sheet to cover layer thickness.

2) Self-cleaning by the in-situ stencil.

3) Finer pitch solder bumps.

4) No need to remove stencil which can serve as a solder mask, plating mask, surface protection or passivation from environment related contamination, and an adhesive dielectric in flip chip structure 

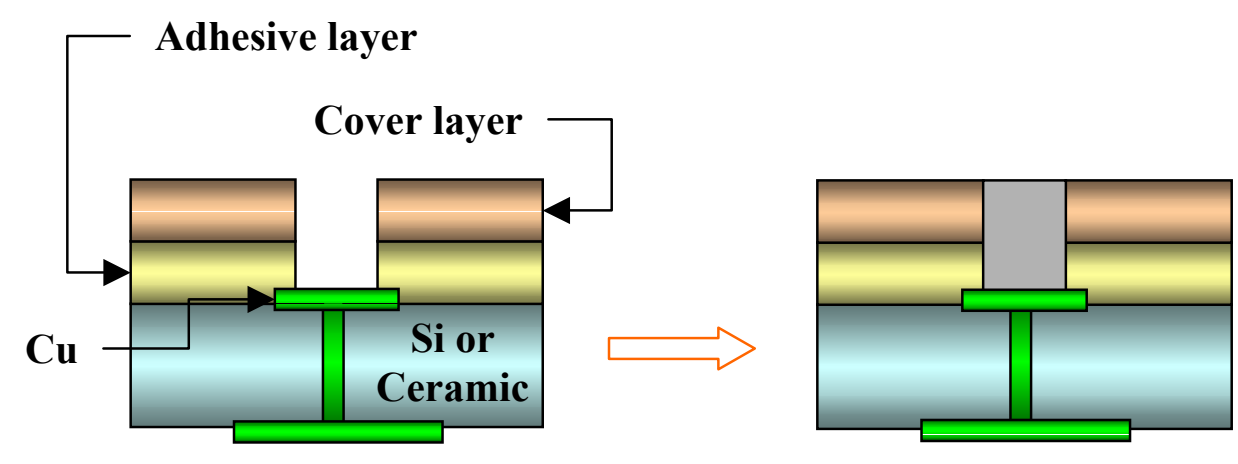

a) Laminating organic films, laser drilling to form cavity

b) Printing solder paste
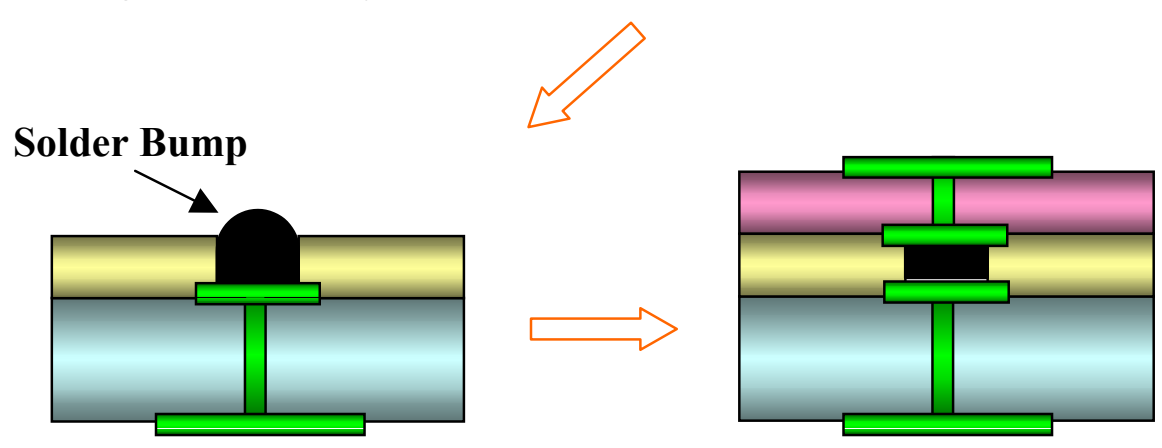

c) Cover layer removal after reflow

d) Joining upper substrate
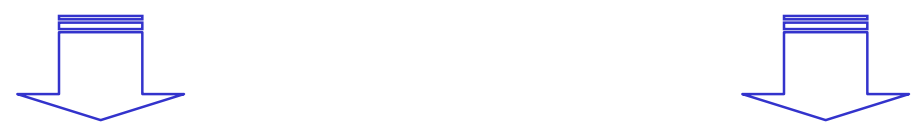

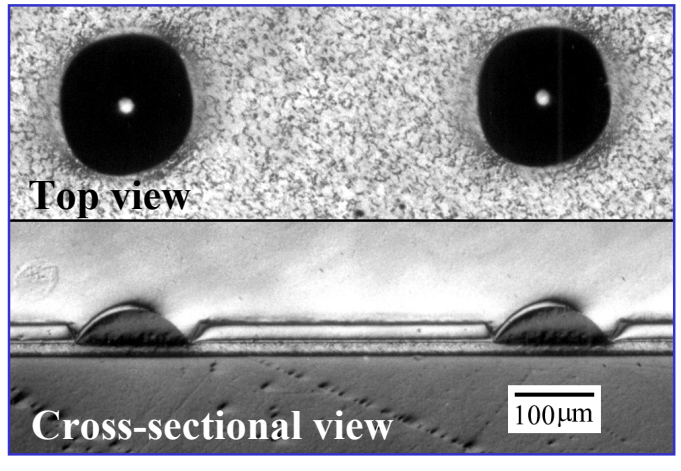

Solder bump sample

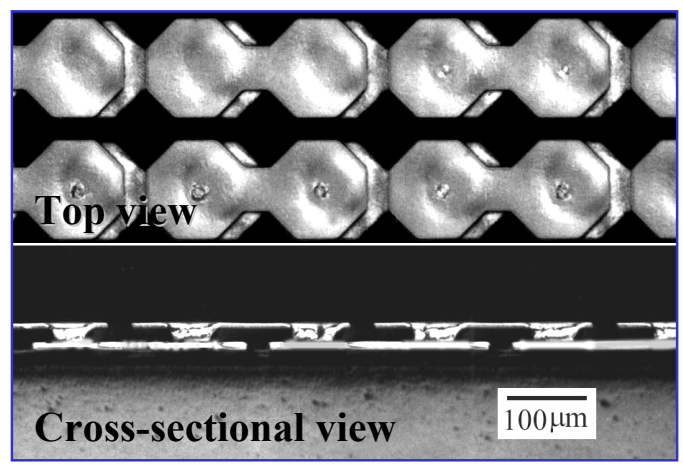

Solder joint sample

Figure A-1. Schematic diagrams of Z-MAJIC ${ }^{\text {TM }}$ processes. 